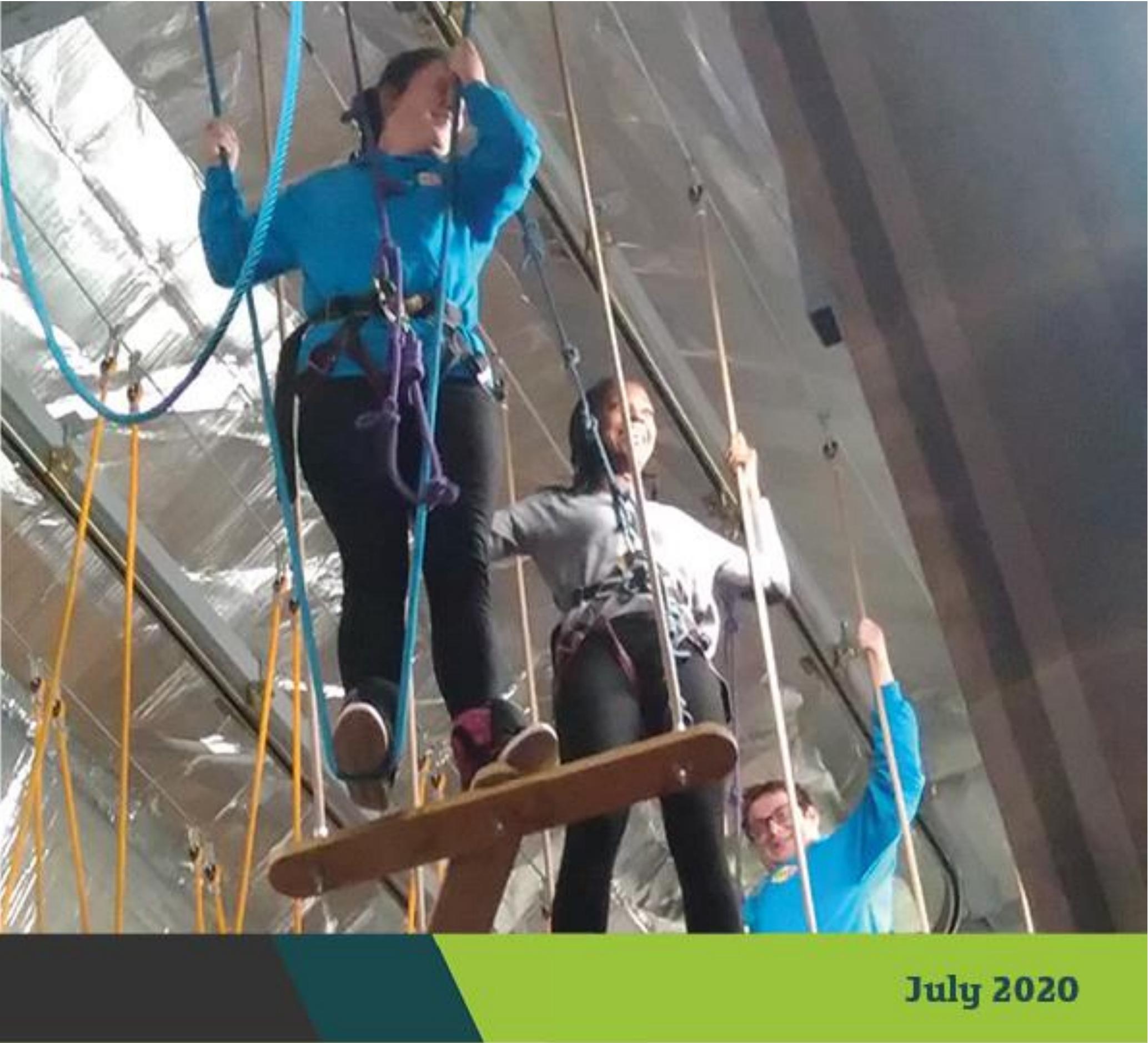




\section{Talent Match Evaluation: Understanding the impact and value of Talent Match}

Centre for Regional Economic and Social Research (CRESR)

Author(s):

Chris Damm

Sarah Pearson

Elizabeth Sanderson

Peter Wells

Ian Wilson

July 2020

DOI: 10.7190/cresr.2020.2031246178 


\section{Acknowledgements}

We are extremely grateful to all those who have helped in the course of the evaluation. We are particularly grateful to the staff, young people and board members of the 21 Talent Match partnerships who have given their time freely to support the evaluation. A particular mention should be made of partnership leads and those involved in setting up the Common Data Framework (CDF). We trust that in time the considerable benefits of the CDF will be seen in terms of contributing to a robust evidence base on which to design future policies and programmes.

A wide range of staff and committee members at The National Lottery Community Fund have helped, supported and advised upon the evaluation. Their time has been invaluable. We are particularly grateful to Jolanta Astle, Sarah Cheshire, James Godsal, Scott Hignett, Scott Hyland and Roger Winhall. We are also grateful to former The National Lottery Community Fund colleagues Matt Poole, Linzi Cooke and Scott Greenhalgh who provided invaluable assistance at the start of the Talent Match Evaluation.

Lastly, we would like to thank the evaluation team at Sheffield Hallam University, the University of Birmingham, the University of Warwick and Cambridge Economic Associates: Duncan Adam, Gaby Atfield, Dr Sally-Anne Barnes, Nadia Bashir, Dr Richard Crisp, Dr Chris Damm, Dr Maria de Hoyos, Dr Will Eadson, Professor Del Roy Fletcher, Dr Tony Gore, Professor Anne Green, David Leather, Elizabeth Sanderson, Emma Smith, Louise South, Professor Pete Tyler, Sarah Ward and Ian Wilson. We would also like to thank our former colleague Ryan Powell who supported the original evaluation design and engagement with all the partnerships.

\section{Peter Wells (Evaluation Director) and Sarah Pearson (Evaluation Project Manager}




\section{Contents}

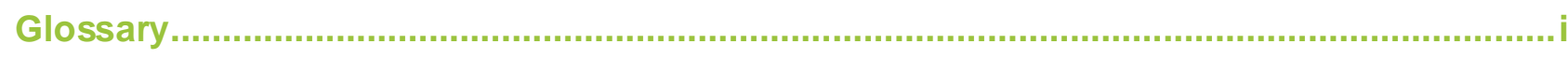

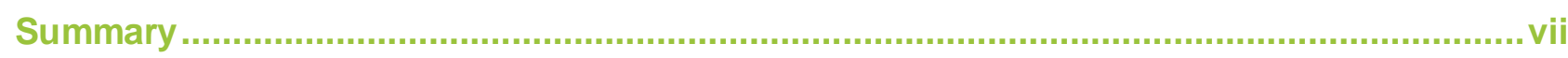

1. Introduction

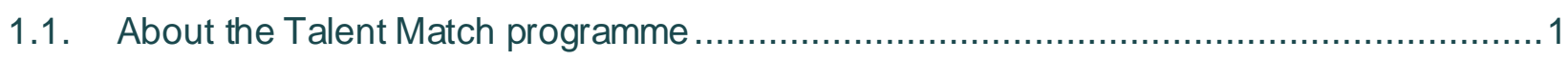

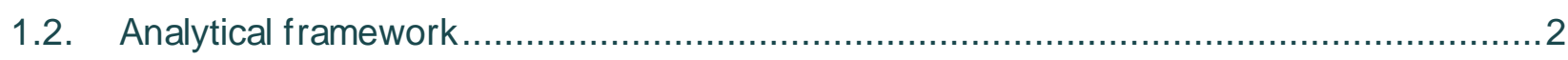

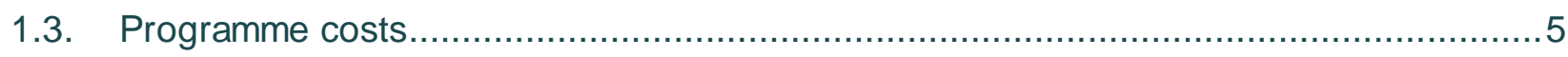

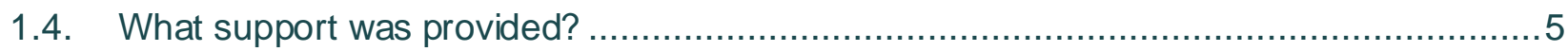

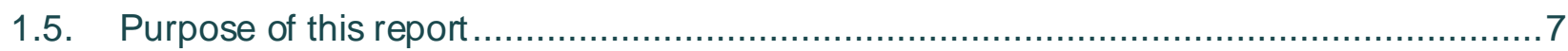

2. Talent Match participants and the support they received ................................. 8

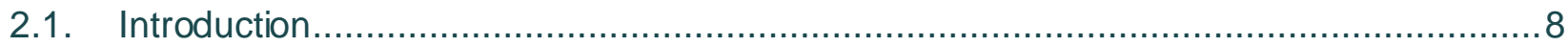

2.2. Young people participating in Talent Match........................................................ 8

2.3. The average cost of Talent Match per participant.............................................

2.4. The characteristics of those who participated in Talent Match .................................. 10

2.5. Support provided by Talent Match ................................................................. 11

2.6. Support related to the needs of the young person .............................................. 12

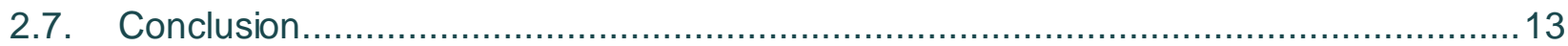

3. Outcomes achieved by Talent Match participants ..................................... 15

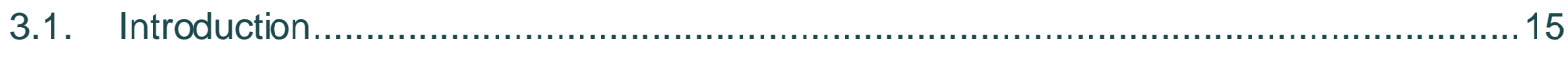

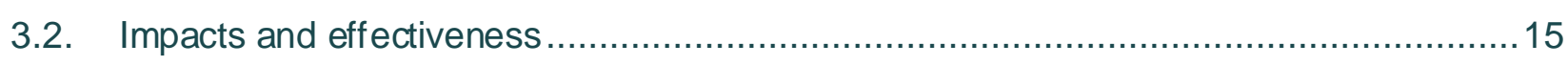

3.3. Average cost per young person into employment/self -employment..........................17

3.4. Nature and quality of employment/seff-employment .......................................... 18

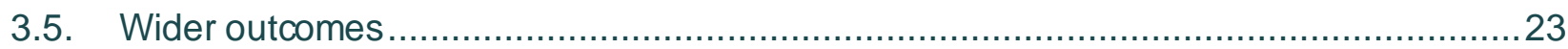

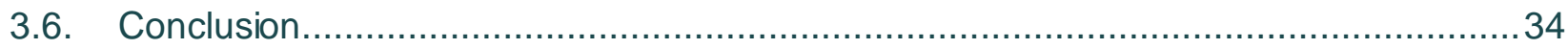

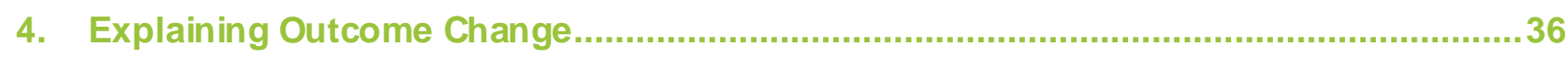

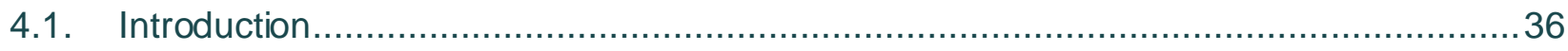

4.2. The relative importance of young person, partnership and area factors .......................36

4.3. Factors associated with gaining an employment outcome ..................................... 37

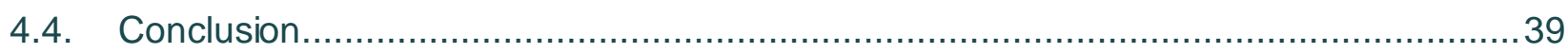

5. Employment add litionality of Talent Match............................................. 40 


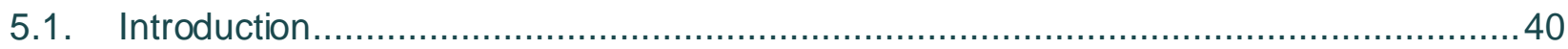

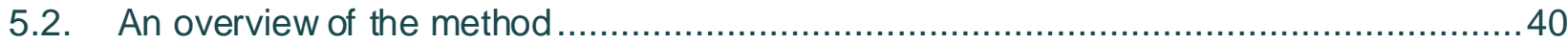

5.3. Employment outcomes compared to a matched Labour Force Survey comparator ........41

5.4. Young people's perceptions of the importance of Talent Match .................................43

5.5. Qualitative reflections about the difference Talent Match made .................................44

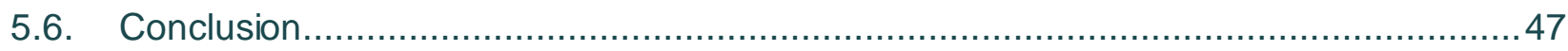

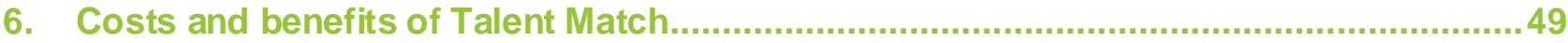

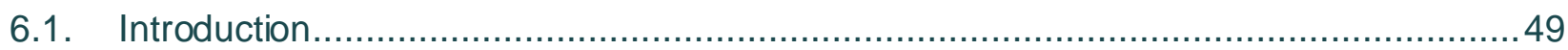

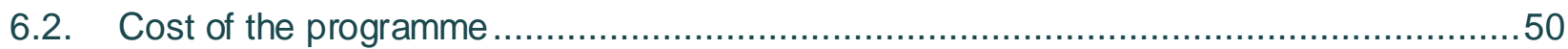

6.3. Additional income of participants achieving an employment outcome ........................50

6.4. Economic output produced by participants achieving an employment outcome..............51

6.5. Additional life satisfaction value gained by participants........................................52

6.6. The direct and indirect change in government spending ...................................... 53

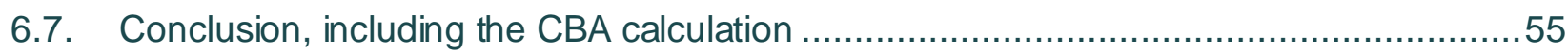

7. Key find ings and implications

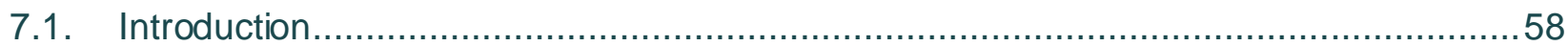

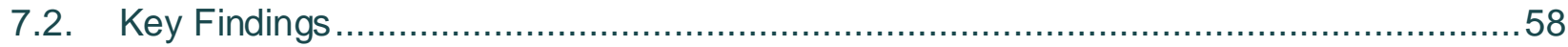

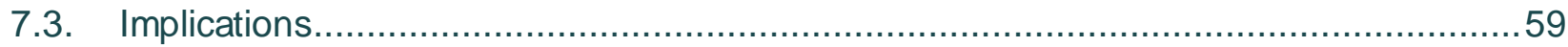

Appendix 1: Characteristics of Talent Match participants......................................62

Appendix 2: My Journey Scale ................................................................................... 67 


\section{Glossary}

\begin{tabular}{|c|c|}
\hline Additionality & $\begin{array}{l}\text { The employment and self-employment jobs gained by participants that } \\
\text { occurred because of - and are attributable to - the Talent Match } \\
\text { programme. They are additional and would not have occurred without } \\
\text { the Talent Match programme. }\end{array}$ \\
\hline Benefit Cost Ratio & $\begin{array}{l}\text { A benefit-cost ratio (BCR) is a ratio used in a cost-benefit analysis to } \\
\text { summarise the overall relationship between the } \\
\text { relative costs and benefits of, in this case Talent Match. A BCR greater } \\
\text { than } 1.0 \text { indicates that Talent Match is expected to deliver positive } \\
\text { benef its greater than its cost. Conversely a BCR less than } 1.0 \text { indicates } \\
\text { costs are greater than the benefits. }\end{array}$ \\
\hline Beneficiaries & $\begin{array}{l}\text { Young people who participated in and received support from the } \\
\text { Talent Match programme. }\end{array}$ \\
\hline \multirow[t]{2}{*}{$\begin{array}{l}\text { Common Data } \\
\text { Framework }\end{array}$} & $\begin{array}{l}\text { A Common Data Framework (CDF) was designed to collect standard } \\
\text { monitoring data from all partnerships on all beneficiaries. The CDF } \\
\text { formed a central part of the evaluation, collecting robust and reliable } \\
\text { beneficiary level data across the programme. This beneficiary data } \\
\text { allowed for the monitoring of who participated in Talent Match; what } \\
\text { they did; what difference it made to them; and what impact it made on } \\
\text { their labour market outcomes. }\end{array}$ \\
\hline & $\begin{array}{l}\text { The CDF was designed in the form of an online questionnaire. Data } \\
\text { was collected at a baseline stage (on entry to the programme) and } \\
\text { then at three, six, } 12,18 \text { and } 24 \text { months. The aim was to understand } \\
\text { progress into employment but also to pick up issues of labour market } \\
\text { progress, other factors (such as health, family circumstance or } \\
\text { housing) and ultimately whether the labour market experience was } \\
\text { 'fulfilling'. }\end{array}$ \\
\hline Cost effectiveness & $\begin{array}{l}\text { Cost effectiveness compares the number of young people who get a } \\
\text { job against the expenditure by Talent Match partnerships. A lower } \\
\text { resulting value indicates greater cost effectiveness since a given } \\
\text { outcome has been produced at a lower cost. }\end{array}$ \\
\hline Cost efficiency & $\begin{array}{l}\text { Cost efficiency compares the number of young people supported by } \\
\text { Talent Match against the expenditure by Talent Match partnerships. A } \\
\text { lower resulting value indicates greater cost efficiency because it costs } \\
\text { less to support/work with a given young person. }\end{array}$ \\
\hline $\begin{array}{l}\text { Distance (proximity) } \\
\text { to the labour market - } \\
\text { mention nearer and } \\
\text { further }\end{array}$ & $\begin{array}{l}\text { A composite distance from the labour market measure was created by } \\
\text { the evaluation team for Talent Match. It seeks to assess the } \\
\text { employability of participants. The assessment is based on } 12 \text { factors } \\
\text { covering educational attainment, previous labour market experiences, } \\
\text { attitudes, competencies and skills, health and engagement with }\end{array}$ \\
\hline
\end{tabular}




\begin{tabular}{|c|c|}
\hline & $\begin{array}{l}\text { services. Using the measure, it is possible identify young people who } \\
\text { are nearer to and further the labour market. }\end{array}$ \\
\hline Economic output & $\begin{array}{l}\text { The estimated value of all the goods and services produced by young } \\
\text { people who get a job through Talent Match. }\end{array}$ \\
\hline Effectiveness & $\begin{array}{l}\text { Effectiveness compares the number of young people who get a job } \\
\text { against the number who are supported by Talent Match partnerships. A } \\
\text { higher resulting value indicates greater effectiveness since a higher } \\
\text { proportion of young people get a job. }\end{array}$ \\
\hline \multirow[t]{2}{*}{ Employability } & $\begin{array}{l}\text { Broadly speaking is defined having the necessary skills, attributes and } \\
\text { competencies to, with little or no help, find, acquire, and keep an } \\
\text { appropriate job. }\end{array}$ \\
\hline & Similar to job readiness. \\
\hline Employment & The state of having paid work. \\
\hline Expenditure & The amount of money spent by Talent Match partnerships. \\
\hline Fiscal benefits & Tax and expenditure benefits for the Government. \\
\hline Future Jobs Fund & $\begin{array}{l}\text { The Future Jobs Fund (FJF) is a fund to support the creation of jobs, } \\
\text { lasting for up to six months, for young jobseekers and disadvantaged } \\
\text { older jobseekers }\end{array}$ \\
\hline Hidden NEETs & $\begin{array}{l}\text { "Hidden NEETs" are participants who were not receiving benefits and } \\
\text { were not working (either less than } 16 \text { hours per week or } 16 \text { hours or } \\
\text { more a week), self-employed, on apprenticeship, in formal education } \\
\text { or in training at the baseline stage. }\end{array}$ \\
\hline \multirow[t]{2}{*}{ Impact } & $\begin{array}{l}\text { The broader, longer-term change that it has caused by Talent Match. } \\
\text { This report focuses on the effects for young people who have } \\
\text { participated in the programme. Impacts can be both intended and } \\
\text { unintended, as well as both positive and negative. }\end{array}$ \\
\hline & $\begin{array}{l}\text { Impacts are calculated by measuring the (gross) outcome change and } \\
\text { subtracting what would have happened anyway (i.e. additionality). }\end{array}$ \\
\hline Inputs & $\begin{array}{l}\text { The resources that partnerships use to carry out their activities and } \\
\text { operations. }\end{array}$ \\
\hline Job readiness & $\begin{array}{l}\text { Broadly speaking is defined having the necessary skills, attributes and } \\
\text { competencies to, with little or no help, find, acquire, and keep an } \\
\text { appropriate job. Similar to employability. }\end{array}$ \\
\hline Labour Force Survey & $\begin{array}{l}\text { The Labour Force Survey (LFS) is a study of the employment } \\
\text { circumstances of the UK population. It is the largest household study } \\
\text { in the UK and provides the official measures of employment and } \\
\text { unemployment together with a wide range of related topics such as } \\
\text { occupation, training, hours of work and personal characteristics of } \\
\text { household members aged } 16 \text { years and over. As well as the main } \\
\text { survey, several sub-sample and derived datasets are also produced, } \\
\text { including longitudinal series and a Eurostat version of the dataset. Key } \\
\text { variables from the LFS and its boost samples are also used to create } \\
\text { the Annual Population Survey (APS). }\end{array}$ \\
\hline
\end{tabular}




\begin{tabular}{|c|c|}
\hline $\begin{array}{l}\text { Labour Force Survey } \\
\text { five quarter } \\
\text { longitudinal dataset }\end{array}$ & $\begin{array}{l}\text { The five-quarter longitudinal datasets include a subset of the most } \\
\text { commonly used variables from the Quarterly Labour Force } \\
\text { Survey (QLFS), covering the main areas of the survey. }\end{array}$ \\
\hline $\begin{array}{l}\text { Local labour market } \\
\text { conditions }\end{array}$ & $\begin{array}{l}\text { This is a summary of the relationship between local demand for } \\
\text { employees by employers and the supply of labour by employees. The } \\
\text { unemployment rate has been used as a proxy for the strength of the } \\
\text { local labour market conditions, with a higher unemployment rate } \\
\text { indicating a weaker labour market given the supply of employees is } \\
\text { greater than the demand by employers. }\end{array}$ \\
\hline Life satisfaction & $\begin{array}{l}\text { The Office for National Statistics life satisfaction question has been } \\
\text { used to assess the degree to which Talent Match participants report } \\
\text { changes in their overall life satisfaction. }\end{array}$ \\
\hline $\begin{array}{l}\text { Local Enterprise } \\
\text { Partnership }\end{array}$ & $\begin{array}{l}\text { Local Enterprise Partnerships (LEPs) are voluntary partnerships } \\
\text { between local authorities and businesses set up in } 2011 \text { by } \\
\text { the Department for Business, Innovation and Skills to help determine } \\
\text { local economic priorities and lead economic growth and job creation } \\
\text { within a local area. They carry out some of the functions previously } \\
\text { carried out by the regional development agencies which were } \\
\text { abolished in March } 2012 \text {. }\end{array}$ \\
\hline \multirow[t]{2}{*}{ Logic Model } & $\begin{array}{l}\text { A logic model is an evaluation tool which represents the theory of how } \\
\text { an intervention produces its outcomes. It represents, in a simplified } \\
\text { way, a hypothesis or 'theory of change' about how an intervention } \\
\text { works. }\end{array}$ \\
\hline & $\begin{array}{l}\text { Logic models commonly include aspects which summarise an } \\
\text { intervention's: inputs/resources, outputs, outcomes/impact, context } \\
\text { and the 'if-then' relationships between them. }\end{array}$ \\
\hline $\begin{array}{l}\text { Maryland Scientific } \\
\text { Methods Scale }\end{array}$ & $\begin{array}{l}\text { The Maryland Scientific Methods Scale classifies and grades studies } \\
\text { evaluating the effects of interventions according to their } \\
\text { methodological quality. It is a five-point scale ranging from one, for } \\
\text { evaluations based on simple cross-sectional correlations, to five for } \\
\text { randomised control trials }\end{array}$ \\
\hline Matched comparator & $\begin{array}{l}\text { The matched comparator in the Talent Match evaluation is a } \\
\text { comparison group from the Labour Force Survey that is used to } \\
\text { compare change with that experienced by Talent Match participants. } \\
\text { The comparison group comprises young people who are matched } \\
\text { based on their 'baseline' characteristics to ensure they are similar to } \\
\text { those of the Talent Match participant group at the beginning of the } \\
\text { intervention. The more similar the two groups are at baseline, the } \\
\text { more likely that the observed difference between the two groups after } \\
\text { the intervention can be attributed to Talent Match, and not to other } \\
\text { pre-existing differences (such as differences in previous labour market } \\
\text { experience) between the two groups. }\end{array}$ \\
\hline Mental health & $\begin{array}{l}\text { Talent Match partnerships identified a range of mental health issues } \\
\text { which were experienced by the young people that they were working } \\
\text { with. These included things like depression and anxiety, which for } \\
\text { some young people affected their ability to progress in the labour } \\
\text { market. . }\end{array}$ \\
\hline
\end{tabular}




\begin{tabular}{|c|c|}
\hline My Journey & $\begin{array}{l}\text { My Journey is a tool developed by the Princes Trust to help young } \\
\text { people and delivery partners measure what skills are developed } \\
\text { through a young person's involvement in an employability related } \\
\text { project. It asks young people to assess their position on a six point } \\
\text { scale in terms of the following aspects: communication, working with } \\
\text { others, setting and achieving goals, reliability, confidence and } \\
\text { managing feelings. }\end{array}$ \\
\hline $\begin{array}{l}\text { The National } \\
\text { Community Lottery } \\
\text { Fund }\end{array}$ & $\begin{array}{l}\text { Formerly the Big Lottery Fund, is a non-departmental public body } \\
\text { responsible for distributing funds raised by the National Lottery for } \\
\text { good causes. }\end{array}$ \\
\hline $\begin{array}{l}\text { New Deal for Young } \\
\text { People }\end{array}$ & $\begin{array}{l}\text { The New Deal for Young People was introduced in Great Britain in } \\
\text { January } 1998 \text { as one of the key parts of the government's welfare to } \\
\text { work strategy. The aims of the programme were to help } \\
\text { the young unemployed people into work and increase their } \\
\text { employability. }\end{array}$ \\
\hline $\begin{array}{l}\text { Not in education, } \\
\text { employment of } \\
\text { training (NEET) }\end{array}$ & $\begin{array}{l}\text { NEET refers to a person who is unemployed, not in school or vocational } \\
\text { training. }\end{array}$ \\
\hline Outcomes & $\begin{array}{l}\text { The changes that result from Talent Match. They can come either } \\
\text { wholly or in part as a direct result of the programme's actions. The } \\
\text { main outcomes measured in the Talent Match evaluation are jobs, } \\
\text { improved employability/job-readiness and improved wellbeing. }\end{array}$ \\
\hline Outputs & $\begin{array}{l}\text { The term outputs is used to refer to the amount of support that Talent } \\
\text { Match provides, and includes things like key worker support, mentoring, } \\
\text { support for job search activity, skills training and volunteering and work } \\
\text { placements. }\end{array}$ \\
\hline Participants & $\begin{array}{l}\text { Young people who have taken part in and been supported by the } \\
\text { Talent Match programme. }\end{array}$ \\
\hline $\begin{array}{l}\text { Positive labour } \\
\text { market actions }\end{array}$ & $\begin{array}{l}\text { These are action such which are typically part of the process of getting } \\
\text { a job or making progress in the labour market, such as completing } \\
\text { work related training, completing a work placement, putting together a } \\
\mathrm{CV} \text {, applying for jobs and taking part in interviews. }\end{array}$ \\
\hline Public purse & The funds raised by a government by taxation or other means. \\
\hline Quasi-experimental & $\begin{array}{l}\text { A quasi-experimental evaluation is an empirical study used to estimate } \\
\text { the causal impact of a programme on its participants without random } \\
\text { assignment. Instead, quasi-experimental designs use another criterion } \\
\text { other than random assignment to control the assignment to the } \\
\text { treatment condition. They are often used where the random allocation } \\
\text { of participants to intervention or control groups is not socially or } \\
\text { ethically desirable. The Talent Match evaluation uses a quasi- } \\
\text { experimental approach by comparing outcomes for Talent Match } \\
\text { participants with those for a matched comparator group drawn from } \\
\text { the Labour Force Survey. }\end{array}$ \\
\hline
\end{tabular}




\begin{tabular}{|c|c|}
\hline Self-employment & $\begin{array}{l}\text { A person is self-employed if they run their business for themselves } \\
\text { and take responsibility for its success or failure. }\end{array}$ \\
\hline Scientifically rigorous & $\begin{array}{l}\text { Scientific rigour means implementing the highest standards and best } \\
\text { practices of the scientific method. It involves minimising bias in subject } \\
\text { selection and data analysis. }\end{array}$ \\
\hline Societal benefits & $\begin{array}{l}\text { Societal benefits are benefits to society resulting from Talent Match. } \\
\text { These benefits include private benefits to the young person } \\
\text { themselves e.g. additional income or improvement in wellbeing plus } \\
\text { any external benefits from their participation, such as the economic } \\
\text { output they produced. }\end{array}$ \\
\hline $\begin{array}{l}\text { Statistically } \\
\text { significant }\end{array}$ & Statistically significant means a result is unlikely to be due to chance. \\
\hline Talent Match & $\begin{array}{l}\text { Talent Match is a five-year, } £ 108 \text { million National Community Lottery } \\
\text { Fund funded programme which supports young people aged } 18 \text { to } 24 \\
\text { years along the road to employment. }\end{array}$ \\
\hline Treasury Green Book & $\begin{array}{l}\text { The Green Book sets out the Treasury's guidance on how to appraise } \\
\text { and evaluate policies, projects and programmes. }\end{array}$ \\
\hline \multirow[t]{2}{*}{ Unemployment } & $\begin{array}{l}\text { The International Labour Organisation (ILO) definition of employment } \\
\text { is those aged } 16 \text { years or over who are without work, available to start } \\
\text { work in the next two weeks and who have either: a) been actively } \\
\text { seeking work in the past four weeks, or. b) are waiting to start a new } \\
\text { job they have already obtained. }\end{array}$ \\
\hline & $\begin{array}{l}\text { Unemployment is different from the Claimant Count, which measures } \\
\text { only those people who are claiming unemployment-related benefits. } \\
\text { The Claimant Count is normally the lower measure because some } \\
\text { unemployed people are not entitled to claim unemployment-related } \\
\text { benefits, or choose not to do so. }\end{array}$ \\
\hline Underemployment & $\begin{array}{l}\text { Situations where young people in a job want to work more hours than } \\
\text { they currently do. Respondents to the CDF, either in employment or } \\
\text { self-employment, were asked if in the past four weeks they had: } \\
\text { looked for an additional job; looked for a new job with longer hours; or } \\
\text { wanted to work longer hours in their current job. Responses to these } \\
\text { questions have been combined. If a respondent indicated they had } \\
\text { done any of the three things above they have been identified as } \\
\text { underemployed as defined by the Office for National Statistics (ONS). }\end{array}$ \\
\hline \multirow[t]{3}{*}{ Value for Money } & $\begin{array}{l}\text { Value for Money refers to the most advantageous combination of cost, } \\
\text { quality and sustainability to meet requirements. The evaluation uses } \\
\text { two criteria to assess the value for money of Talent Match }\end{array}$ \\
\hline & $\begin{array}{l}\text { Efficiency: the relationship between the output from goods or } \\
\text { services and the resources to produce them - spending well; and }\end{array}$ \\
\hline & $\begin{array}{l}\text { Effectiveness: the relationship between the intended and actual } \\
\text { results of public spending (outcomes) - spending wisely. }\end{array}$ \\
\hline
\end{tabular}




\begin{tabular}{|l|l|}
\hline Wellbeing & $\begin{array}{l}\text { Well-being is a broad concept which covers the experience of health, } \\
\text { happiness, and prosperity. It includes having good mental health, high } \\
\text { life satisfaction, a sense of meaning or purpose, and ability to manage } \\
\text { stress. } \\
\text { The Office for National Statistics' four wellbeing questions have been } \\
\text { used to measure the wellbeing of young people participating in Talent } \\
\text { Match. This asks respondents to rate their life satisfaction, feelings of } \\
\text { being worthwhile, happiness and anxiety, each on a scale of } 0 \text { to } 10 .\end{array}$ \\
\hline Work Programme & $\begin{array}{l}\text { The Work Programme (WP) was a government employability } \\
\text { programme introduced in Great Britain in June } 2011 \text {. It was the } \\
\text { flagship employment support scheme of the } 2010-2015 \text { UK coalition } \\
\text { government. Under the Work Programme the task of getting the long - } \\
\text { term unemployed into work was outsourced to a range of public } \\
\text { sector, private sector and third sector organisations. }\end{array}$ \\
\hline Young people & \begin{tabular}{l} 
In Talent Match, young people are those aged 18 to 24 years. \\
\hline
\end{tabular}
\end{tabular}




\section{Summary}

\section{Key findings}

- Talent Match supported almost 26,000 young people over the course of the programme.

- Talent Match supported young people who were often those furthest from the labour market and who faced substantial challenges to labour market participation, including low levels of mental health and wellbeing.

- Almost half of the programme participants moved into employment, and 17 per cent sustained employment for six months or more.

- Many young people would not have moved into work without the support of Talent Match (up to 28 per cent would not have gained a job without participating in the programme).

- Talent Match participants moving into work reported high levels of job satisfaction.

- Being in a stronger local labour market (with lower levels of unemployment) and having a greater level of job readiness were associated with a greater likelihood of finding work.

- Talent Match helped support participants to improve their wellbeing. The percentage of participants with a high life satisfaction more than doubled from nine to 24 per cent, to just below the national average. Seventy per cent of young people who gained a job reported improved life satisfaction. Even amongst those participants who did not find a job, three fifths (60 per cent) still reported an improvement in their life satisfaction.

- At least $£ 3.08$ of public value has been generated for every £1 spent on Talent Match programme delivery. This means that there is a positive social benefit associated with Talent Match.

- Substantial investment is required to support young people who are most disadvantaged in the labour market.

- The nature of employment opportunities open to young people meant that many participants who found a job remained eligible for welfare benefits and had low levels of taxation and National Insurance responsibility. Therefore, the evaluation did not identify a positive fiscal benefit from the programme.

\section{Introduction}

This report provides an assessment of the impact and value for money (VFM) of the Talent Match programme. This analysis forms one part of a wider evaluation of Talent Match which has looked across all aspects of the programme. The analysis presented here addresses the impact of the programme in relation to the progression of young people towards sustainable employment. It also provides an assessment of the costs and financial benefits associated with this goal. 
This report is one of a series of outputs from the evaluation. Other reports provide evidence on the success of Talent Match in developing local models and of support and co-production with young people. ${ }^{1}$ The aims of this report are as follows:

- To estimate the number of additional participants who have gained a job because of Talent Match.

- To provide the average cost of both delivering the programme for young people (its cost efficiency) and supporting participants into job outcomes (its cost effectiveness).

- Place a monetary value on the impact of the programme and from this provide a Benefit Cost Ratio (CBR).

We define all 'technical' terms where they are first used and also provide a glossary of terms at the start of this report.

\section{About Talent Match and its evaluation}

Talent Match was an $£ 108$ million strategic programme of The National Lottery Community Fund (The Fund), funded by the National Lottery. Talent Match was launched in 2012 against the backdrop of record levels of youth unemployment and implemented from 2014-18. Funding was distributed to 21 voluntary and community sector (VCS) led partnerships across England. The programme was one of five strategic programmes of The Fund, each with a common goal to support 'fulfilling lives'.

Talent Match was an innovative programme which focussed on bringing a youth centred, asset-based approach to the challenge of youth unemployment. Five defining features of the programme set it apart from any previous youth employment programme delivered at this scale in England:

- Support was provided on a personalised and individual basis, responding to the needs of participants.

- The programme aimed to support young people aged 18-24 who were furthest from the labour market to make progress towards sustainable employment.

- The programme was voluntary (participation could not be mandated) which was in contrast to government funded employment programmes at the time.

- The programme adopted a test and learn approach, designed explicitly to provide partnerships with scope to develop and adapt bespoke solutions, which responded to local priorities and opportunities.

- And above all, the programme was co-designed and co-delivered with young people.

As such, and unlike many previous employment interventions, Talent Match was not solely focused on the delivery of a narrow set of training and employment outcomes. Although helping young people to access job opportunities was an important goal for the programme, other goals were also integral to the approach. These included improving young people's wellbeing, developing responsive models of holistic support, building capacity in local areas to meet young people's needs, and increasing young people's influence on services.

The focus on developing more holistic and bespoke models of support also meant that Talent Match did not directly focus on achieving outcomes at a minimised cost. Whilst cost-efficiency is an important consideration for all public programmes, in Talent Match assessments of the costs and economic benefits of the programme need to be considered in the context of other

\footnotetext{
${ }^{1}$ See https://blogs.shu.ac.uk/talentmatch/
} 
programme priorities including youth engagement and local capacity building through partnership working. These are important caveats to the analysis presented in this report, and should be considered in particular when comparing the costs of Talent Match against those of other programmes which might have narrower objectives or more restricted delivery models.

There are considerable challenges in delivering and evaluating a complex social programme such as Talent Match:

- Against some high level design principles set by the National Lottery Community Fund, partnerships had considerable scope to design and develop activities to meet local needs and which young people requested. This meant that there were no prescribed approaches, but rather partnerships sought to improve effectiveness as the programme progressed (integral to the test and learn approach).

- The policy and economic landscape also changed considerably during the course of the programme. National government rolled out new policies such as apprenticeships and traineeships, the headline claimant rate of youth unemployment fell markedly, and also there was a concern that a greater proportion of young unemployed people were off benefits and beyond official statistics.

- And finally, there was a growing concern around low levels of mental health and wellbeing experienced by young people generally and young unemployed people in particular. These issues arose from young people's negative labour market experiences (including unemployment and cycles of low pay and precarious employment) and sometimes acted as a barrier to achieving sustained work. Consequently, Talent Match partnerships focussed on implementing interventions to address the causes and symptoms of low mental health and wellbeing alongside more standard packages of employability support (focused on qualifications, skills and workplace attributes).

These challenges and changes are not unique in the implementation of youth employment programmes. They do however present challenges to evaluation - it is simply not possible to implement Talent Match in one place and hold other things constant in another place.

The analysis presented in this report follows much prior work on employment programme evaluation in seeking to combine and triangulate methods to estimate the impact and value for money of the programme. It follows the UK Government Treasury guidance on the evaluation of social interventions. Whilst this is widely accepted to be the most robust approach to impact and value for money assessment there are also some important limitations to note:

- The method does not capture all the benefits associated with the Talent Match programme: there are likely to be other benefits for young people and communities which it has not been possible to capture.

- The evaluation has only captured benefits over a limited time period. Although Talent Match has developed an important and substantial dataset on the employment outcomes for young people there is insufficient evidence available for us to estimate the longer term benefits for young people who moved closer to the labour market.

- Not all of the benefits associated with Talent Match can be assigned a monetary value.

\section{What did Talent Match achieve?}

By the end of December 2018, 25,885 young people had participated in Talent Match and £96 million of the original programme budget had been spent. This represents 93 per cent of the original target for participant numbers and 89 per cent of the originally planned expenditure. 
Compared to the national population of young people not in education, employment or training (NEET), Talent Match participants were more disadvantaged and further from the labour market. In addition, Talent Match participants also reported low levels of mental health something which is known to be a key barrier to work.

Differences between Talent Match partnerships (such as the strength of the local labour market and whether partnerships tended to work with young people closer to or further from the labour market) explained some of the differences in the costs incurred by partnerships. In simple terms working with young people further from work and in weaker labour markets (indicated by higher levels of unemployment) cost significantly more.

The original goal of the programme was to assist two fifths (40 per cent) of participants into employment, including one fifth (20 per cent) of those supported into sustained employment. Summarising the achievements of Talent Match:

- 46 per cent of participants (11,940 young people) were supported into employment/selfemployment; at an average cost of £8,052 per participant.

- This included 17 per cent (4,479 young people) for whom this was sustained; at an average cost of $£ 21,468$ per participant.

- Over four fifths of young people were satisfied with the work that they had found.

- Talent Match helped support participants to improve their wellbeing, with 70 per cent of participants who gained a job reporting an improvement in their life satisfaction. Similarly, even amongst those participants who did not find a job, 60 per cent still reported an improvement.

- Where Talent Match participants were unable to gain a job many were able to improve their job readiness and well-being and had taken positive actions towards getting a job, such as putting a CV together, applying for a job and attending an interview.

\section{Explaining achievements}

Further analysis identified factors that were associated with a young person finding work. Factors relating to the participants themselves, such as their qualifications or previous employment experience, explained nearly all of the variation in the likelihood of a young person securing work. However, factors relating to where the participant lived were also found to have a statistically significant effect.

This means that the health of the local labour market and young people's initial level of job readiness were found to be associated with the likelihood of a participant securing employment/self-employment. These factors shape what any employment programme can achieve.

Our analysis also identified the factors which were associated with an increased likelihood of getting a job:

- Participants who received many different interventions (whether this be one-to-one support, counselling, transport support or childcare) were more likely to gain employment.

- Completing labour market activities such as attending interviews, applying for jobs and completing an apprenticeship were associated with an increased likelihood of finding employment.

- Improved job readiness was associated with an increased likelihood of finding employment. The strongest relationships - and hence the most important aspects to target - were identified as being overall proximity to the labour market, job specific skills, motivation, teamwork skills and reliability. 


\section{Additional employment and other outcomes}

The evaluation made an assessment of the degree to which participation in Talent Match contributed to a young person getting a job. This assessment of additionality (the additional benefit of the programme) acknowledges that some of the participants would have secured a job even without participating in Talent Match. It is not to say that the programme hasn't made a positive difference to their lives and employment prospects but rather other factors mean that they would have got a job in any case. The evaluation adopted a quasi-experimental approach to this assessment. This involved comparing the number of participants gaining a job against a matched group of similar young people from the Labour Force Survey (LFS); an employment survey run by the Office of National Statistics. ${ }^{2}$

The approach surpasses many previous UK evaluations of employment initiatives in terms of scientific rigour. As such, the assessment outlined in this report may appear harsher, albeit more realistic, than those which rely on other, of ten more qualitative, methodologies. However given the complexities involved in the method and some limitations in the data (see Chapter 5 ), the report provides a range between two estimates for the number of additional participants who gained a job because of Talent Match. These show that up to 28 per cent of participants who secured a job would not have done so without Talent Match. This implies 3,298 additional young people gaining a job (13 per cent of participants); including 1,237 obtaining a secure job (five per cent of participants).

Both the lower and upper estimates suggest that Talent Match has achieved a high level of additionality compared to previous interventions targeted at young people. It is important to view the level of impact in light of the relative scale of influence that Talent Match would be expected to have on the likelihood of a young person finding a job, over and above other factors. Other important influences will include changes in personal circumstances, involvement in mandatory and voluntary labour market interventions and job search as well as a growth in the supply of jobs in the wider labour market.

The benefits of Talent Match were not only in terms of the employment and self-employment jobs gained. Programme participants also experienced improvements in job readiness and well-being and were overwhelmingly positive about their experiences on the programme.

\section{Costs and benefits of Talent Match}

All employment programmes will bring benefits to society (mainly for the individuals directly benefiting from a programme) and for government in terms of reductions in spending and greater receipts from taxation. These are two different things: one is the valuation of wider societal benefits (public) whilst the other is the narrower direct monetary effects on the public purse (these are called fiscal benefits). The relationship between the costs of programme delivery and the monetary value of benefits achieved is expressed as a Benefit Cost Ratio (BCR).

A detailed consideration of the public and fiscal benefits, and how these are established, is provided in Chapter 6.

The monetised value of the additional public benefits considered is found to exceed the programme's cost with at least $£ 3.08$ of public benefit being created for every $£ 1$ spent. This $\mathrm{BCR}$, of at least 3.08:1, is an impressive outcome for the Talent Match programme, and testament to the emphasis placed by Talent Match partnerships on developing holistic support

\footnotetext{
2 The analysis compared the number of Talent Match participants who gained a job in a 12 -month period to a matched group of similar young people from the Labour Force Survey Five Quarter Longitudinal Panel. More information about the Labour Force Survey Five Quarter Longitudinal Panel can be found here: https://www.ons.gov.uk/employmentandlabourmarket/peopleinwork/employmentandemployeetypes/methodologie s/labourforcesurveyuserguidance\#labour-force-survey-lfs-user-guides
} 
models which addressed multiple aspects of disadvantage experienced by young people who were participating in the programme. However, the immediate fiscal benefits were small and did not exceed the cost of the programme: up to $£ 0.08$ of additional fiscal benefit is provided per $£ 1$ of Talent Match expenditure. This reflects the substantial investment that is required to support young people who are most disadvantaged in the labour market. In addition, the nature of employment opportunities open to young people meant that many participants who found a job remained eligible for welf are benefits and had low levels of taxation and National Insurance responsibility.

It should also be stressed that the design and implementation of Talent Match, as a strategic, innovative and to some extent experimental programme, brought with it additional costs in terms of programme delivery. If Talent Match was replicated, and the lessons around design and implementation learned through programme evaluation were reflected in new delivery models, then the BCR of a future programme would be even higher.

\section{Reflections}

Talent Match was an innovative programme containing a range of experimental and novel features and with an explicit objective to support young people who were facing labour market disadvantage. Beyond the narrow scope of impact, the participative and inclusive approach was found to improve the legitimacy of the programme and Talent Match is best understood as a wider youth engagement and capability building programme as opposed to one that was narrowly focused on employment outcomes. Improving job readiness, employability and wellbeing for individuals, as well as involving young people and develop ing sustainable models of holistic support were equal to the programme's aims to support participants into sustainable jobs.

This highlights the important elements to consider when assessing the impact and value for money. The following key reflections can be drawn from this work:

- In order to achieve the work outcomes that it did Talent Match provided resource intensive in-depth, person-centred packages of holistic support to its participants. This has important implications for designing and setting expectations for future employment initiatives. In particular, lower employment outcome expectations and significant additional resourcing are required when supporting those furthest from the labour market in weaker labour market areas. There is also a need for work with employers to increase the number of jobs in weaker labour market areas and to improve the access to jobs for young people. This will require large scale interventions that are likely to go far beyond what programmes such as Talent Match can plausibly achieve.

- Although the vast majority of participants were satisfied in the jobs that they had found, where issues existed they often related to increasingly common features of the modern labour market (such as zero-hours contracts and underemployment). Addressing these will require significant work to affect the types of jobs in the economy as well as with employers to improve their terms and conditions, again something well beyond what Talent match tried, or would have been able to achieve.

- Talent Match has highlighted the importance of capturing a wider range of employability and well-being outcomes. This includes improving skills and competencies, and improving wellbeing as well as the completion of positive labour market actions such as work-related training, work placements, applying for jobs and taking part in interviews. The cost benefit analysis reveals how the fiscal benefits of Talent Match are far lower than the cost of the programme. This is because the nature of employment opportunities open to young people means that many participants who gain a job remain eligible for welfare benefits and have low levels of taxation and National Insurance responsibility. Therefore, the case for Talent Match lies in the substantial social value that it has provided by improving the life 
satisfaction of its participants through, for example, raising their confidence and employability as well as supporting young people into work.

- It is important to note however, that the support provided by Talent Match partnerships was not always enough to address low levels of reported wellbeing amongst young people participating in the programme. For example, life satisfaction got worse for just under a quarter of young people who did not find employment. Whilst lots of factors determine levels of subjective wellbeing, that a significant group of young people are reporting low levels of wellbeing should raise concerns not just for future employment programmes but more broadly for policies supporting young people. Negative labour market experiences will be a contributing factor to these issues and low wellbeing will act as a barrier to achieving sustained work. Consequently, interventions addressing the causes and symptoms of low mental health and wellbeing need to be a core feature of holistic employability support.

As such, additional benefits to future programmes could be derived through the following:

- A clearer assessment of which young people in a local area the partnership has the capability to support. As a voluntary programme without mandated referral routes Talent Match partnerships did need to support those who engaged. However, greater focus of support after this point may have yielded more benefits in specific targeting of those furthest from the labour market. This may have been helped by a more critical reflection by partnerships as to which groups of young people they could help most effectively.

- The wider development of a local network or ecosystem of employment support, including education and training providers, Jobcentre Plus, health and mental health services, employers, and the voluntary and community sector was needed to avoid duplication. Many Talent Match partnerships sought to convene this, and with some success, however many also faced considerable barriers and had to fall back on delivering the support to young people without being able to engage other partner organisations.

- And possibly whilst partnerships took a broad approach to 'test and learn' there may have been greater efficiencies by taking a genuinely innovative approach which targeted and tested more specific approaches. This might be in terms of either working with more particular groups of young people, trying more specific interventions, or looking more closely at the outcomes which were being sought.

These lessons can be distilled into recommendations for public policy, for funders of the voluntary and community sector, for commissioners, and for local VCS organisations.

- Public Policy. Talent Match has surfaced the complex and deep-seated challenges many young people face. At the time of Talent Match, other programmes were not directly addressing these challenges. The evidence from the programme calls for a rethink into the main direction youth policy.

- VCSE Funders. Talent Match intervened at a local - Local Enterprise Partnership - level. This was a novel level for the National Lottery to work at and on balance was the right one. However, it also brought additional costs in terms of developing and then coordinating partnerships at this new level.

- Commissioners. Local commissioners of youth employment interventions, such as Combined Authorities, may bring greater convening powers than was possible under Talent Match. This may also bring efficiencies in terms of more streamlined governance. However, a key benefit of Talent Match - around the role of VCSE organisations in engaging young people - should not be lost.

- VCSE Organisations leading Partnerships. This role was a necessary one to ensure local coordination and consistent approaches to performance management. The skills and capabilities of organisations to play this role did however vary. 
Youth unemployment is likely to increase in the future and consequently may become a national policy priority. Talent Match demonstrates the benefits of local approaches in supporting those who are furthest from the labour market. 


\section{Introduction}

\subsection{About the Talent Match programme}

The National Lottery Community Fund (formerly the Big Lottery Fund, hereafter The Fund) invested $£ 108$ million in Talent Match, an innovative programme designed to address unemployment amongst 18-24 year olds; and in particular the high levels of youth unemployment following the financial crash of 2007/08 and subsequent recession. The programme, funded by the National Lottery, was delivered through voluntary and community sector (VCS) led partnerships in 21 Local Enterprise Partnership (LEP) areas in England. It aimed to support those furthest from the labour market in their journey towards sustainable employment. The 21 Talent Match partnerships started worked with participants from 2014-2018.

Talent Match was an innovative and novel programme which focussed on bringing a youth centred, asset-based approach to the challenge of youth unemployment. Five defining features of the programme set it apart from any previous youth employment programme delivered at this scale in England:

- Support was provided on a personalised and individual basis, responding to the needs of participants.

- The programme aimed to support young people aged 18-24 years who were furthest from the labour market to make progress towards sustainable employment.

- The programme was voluntary (participation could not be mandated) which was in contrast to government funded employment programmes at the time.

- The programme adopted a test and learn approach, designed explicitly to provide partnerships scope to develop and adapt bespoke solutions, which responded to local priorities and opportunities.

- And above all, the programme was co-designed and co-delivered with young people.

As such, and unlike many previous employment interventions, Talent Match was not solely focused on the delivery of a narrow set of training and employment outcomes. Although helping young people to access job opportunities was an important goal for the programme, other goals were also integral to the approach. These included improving young people's well-being, developing responsive models of holistic support, building capacity in local areas to meet young people's needs, and increasing young people's influence on services. 


\subsection{Analytical framework}

The assessment provided in this report has been informed by a Logic Model underlying the Talent Match programme (Figure 1.1) and has been based on an Impact and Value for Money (VFM) framework rooted in The Treasury's Green Book principles ${ }^{3}$. As far as possible this involves establishing a scientific 'experimental' type approach. The framework includes reporting inputs, outputs, outcomes and net additional impacts as well as calculating cost efficiency and cost effectiveness. In simple terms:

- The assessment of impact involves computing the number of additional participants who have gained a job because of Talent Match, over and above those would have found a job in any case; this is called additionality.

- And VFM assesses:

- The average cost of the support provided to participants: the programme's cost efficiency.

- The average cost of Talent Match per job gained: the programme's cost effectiveness.

Ultimately it is possible to put a monetary value on the additional impact of the programme and from this to provide a Benefit Cost Ratio (BCR). The Benefit Cost Ratio therefore shows what additional impact has been achieved for every additional unit of money spent (in pound sterling).

In estimating the additionality and value for money of Talent Match we have drawn on a range of datasets and used different analytical techniques. At the heart of the approach has been the data gathered on every participant in Talent Match, collected through a Common Data Framework ${ }^{4}$ (CDF). From this we have been able to understand the characteristics of those who have participated in Talent Match, the support that they have received and the outcomes they have achieved - ranging from job outcomes to improved job-readiness and well-being. These can be compared across partnership participant groupings.

This data collection has been supported by qualitative research to understand, for example, how outcomes were achieved (or why not) for individuals. Importantly job outcomes for Talent Match participants have been compared against a matched wider population group using the Office for National Statistics Labour Force Survey Five Quarters Longitudinal Sample. This quasi-experimental comparative method gives a scientifically rigorous measure of additionality: the 'difference' Talent Match made to participants over and above what would have happened in any case.

It is important to note however that there are considerable challenges in delivering and evaluating a complex social programme such as Talent Match:

- Against some high level design principles set by the National Lottery Community Fund, partnerships had considerable scope to design and develop activities to meet local needs and which young people requested. This meant that there were no prescribed approaches but rather partnerships sought to improve effectiveness as the programme progressed (integral to the test and learn approach).

\footnotetext{
${ }^{3} \mathrm{HM}$ Treasury (2003) The Green Book: Appraisal and Evaluation in Central Government. London: TSO. http://www.hm-treasury.gov.uk/d/green book complete.pdf

${ }^{4}$ Detailed information about the Common Data Framework is contained within the technical report that sits alongside the final suite of Talent Match reports.
} 
- The policy and economic landscape also changed considerably during the course of the programme. National government rolled out new policies such as apprenticeships and traineeships, the headline claimant rate of youth unemployment fell markedly, but also there was a concern that a greater proportion of young unemployed people were off benefits and beyond official statistics.

- And finally, there was a growing concern around low levels of mental health and wellbeing experienced by young people generally and young unemployed people in particular. These issues arose from young people's negative labour market experiences (including unemployment and cycles of low pay and precarious employment) and for some acted a barrier to achieving sustained work. Consequently, Talent Match partnerships focussed on implementing interventions to address the causes and symptoms of low mental health and wellbeing alongside more standard packages of employability support (focused on qualifications, skills and workplace attributes).

These challenges and changes are not unique in the implementation of youth employment programmes. They do however present challenges to evaluation - it is simply not possible to implement Talent Match in one place and hold other things constant in another place.

Our approach to the assessment of impact and value for money follows much prior work on employment programme evaluation in seeking to combine and triangulate methods to estimate the impact and value for money of the programme and follows Treasury guidance on the evaluation of social interventions. Whilst this is widely accepted to be the most robust approach to impact and value for money assessment there are also some important limitations to note:

- The method does not capture all the benefits associated with the Talent Match programme: there are likely to be other benefits for young people and communities which it has not been possible to capture.

- The evaluation has only captured benefits over a limited time period. Although Talent Match has developed an important and substantial dataset on the employment outcomes for young people there is insufficient evidence available for us to estimate the longer term benefits for young people who moved closer to the labour market.

- Not all of the benefits associated with Talent Match can be assigned a monetary value.

Finally, the focus on developing more holistic and bespoke models of support also meant that Talent Match did not directly focus on achieving outcomes at a minimised cost. Whilst cost-efficiency is an important consideration for all public programmes, for Talent Match assessments of the impact and value of the programme need to be considered in the context of other programme priorities including youth engagement and local capacity building through partnership working. These are important caveats to the analysis presented in this report, and should be considered in particular when comparing the costs of Talent Match against those of other programmes which might have narrower objectives or more restricted delivery models. 
Figure 1.1: Talent Match Logic Model

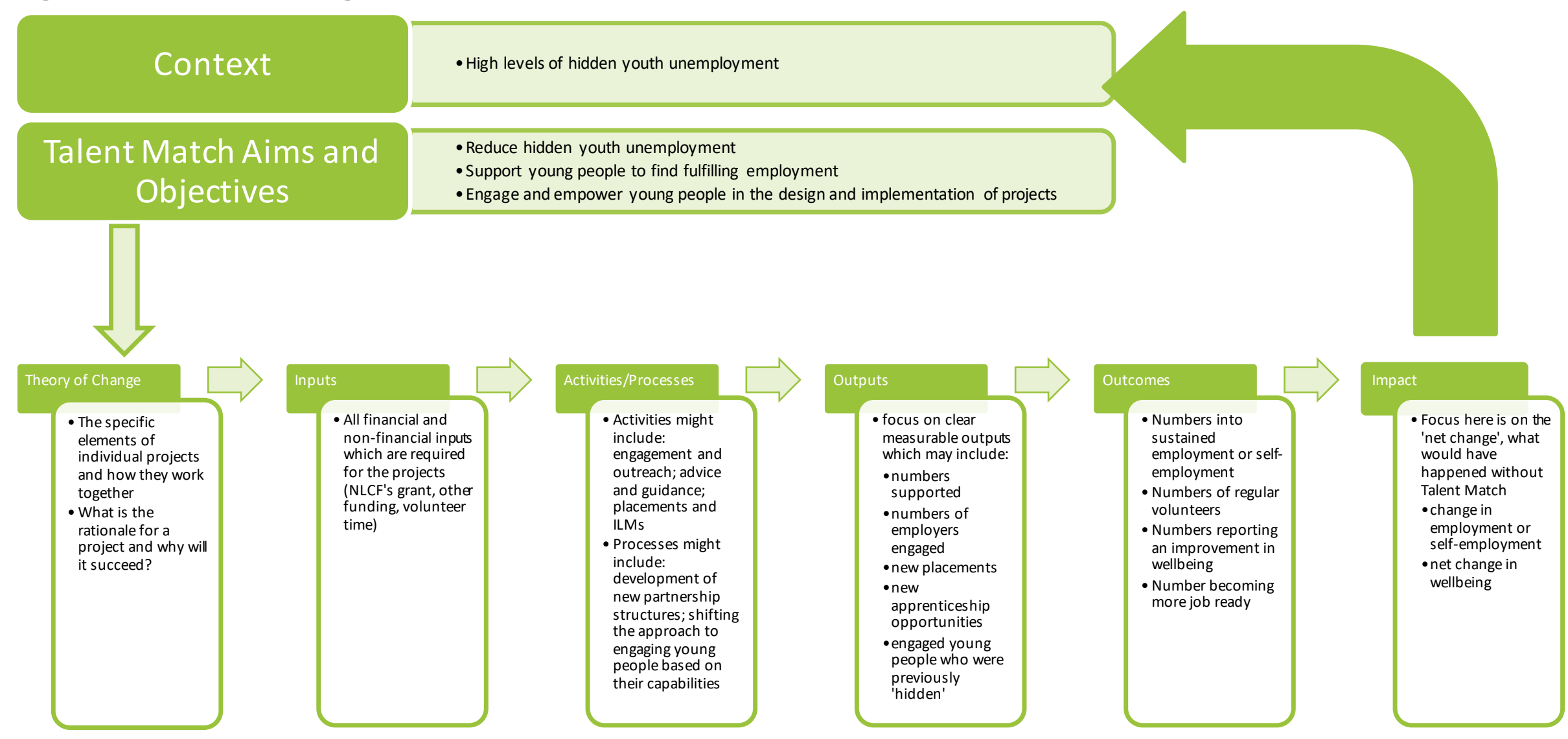




\subsection{Programme costs}

This section provides an assessment of expenditure to 31 December 2018 - the main date for the end of the programme.$^{5} \mathbf{£ 9 6 . 1 4 4}$ million of grant expenditure had been spent by the end of 2018.

There were large differences in expenditure between partnerships (ranging from £1.1 million to $£ 10.5$ million) reflecting the size of the original grant allocations they received. Original allocations were based on many factors including the size of the areacovered, the scale of youth unemployment and the challenges to be addressed as well as the delivery model and interventions that were being applied.

The cost of the programme is used throughout this report to calculate the average cost of working with participants, the average cost per participant into work and as part of a comparison of monetised benefits to cost. In these calculations it should be noted that the figure represents the total expenditure by the 21 Talent Match partnerships, including both delivery and non-delivery specific costs. Many non-delivery specific costs - such as those for local evaluation and partnership development - would not be part of a 'mainstreamed' version of Talent Match. Talent Match also did not directly focus on minimising costs. Instead it sought to provide the freedom for partnerships to 'test and learn', facilitate the development of partnerships and capacity building, and enabling more resource intensive activity with those who need it.

\subsection{What support was provided?}

There was a relative degree of consistency in terms of partnership approaches to preemployment support. All partnerships engaged participants in some form of preemployment support, from an initial assessment on first engagement through to more specialised services and job search. The following were typical activities prominent in many partnerships. With the exception of therapeutic support and peer mentoring some of the more innovative approaches - all 21 partnerships provided these services or offered referral routes to them:

- initial assessment

- development of an individualised plan

- information, advice and guidance (IAG)

- basic skills (e.g. literacy and numeracy provision)

- soft skills (e.g. confidence building)

- employability skills

- peer mentoring

- therapeutic support

- specialist support

- job search.

${ }^{5} \mathrm{~A}$ small number of partnerships continued Talent Match funded activity into 2019 using underspends in the programme. 
Likewise, in terms of pre-employment training that takes place in the workplace, the vast majority of partnerships offered:

- Pre-enterprise advice and support (often through a mentoring approach with an established entrepreneur or businessperson).

- Short term work experience and work placements to give an initial or recent experience of employment.

- Structured volunteering with clear benefits for volunteers in terms of job skills.

- Internships were less popular among partnerships, reflecting negative press they had received, resulting in them sometimes being seen as an exploitative form of cheap labour.

\section{$\underline{\text { SCR }}$}

This single 18-year-old white male was living in a hostel and had been claiming Jobseeker's Allowance (JSA) for over two years prior to participation in Talent Match (TM). He was looking for employment in retail, IT or catering but reported that low confidence, a lack of qualifications and previous work experience were key labour market barriers. He also had a learning disability which could make personal communication more difficult. His highest qualifications were Level 1 (GCSEs D-G).

During his time on the programme he had received a range of support including help with applying for jobs and interviews, work experience and volunteering, one-to-one support, IAG, support with travel and in-work support. He rated the support received from as 'very good'. This had allowed him to move from the hostel into private rented accommodation and secure a full-time job. The training provider selected him for an award to recognise his achievements which also involved a visit to the House of Commons. He indicated that Talent Match support was 'very important' in gaining employment. The job was described as interesting but had limited promotion prospects. Consequently, it was viewed primarily as a 'stepping stone' in the labour market. He was also receiving on-going in-work support related to his communication difficulties.

Though the exact nature of pre-employment support varied by partnership and by individual, there was a degree of commonality in the kinds of support that Talent Match partnerships had in place.

There was more divergence with regard to employer engagement and the inclusion of employer focused interventions. Almost all partnerships performed some form of job brokerage - linking beneficiaries to labour market opportunities. A majority also engaged with employer mentors. That is, local employers who supported beneficiaries in various ways, such as through enterprise development and support. All partnerships also provided opportunities for work experience or placements which provided beneficiaries with important experience in the work environment.

There was less consistency in terms of job creation activities and the development of demand-side interventions. Around half the partnerships provided employment opportunities directly through the Talent Match programme. Typically, this related to Talent Match apprentices employed through the projects or other job roles being filled by Talent Match beneficiaries.

Direct employment at Talent Match partnerships aside, only eight partnerships engaged in employer focused activities involving the creation of jobs for Talent Match 
participants. These tended to be the larger urban partnerships and those which received the larger grants: the Black Country, Birmingham and Solihull, Derbyshire and Nottinghamshire, Leeds, Liverpool, London and Manchester. New Anglia represented an outlier in this regard given its mixed urban-rural context and a relatively smaller grant. However, it should be noted that a rationale of the Prince's Trust led partnerships, which include New Anglia, was to feed into other provision offered by the Prince's Trust.

Seven partnerships provided employersubsidies to those who employed Talent Match beneficiaries with a view to more sustainable employment further down the line. Again these tend to be larger urban partnerships with sizeable grants.

\subsection{Purpose of this report}

This report provides an assessment of the Impact and Value for Money (VFM) of the Talent Match programme. In simple terms it:

- Considers the difference Talent Match has made to the outcomes of young people (this is called additionality).

- Assesses the value for money (VFM) of both outputs (the programme's cost efficiency) and outcomes (its cost effectiveness).

- Puts a monetary value on the additional impact of the programme and from this provides a Benefit Cost Ratio (BCR). The Benefit Cost Ratio shows what additional impact has been achieved for every additional unit of money spent (in pounds sterling).

Essentially this report proceeds in a step-wise fashion in building up the evidence base to estimate additionality and to assess value for money. It starts by looking at the costs of Talent Match, and then considers the benefits of the programme. 


\section{Talent Match participants and the support they received}

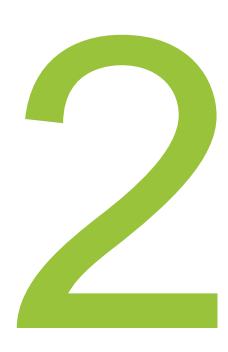

\subsection{Introduction}

This chapter examines:

- The number of young people engaged and how this compares against targets.

- The average costs of engag ing participants (the cost efficiency of the programme).

- The characteristics of participants and how they compare to other populations.

- The activities and support received by young people from the partnerships.

\subsection{Young people participating in Talent Match}

By the end of December 2018, 25,885young peoplehad participated in Talent Match. ${ }^{6}$ This represented 93 per cent of the targeted number of participants that collectively Talent Match partnerships set out to engage, as set out in their applications to The National Lottery Community Fund.

\section{5,885 young people participated in Talent Match}

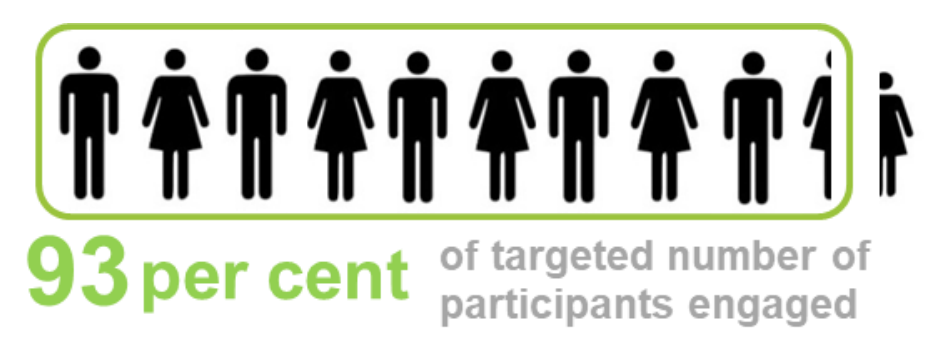

There was a large variation between partnerships, both in the absolute number of young people engaged and in the progress that partnerships made towards their own target. Nine partnerships had exceeded their target by the end of December 2018. Conversely 12 partnerships had not attained their target by this point. It is important to note however, that the National Lottery Community Fund

\footnotetext{
${ }^{6}$ Based on baseline questionnaire responses to the Common Data Framework (CDF).
} 
took a flexible approach to target setting. This included promoting innovation and the quality of outcomes for young people over the numbers of young people supported and maximising value for money.

\subsection{The average cost of Talent Match per participant}

The average cost - or cost efficiency - of Talent Match per participant is calculated by comparing the total amount of expenditure to the number of young people who participated in the programme over the same time period. Across the programme as a whole:

\section{$£ 3,714=$ the cost per participant}

As discussed in section 1.3, this is based on the total expenditure by the 21 Talent Match partnerships, including both delivery and non-delivery specific costs. Therefore it will overstate the average operating cost of delivering Talent Match since it includes non-delivery specific costs, such as local evaluation and partnership development. The evaluation did attempt to disentangle different types of costs but differences in reporting by partnerships meant this proved unsuccessful.

The average cost efficiency figure masks considerable variation in the true cost of working with young people with very different support requirements. In light of this a four-fold typology was created to explore differences between partnerships, based both on the characteristics of the young people and their local labour market conditions. Partnerships were assigned to groups based on the proportion of participants who were classed as 'far from the labour market' ${ }^{7}$ as well as the prevailing unemployment rate $^{8}$ in their LEP area (in June 2016). Table 2.1 shows the number of partnerships in each category.

Table 2.1: Typology of Talent Match partnerships by participant characteristics and local labour market conditions

\section{Classification \\ Labour market distance / local labour market conditions}

1. Further from LM - Higher

unemployment

2. Further from LM - Lower unemployment

3. Nearer to LM - Higher unemployment

4. Nearer to LM - Lower unemployment
Partnerships

Black Country, Greater Manchester, Humber, Liverpool City Region, Sheffield City Region, Tees Valley

Cornwall \& Isles of Scilly, Coventry \&

Warwickshire, Derbyshire \& Nottinghamshire,

Greater Lincolnshire, Leeds City Region,

Northamptonshire, Stoke on Trent \& Staffordshire, Worcestershire

Greater Birming ham \& Solihull, North East

Leicester \& Leicestershire, London, New Anglia, South East, The Marches

\footnotetext{
${ }^{7}$ Based on a composite distance from the labour market measure, created by the evaluation team for Talent Match. The assessment is based on 12 factors covering educational attainment, previous labour market experiences, attitudes, competencies and skills, health and engagement with services.

8 The claimant unemployment rate is used as an indicator of the health of the local labour market, with a higher unemployment rate indicating a weaker local labour market.
} 
Table 2.2 compares the average cost per participant for the four partnership typology groupings. It reveals a higher average cost for partnerships working with young people furthest from the labour market and in high unemployment (i.e. weaker labour market) areas, compared to the other three groupings. Conversely, the average cost per young person was lowest for the grouping working with more young people nearer to the labour market and in a healthier labour market area (with a lower unemployment rate). These findings highlight the extra resourcing that is required to support young people furthest from the labour market and in weaker labour market contexts.

Table 2.2: Cost per participant, all who have started on the programme by partnership typology

\begin{tabular}{lrc}
\hline Classification & $\begin{array}{c}\text { Participants } \\
\text { engaged }\end{array}$ & $\begin{array}{c}\text { Cost per } \\
\text { participant } \\
(£)\end{array}$ \\
\hline 1. Further from LM - Higher unemployment & 9,124 & $£ 4,388$ \\
2. Further from LM - Lower unemployment & 5,970 & $£ 3,591$ \\
3. Nearer to LM - Higher unemployment & 3,404 & $£ 3,403$ \\
4. Nearer to LM - Lower unemployment & 7,387 & $£ 3,125$ \\
\hline Talent Match Total & $\mathbf{2 5 , 8 8 5}$ & $£ 3,714$ \\
\hline
\end{tabular}

\subsection{The characteristics of those who participated in Talent Match}

This section considers the characteristics of those who participated in Talent Match. Where possible comparison to the wider NEET population in England has also been provided.

Compared to the national NEET population, Talent Match participants were:

- broadly representative in terms of their ethnicity and their sexuality

- notably more likely to be male

- slightly younger and more likely to be in the 18-20 years age range

- more likely to receive benefits and therefore less likely to be 'hidden NEETs'

- more likely to have low levels of life satisfaction

- less likely to have a disability, especially one that limits their activities

- $\quad$ slightly less likely to be parents

- slightly less likely to have any form of religion

- less likely to have five $A^{*}$ to C GCSEs including Maths and English

- less likely to have previously held employment.

Many of these characteristics such as life satisfaction, qualifications and previous employment characteristics marked Talent Match participants out as more disadvantaged, and further from the labour market, than the wider population of NEETs in England. Furthermore, one in six participants had previously been homeless, one in eight had been convicted of a criminal offence and 58 per cent lived in the most deprived 20 per cent of neighbourhoods nationally. These factors combined for many Talent Match participants significantly reducing their likelihood of entering the labour market. Addressing these factors, and working with the respective assets of young people, required significant intervention by the Talent Match partnerships. 
On a limited number of other characteristics, notably disability, Talent Match participants were less disadvantaged than the wider NEET population. However, differences in the question used to measure disability mean the national measure is likely to be more inclusive, increasing the proportion identified. Furthermore, a sizable proportion of NEETs with a disability in the national data will be economically inactive and not seeking employment. In this context the national comparator is not a like for like benchmark of the population of Talent Match beneficiaries. This is particularly the case for young people included in the national measure of NEETs with a severe disability which makes their labour market participation extremely unlikely. As such they would not seek engagement in a voluntary employment programme such as Talent Match.

\subsection{Support provided by Talent Match}

In follow up CDF returns - from three months onwards - participants were asked to identify the forms of support that they had received through the Talent Match programme. Figure 2.1 shows that the most commonly cited forms of support were:

- $\quad$ one to one support (98 per cent)

- information, advice and guidance about careers (94 per cent)

- $\quad$ and advice on personal development (87 per cent).

Figure 2.1: Proportion of young people receiving types of support

One to one support

Information, advice and guidance about careers

Advice on personal development

Support in addressing practical barriers

Support with travel

Financial support

Basic skills (reading/numbers) training

In-work support

Peer mentoring

Counselling

Other
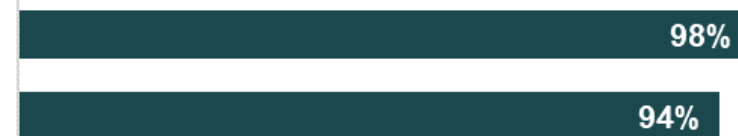

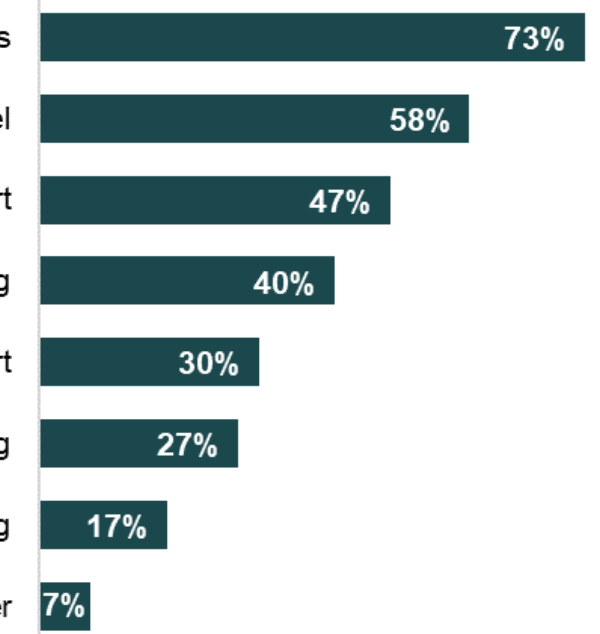

Base: 19,421 (unweighted)

On average, Talent Match participants identified that they received 5.8 different forms of support (Figure 2.2). The actual number ranged from one to 11 different forms of support. Half of participants received between five and seven forms of support. 


\subsection{Support related to the needs of the young person}

The delivery of the Talent Match programme was through person-centred support, tailored to the needs of the individual. This meant that greater and more intensive forms of support were provided to those furthest from the labour market. We were able to explore how the amount of support varied by relative distance to the labour market using a bespoke distance from the labour market measure - a summary measure which considers a range of achievements, attitudes, competencies, situations and skills which affect the likelihood of a young person being in work.

A small positive relationship was identified between the number of forms of support received and a person's initial distance the labour market. Young people in the category furthest from the labour market received on average six forms of support compared to those in the category nearest to the labour market, who received on average five and a half forms of support.

Figure 2.2: Number of forms of support received

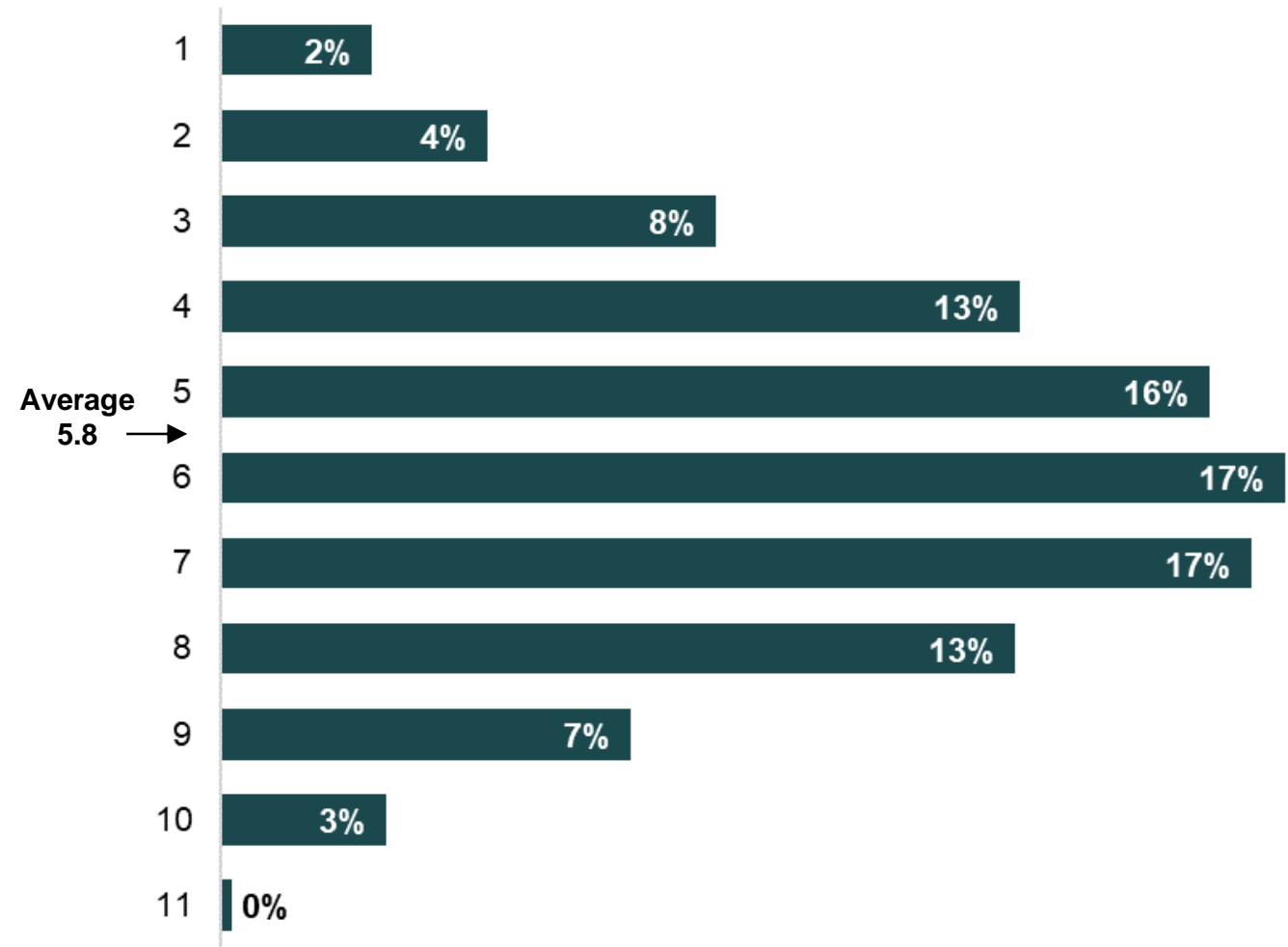

Base: 19,421 (unweighted)

The type of support received also varied by distance from the labour market:

- In-work support: this ranged from 24 per cent of those furthest from the labour market to 42 per cent amongst those that were closest.

- Counselling: this ranged from 26 per cent of those furthest from the labour market to eight per cent amongst those that were closest.

- Support with basic skills: this ranged from 47 per cent of those furthest from the labour market to 34 per cent amongst those that were closest.

- Support in addressing practical barriers: this ranged from 80 per cent of those furthest from the labour market to 64 per cent amongst those that were closest. 
- Financial support: this ranged from 51 per cent of those furthest from the labour market to 43 per cent amongst those that were closest.

- Support with travel: this ranged from 63 per cent of those furthest from the labour market to 51 per cent amongst those that were closest.

The average number of forms of support received also varied by partnership typology grouping. The mean number of forms of support was six in partnerships working with young people far from the labour market in both high and low unemployment areas and those working with young people near to the labour market in high unemployment areas. In partnerships working with young people near to the labour market in low unemployment areas, the mean number of support forms received by Talent Match participants was five.

Analysis of qualitative data collected via interviews with Talent Match participants confirms that more intensive forms of support were provided to those furthest from the labour market.

For those closest to the labour market, work preparation activities of ten started soon after joining the programme. This tended to focus on creating or updating CVs and developing job search strategies:

I think l'm pretty much confident anyway... I just needed a bit of support with finding a course and finding a job and stuff...

I got my CV checked, that was fine and then just help with applying for jolos and looking for work.

For participants with more complex barriers to work, more extensive support was of ten required before commencing a job search. For example, there was a high prevalence of mental health issues among Talent Match participants and for these young people addressing these issues, either via a counsellor or more informally with their key worker, formed a key part of their support package. Confidence-building was also an important form of support for those further away from the labour market. This often went hand-in-hand with support to address practical barriers:

I get counselling as well cos of certain reasons and home and everything else, but I know my mentor's really supportive with it...I know she'll help me out all the time so l've had food bank and every thing with them.

Anything I needed, at one point, I'm not really good at food shopping...I asked her [key worker] if she'd come out food shopping with me and she done that, she's helped me prepare for interviews, helping me with budgeting my money, anything I needed help with.... all that's left now really is to get a job where a year ago I were at rock bottom.

They help me with everything from bills to housing to getting me own flat to keeping me confidence up.

\subsection{Conclusion}

The Talent Match partnerships worked with 25,885 young people. Based on the total expenditure by the 21 partnerships this translates to an average cost of $£ 3,714$ per participant. This average cost should be viewed in the context of the support required by participants. Analysis of the characteristics of Talent Match participants highlights how they tended to be more disadvantaged and further from the labour market than the wider population of NEETs in England. Added to this, low well-being and mental 
health issues also emerged as key barriers. These factors combined for many participants and had a significant effect on their likelihood of entering the labour market. Addressing these factors, and working with the respective strengths of young people, required significant intervention by the Talent Match partnerships.

A pattern was identified at a partnership level between the average cost per participant, the distance from the labour market of participants and the health of the local labour market. This showed that it is more expensive to support larger concentrations of young people furthest from the labour market and in weaker labour markets. Extracting out from this it is reasonable to conclude that Talent Match - which has targeted young people furthest from the labour market - will be less cost efficient (more expensive) compared to more mainstream employment programmes working with young people more typical of the wider NEET population.

The chapter concluded by showing how Talent Match partnerships tailored their support both to the individual characteristics faced by young people and the local labour market conditions they were working within. Notably, those who began furthest from the labour markets on average received more types of support. This reinforces the need for larger, and more holistic, packages of support when working with those who have multiple barriers to work, which - as is noted above - will increase the level of resourcing required. 


\section{Outcomes achieved by Talent Match participants}

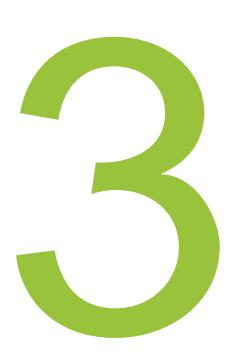

\subsection{Introduction}

This chapter assesses the jobs achieved by young people and the cost effectiveness of the Talent Match partnerships in achieving these. However, Talent Match was not simply an employment programme. It had a strong focus on supporting young people to find fulfilling and sustainable employment and moving them closer to the labour market. Therefore, this chapter also considers:

- The nature and quality of the employment/self-employment taken up by Talent Match participants.

- Wider improvements in outcomes which indicate participants:

- Becoming more ready for the labour market such as improving skills and competencies, moving closer to the labour market and improving wellbeing.

- Completing positive labour market actions such as work-related training, work placements, applying for jobs and taking part in interviews.

\subsection{Impacts and effectiveness}

The original aim of Talent Match was to support 40 per cent of participants into employment or self-employment. By the end of 2018:

\section{1,940 young people had secured employment / self-employment}

This represented 46 per cent of the 25,885 young people who had been engaged by the programme:

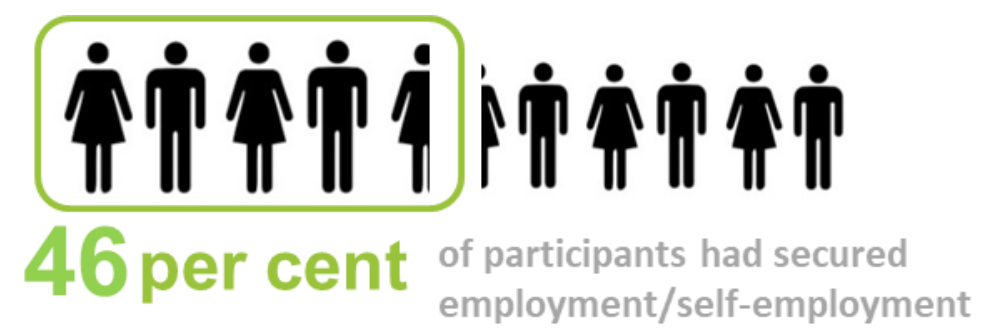

Nineteen of the 21 Talent Match partnerships had assisted two fifths (40 per cent) or more of their participants into employment/self-employment. 
A second aim of the programme was that one fifth (20 per cent) of those supported would gain sustained employment or self-employment. Here sustained employment is defined as employment for at least six months or self-employment/enterprise for at least 12 months.

Our analysis suggests: ${ }^{9}$

\section{4,479 young people had secured sustained employment/self-employment}

When presented as a percentage of the 25,885 engaged overall:

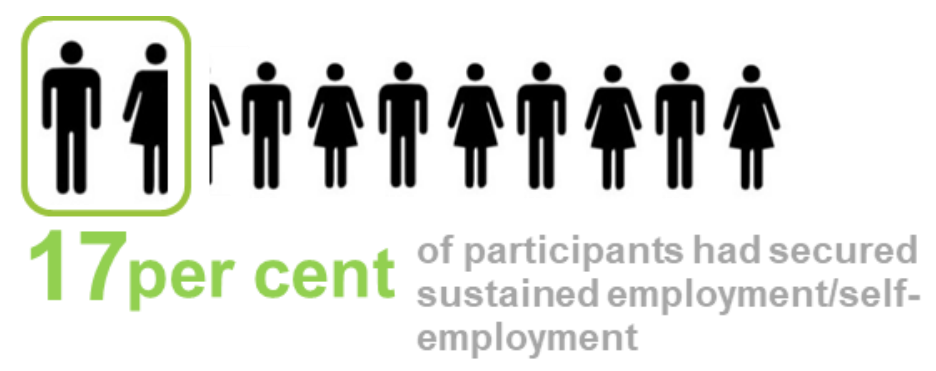

Five partnerships supported one fifth or more of their participants into sustained jobs. Table 3.1 compares the proportion of participants gaining employment/selfemployment and sustained employment/self -employment in four partnership typology groupings, identified in Chapter 2 (Table 2.1). This analysis identifies that it is the combination of participants who are furthest from the labour market and working in weak labour market areas which has the biggest effect on the effectiven ess of Talent Match partnerships to successfully support young people into jobs, rather than either of the factors separately.

Partnerships working with higher proportions of young people furthest from the labour market in higher unemployment areas assisted a lower proportion of participants into employment (43 per cent) and sustained employment (15 per cent); compared to the other three partnership typology groupings. The differences between the other three partnership typology groupings are more similar.

${ }^{9}$ The CDF has been used to estimate the impacts achieved from the programme. Responses received have been grossed up using weights to provide population estimates. 
Table 3.1: Effectiveness of partnership typology groupings in achieving employment and self-employment outcomes

\begin{tabular}{lcccc}
\hline & $\begin{array}{c}\text { Employment/self- } \\
\text { employment }\end{array}$ & \multicolumn{2}{c}{$\begin{array}{c}\text { Sustainable } \\
\text { employment/self- } \\
\text { employment }\end{array}$} \\
Typology category & $\begin{array}{c}\text { Number } \\
\text { securing } \\
\text { Effective- } \\
\text { ness }{ }^{*} \text { of } \\
\text { of those } \\
\text { engaged) }\end{array}$ & $\begin{array}{c}\text { Number } \\
\text { securing }\end{array}$ & $\begin{array}{c}\text { Effective- } \\
\text { ness } \\
\text { of }(\%) \\
\text { engaged }\end{array}$ \\
\hline 1. Further from LM - Higher unemployment & 3,956 & 43 & 1,358 & 15 \\
2. Further from LM - Lower unemployment & 2,824 & 47 & 1,116 & 19 \\
3. Nearer to LM - Higher unemployment & 1,662 & 49 & 673 & 20 \\
4. Nearer to LM - Lower unemployment & 3,497 & 47 & 1,332 & 18 \\
\hline Talent Match Total & $\mathbf{1 1 , 9 4 0}$ & $\mathbf{4 6}$ & $\mathbf{4 , 4 7 9}$ & $\mathbf{1 7}$ \\
\hline
\end{tabular}

* the number who secured employment/self-employment as a percentage of the total number of participants who engaged in Talent Match (as set out in table 2.2)

** the number who secured sustained employment/self-employment as a percentage of the total number of participants who engaged in Talent Match (as set out in table 2.2)

\subsection{Average cost per young person into employment/self-employment}

This section calculates the average cost per participant into employment/selfemployment and sustained employment/self-employment. ${ }^{10}$ In evaluation terms this is the cost effectiveness of the Talent Match programme. Based on the full cost of the programme, including delivery and non-delivery specific costs: ${ }^{11}$

\section{$£ 8,052=$ the cost per participant into employment/self-employment}

\section{$£ 21,468=$ the cost per participant into sustained employment/self- employment}

Analysis by the four partnership typology groupings shows how 'cost effectiveness' is affected by context. Partnerships working with more disadvantaged participants and in harsher labour markets had a higher cost per participant gaining a job compared to those in other categories (Table 3.4). On average it costs $£ 10,120$ per participant into a job in partnerships working with higher proportions of participants furthest from the labour market in higher unemployment areas. This compares to just $£ 6,601$ per participant in partnerships working with lower proportions of participants furthest from the labour market in lower unemployment areas. Similarly, the average cost per participant into sustainable employment/self-employment ranged:

\footnotetext{
${ }^{10}$ These estimates are based on 'gross' estimates of impact and do not consider additionality, that is what would have happened without Talent Match. Applying additionality coefficients, it is likely to lead to far less variation.

${ }^{11}$ This is discussed further in Section 1.3.
} 
- From $£ 29,489$ in partnerships working with higher proportions of participants furthest from the labour market in higher unemployment areas.

- To $£ 17,215$ in partnerships working with lower proportions of participants furthest from the labour market in higher unemployment areas.

The pattern is consistent with that presented in Table 3.2 and therefore has similar implications for designing and setting expectations for employment projects such as Talent Match. It highlights how extra resourcing is required to support young people furthest from the labour market, and in weaker labour market contexts, into positive labour market situations. Consequently, it is not surprising that the average cost effectiveness figures may appear high, given partnerships targeted those furthestfrom the labour market and were of ten operating in weaker labour market areas.

Table 3.2: Cost effectiveness by partnership typology

\begin{tabular}{lrrrr}
\hline & $\begin{array}{c}\text { Employment/self- } \\
\text { employment }\end{array}$ & $\begin{array}{c}\text { Sustainable } \\
\text { employment/self- } \\
\text { employment }\end{array}$ \\
\hline Typology & $\begin{array}{c}\text { Number } \\
\text { securing }\end{array}$ & $\begin{array}{c}\text { Cost per } \\
\text { outcome* } \\
(£)\end{array}$ & $\begin{array}{c}\text { Number } \\
\text { securing }\end{array}$ & $\begin{array}{c}\text { Cost per } \\
\text { outcome* } \\
(£)\end{array}$ \\
\hline 1. Further from LM - Higher unemployment & 3,956 & $£ 10,120$ & 1,358 & $£ 29,489$ \\
2. Further from LM - Lower unemployment & 2,824 & $£ 7,590$ & 1,116 & $£ 19,215$ \\
3. Nearer to LM - Higher unemployment & 1,662 & $£ 6,969$ & 673 & $£ 17,215$ \\
4. Nearer to LM - Lower unemployment & 3,497 & $£ 6,601$ & 1,332 & $£ 17,327$ \\
\hline Talent Match Total & $\mathbf{1 1 , 9 4 0}$ & $£ 8,052$ & $\mathbf{4 , 4 7 9}$ & $£ 21,468$ \\
\hline * total expenditure by partnerships divided by the number of participants who secured employment/self- \\
employment. \\
** total expenditure by partnerships divided by the number of participants who secured sustained \\
employment/self-employment.
\end{tabular}

\subsection{Nature and quality of employment/self-employment}

This section considers the nature and quality of the jobs taken up by Talent Match participants. Generally, the analysis found that a sizable majority of young people were positive about the work that they had found However, some participants did highlight being on a more insecure contract, being underemployed and a lack of career potential and this goes some way to explaining why the proportion achieving a sustained job outcome was well below the proportion gaining a job in any time period. Addressing these increasingly common features of the modern labour market will require more substantial policy intervention aimed at affecting the nature and terms of jobs available and reflects an approach far beyond what Talent Match partnerships alone could feasibly achieve.

Respondents who indicated they were working at any of the Common Data Framework (CDF) follow-up stages were asked a series of questions about the nature of their employment, including their: overall level of job satisfaction, how they perceive aspects of their job, contract-type and degree of underemployment. 
In the main, Talent Match participants who had found work were satisfied with the job that they had found. On a scale of one to seven where one is 'completely dissatisfied' and seven is 'completely satisfied' the majority respondents gave a score of five or above:

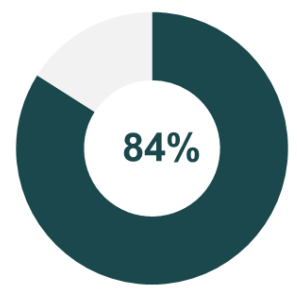

Satisfied with their present job overall

Young people in employment or self-employment were also asked to what extent they agreed with a series of statements about their current job and future career. Figure 3.1 below shows the proportions of young people who secured ajob who agreed with each statement. There were generally high levels of agreement across the statements, reflecting the high level of overall satisfaction that participants had in their job. For example, 81 per cent agreed their job was worthwhile and made them feel important and 80 per cent found their job interesting. Only 18 per cent agreed with the statement 'I can't see this job going anywhere, there are no promotion prospects.'

Figure 3.1: Proportion of young people agreeing with statements about their current job/future career (who had secured a job)

I see my job as a stepping stone, to provide me with worthwhile experience for my future career

My job is important and it makes me feel worthwhile

My job is interesting

All things considered, I am happy with the level of pay

I see my present job as part of a career

I can't see this job going anywhere, there are no promotion prospects*
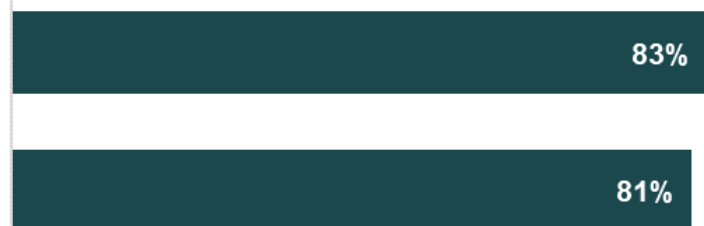

$81 \%$

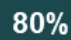

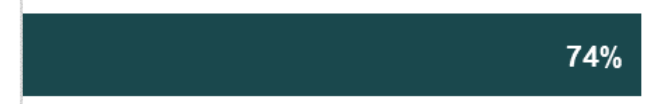

Base: 5,551 (unweighted 6/12/18 month)

*This statement is negative while the others are positive.

\section{Contract Types}

Figure 3.2 shows the type of contract those in a job held. Fewer participants had a permanent contract when compared to the proportion nationally for 18-25 year olds: 
71 per cent of Talent Match participants had a permanent contract compared to more than 85 per cent nationally. ${ }^{12}$ The growth in the 'gig economy' ${ }^{13}$ and use of zero-hours contracts particularly for those in lower-skilled and labour market entry jobs is likely to explain some of this gap.

Eleven per cent of participants who gained a job had a zero-hours contract, which is four percentage points higher than the UK figure for 16 to 24 year olds in employment. ${ }^{14}$ Although differentviews exist about zero-hours contracts it is important to note that four fifths of those with a zero-hours contract would prefer a contract with guaranteed hours. Addressing the number of participants ending up on a zero-hour contract is likely to require a more substantial labour market policy intervention targeted at job quality and conditions, far beyond what Talent Match partnerships sought to achieve.

Figure 3.2: Nature of contract

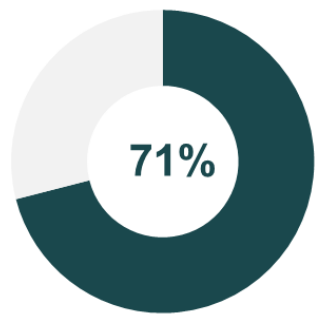

Permanent job
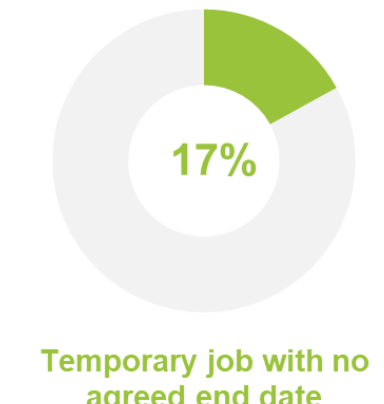

Temporary job with an agreed end date

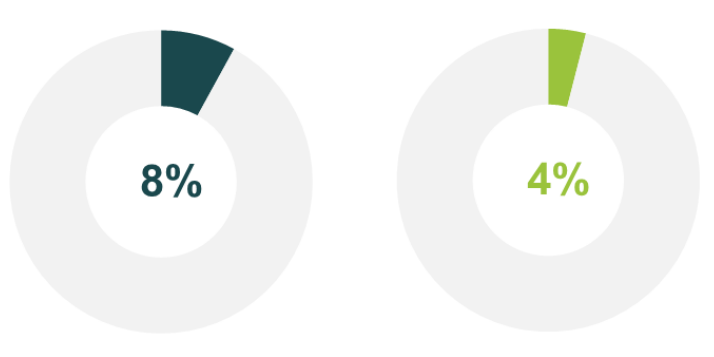

Self-employed
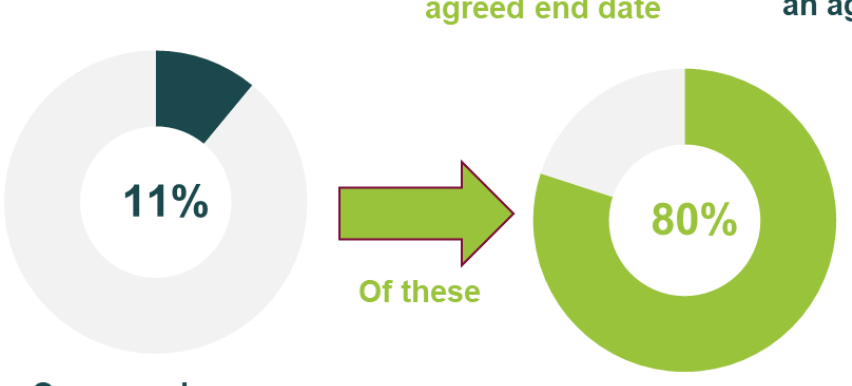

would prefer a

contract with

guaranteed hours

On a zero hours

contract

\section{Underemployment}

Respondents to the CDF, either in employment or self-employment, were asked if in the past four weeks they had: looked for an additional job; looked for a new job with longer hours; or wanted to work longer hours in their current job. Responses to these questions have been combined. If a respondent indicated they had done any of the three things above they have been identified as underemployed as defined by the Office for National Statistics (ONS). This analysis shows a significant level of underemployment (37 per cent) among participants, compared to just 16 per cent amongst the wider population of 18 to 24 year olds in England. ${ }^{15}$

\footnotetext{
12 Papoutsaki, D., Byford, M., Wilson, T. and Newton, B. (2019) Young People's Future Health Inquiry: The quality of work on offer to young people and how it supports the building blocks for a healthy life. Institute for Employment Studies Report https://www.employment-studies.co.uk/system/files/resources/files/532 2.pdf

${ }^{13} \mathrm{~A}$ labour market characterised by the prevalence of short-term contracts or freelance work, as opposed to permanent jobs.

14 The ONS Labour Force Survey estimates 7 per cent of 16 to 24 year olds in employment were on a zero -hours contact between April and June 2018.

${ }_{15}$ Papoutsaki, D., Byford, M., Wilson, T. and Newton, B. (2019) Young People's Future Health Inquiry: The quality of work on offer to young people and how it supports the building blocks for a healthy life. Institute for Employment Studies Report https://www.employment-studies.co.uk/system/files/resources/files/532 2.pdf
} 


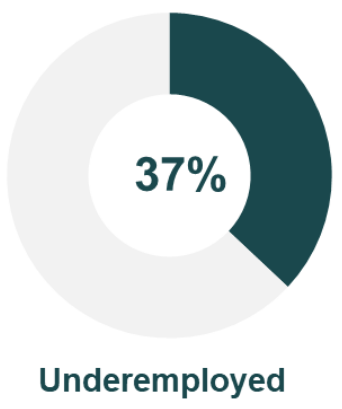

The health of the local labour market emerged as being more important in affecting the level of underemployment compared to the skills, competencies and experiences of young people. For example, levels of underemployment were highest among partnerships working with participants nearer to the labour market in higher unemployment areas. The lowest levels of underemployment were among partnerships working with young people close to the labour market in areas with a lower unemployment. Therefore, addressing levels of underemployment more effectively will require macro-economic policy aimed at boosting the health of the local labour markets.

\section{Employment progression}

Young people who took part in the in-depth qualitative interviews and who had achieved work saw employment progression in relation to opportunities for acquiring additional skills, experience or confidence within the current role in order to be promoted:

[I want] more knowledge and skill on the job....so hopefully in a year's time I'll be fully trained and fully qualified. I am qualified but there's still a lot of stuff I need training so I hope I'm confident in my work...I'm the junior HR administrator and then there's the advisors and then the team leaders so yeah I'd like to have an advisor's job there.

Other interviewees already in employment were more focussed on sustaining their current post than seeking to achieve some form of in-work progression. One said:

\section{Just working I guess, working in my job, I don't know, cos I'm so content that l've never even looked for another job or tried to get anything else, I've never give myself the opportunity, just in employment still, earning money is the main thing.}

These quotes highlight that progression in some form is not always an aspiration for participants for whom maintaining current circumstances may be a valuable outcome in itself. At the same time aspirations can change, as shown in the case of a participant who expressed a desire for promotion to escape the apparent monotony of his work:

I'd like to finally make that progression to supervisor fingers crossed, where I won't be repeating the same thing over and over again so I'll have a bit more to talk about.

In some cases, a move into employment was not just seen as an end goal in itself but a platform on which to build long-term careers. One interviewee with an aspiration to work in business administration had realised this and, whilst currently enjoying the job, was also aware of how it improved her longer-term prospects, especially compared with her situation just a couple of years before: 
Yeah I think this job's definitely opened up opportunities for me... I think a lot of [my past job search activities] was just anything, retail, I was just desperate at some point, I was like I just need a job... I think if I went into jolb searching now l'd maybe have a better time.

Employment-related progress could also trigger change in other aspects of personal circumstances. In the case of one apprentice, a shift from apprenticeship wages to the National Minimum Wage enabled a move out of unsuitable supported accommodation and accelerated progress on a business administration diploma:

As soon as I got minimum wage / were able to put my passion into work and ... get myself out of that property and that's exactly what I did ... once I moved out and I were able to have control of my own life and didn't feel I had to have a key worker ... I've been able to purchase a desk and install Microsoft Office.... I'm one of the best students there now.

There was a clear sense of progression in this case where a rise in earnings enabled greater housing security which, in turn, brought about a step change in personal capacity to study.

For other interviewees the sense of progress was less dramatic. Some noted that they had made progress in relation to training or jobs, but this was often caveated as not fulfilling initial aspirations. Specifically, a handful of interviewees described failing to secure work in line with ambitions based on previous training and or education. As a result, they had been forced to downgrade expectations and look for, or take up, employment options they deemed less attractive.

This was sometimes expressed in terms of 'thwarted' ambitions where participants had been unable to capitalise upon skills, qualifications or interests. One interviewee who outlined aspirations to find a job related to her diploma in working with animals or interests in photography had ended up lowering expectations to take up work as a barista in a coffee shop:

I hope to be somewhere different [in 12 months" time], I don't want to be where I am, working nearly every day and doing the same thing at Costa. I would hope to go a bit more in the direction that l've been wanting to go, so more the photography. I think the past year l've just played it safe and stuck with Costa cos I did need a job so I thought l'd stick with it and see what would happen but it has been pretty much the same since last year, nothing's changed and doing the same thing every day.

Another respondent with ambitions to work in graphic design expressed pessimism about the likelihood of finding this kind of work. They also described the challenges of working in the fast food job they had secured and how this constrained time for creative activity:

Graphics, that probably won't happen ... I don't know [what I'Il be doing in 12 months]. I'm not very good at thinking that far in the future ... If it's a really, really bad day, like you're expecting a customer every 20 seconds and it's just like you're bombarded and it's really exhausting. It's fun but kind of exhausting and it also doesn't leave room for creativity outside of work cos you're really exhausted.

Similarly, one participant expressed frustration at being unable to secure employment in IT for which they were qualified, compelling them to take up a position in the fast food sector that they did not enjoy: 
I wanted to do IT work... I still want to look for something else. I want a job I look forward to, instead of dreading getting up in the morning cos l've got to go to work. I don't mind working at all, I just want a job that I'm happy in.

Other interviewees were less concerned by their inability to achieve their desired job in a specific occupation or sector, and more preoccupied by their failure to find adequate hours or earn sufficient pay to achieve the independence they would like. One participant who expressed a desire to have a full time job and their own place reflected that he had achieved "two part time jobs so about a quarter of the way there". These part-time jobs in cleaning and bar work left him unable to move out of his parents' home as he couldn't afford rents in the expensive housing market in the university town in which he lived and work.

Securing work did not always feel like progress, if there was neither an obvious progression route within the role nor prospects of a more attractive job. One participant described feeling trapped within a night-time security job which, whilst undemanding, provided little job satisfaction and no opportunities for progression:

\begin{abstract}
I'm not happy with my jolb but then I need a good enough reason to leave it cos it's so easy, it might sound bad but everybody likes easy money and all I have to do is check the cameras and then play the PlayStation, but in the end l'm not going to get no satisfaction out of that ... I know I want something else but it would have to be better paid anyway cos you always take more money in the end ... it's a really simple job but it's not good for social life and seeing people.
\end{abstract}

\title{
CAW
}

This single 23-year-old white male was homeless ('sofa surfing') and claiming JSA prior to participation in the TM programme. He had been looking for work for three years principally in security and customer services. His main labour market barriers included lack of confidence, lack of prior work experience and a lack of interview skills. His highest qualifications were Level 2 (GCSEs A-C).

During his time on the programme he had received a range of help including one-to-one support, IAG, help with personal development, financial support, and support with travel. He rated the support as 'very good'. He eventually found employment working as a secur ity officer and judged that TM had been 'very important' in his ability to secure work. However, the job was monotonous, entailed working unsocial hours, and had no promotion prospects. Moreover, he was on a zero hours contact and was unsure what his take home pay would be on a week-to-week basis. Consequently, he was still 'sofa surfing', regarded the job as a 'stepping stone' and expressed a desire for better employment with guaranteed hours and better prospects.

\subsection{Wider outcomes}

Although employment is the primary outcome of Talent Match it is also important to consider wider outcomes such as progression towards the labour market, completion of positive labour market actions and improved well-being. This section demonstrates the outcome change that has been achieved by Talent Match participants in the following areas:

- $\quad$ subjective wellbeing

- moving closer to the labour market 
- communication, confidence/self-esteem, managing feeling, reliability, setting and achieving goals and working with others, measured through the My Journey Scale ${ }^{16}$

- positive labour market actions.

\section{Wellbeing}

Measurement of change

The four ONS wellbeing questions were included in the CDF questionnaire to assess the impact of the programme on the subjective wellbeing of participants.

On all four measures the percentage of young people reporting a positive high score increased consecutively over the waves of the survey (Figure 3.3). For example, the proportion with 'very high' life satisfaction has increased from nine per cent to 24 per cent from their baseline to last response.

${ }^{16}$ The My Journey Scale is a six-point self-assessment tool developed by The Princes Trust to assess a young person's capabilities and progression across six do mains which relate to their readiness for work. 
Figure 3.3: Well-being - percentage giving a 'very high' score
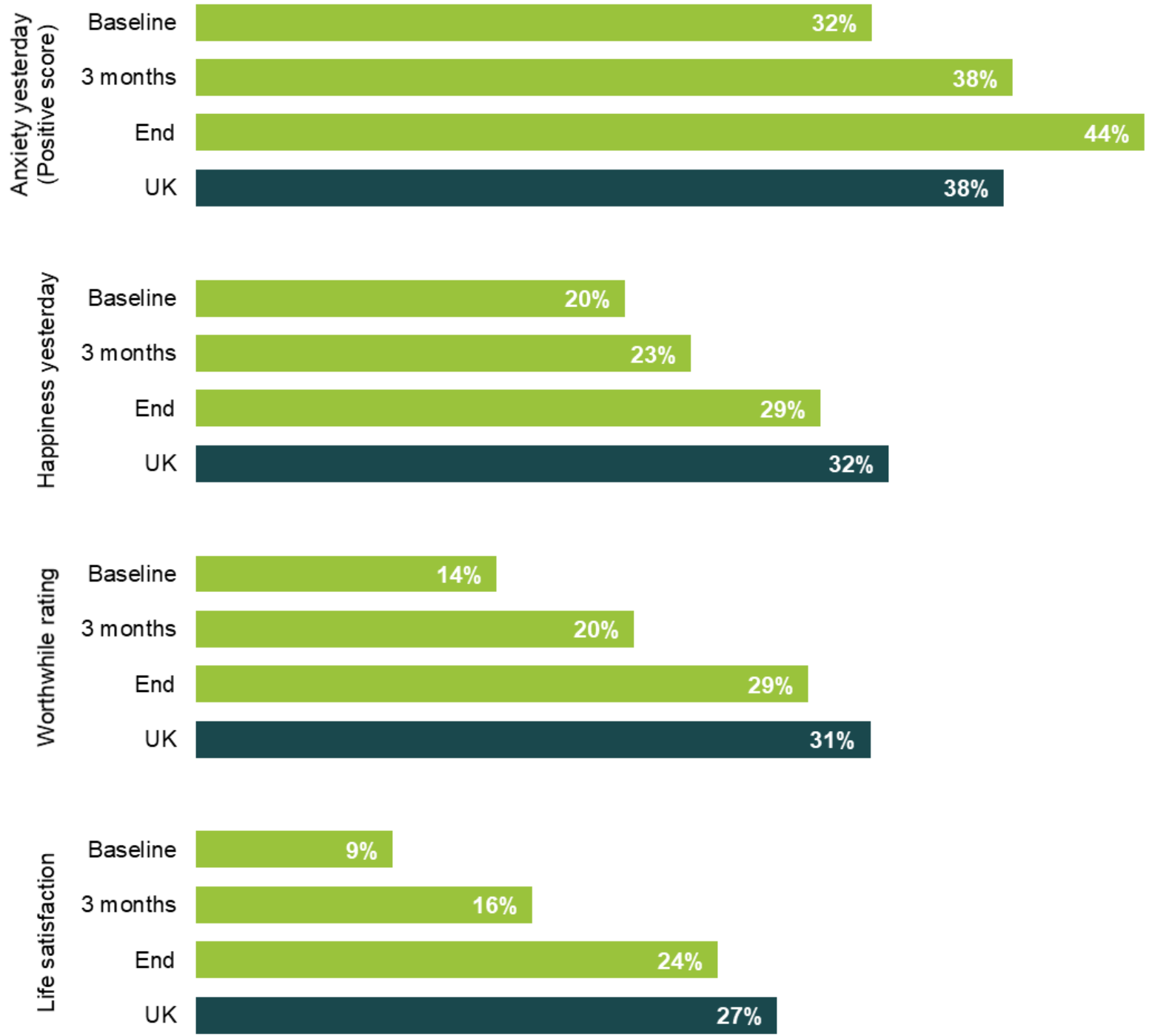

Min. Base: 25,145 (unweighted Baseline); 16,767 (unweighted 3 months); 15,626 (unweighted 6/12/18 month (End)) UK figures for 20-24 (Estimates of personal well-being from the Annual Population Survey (APS): for UK and constituent countries in the UK, for the time periods January to December from 2012 to 2018: ONS (2019), April 2019 release).

Figure 3.4 shows how scores for individual Talent Match participants changed between the baseline and their last response, with the results broken down by whether an employment outcome had been achieved or not. For those who had achieved employment, between 53 per cent and 70 per cent gave a higher score at their last response when compared to the baseline across the four measures.

The percentage reporting a positive improvement was lower on all measures of wellbeing for those not achieving an employment outcome, although there were - still notable improvements -. For example, 70 per cent of participants who achieved an employment outcome reported improved overall life satisfaction compared to 60 per cent of participants who did not achieve an employment outcome. In contrast, the proportion giving a lower score on each measure of wellbeing was higher for those who did not achieve an employment outcome. Over one fifth of those who did not achieve an employment outcome gave a more negative response on each of the measures. 
Figure 3.4: Well-being - individual change from baseline to $3 / 6 / 12 / 18$ months by whether an employment outcome had ever been achieved (yes) or not (no)

- Negative change $\quad$ No change $\quad$ Positive change

\begin{tabular}{|c|c|c|c|}
\hline Yes & $26 \%$ & $21 \%$ & $53 \%$ \\
\hline No & $32 \%$ & $20 \%$ & $48 \%$ \\
\hline
\end{tabular}

\begin{tabular}{|c|c|c|c|}
\hline \multirow{2}{*}{ 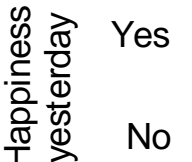 } & \multicolumn{2}{|l|}{$25 \%$} & $58 \%$ \\
\hline & $25 \%$ & $17 \%$ & $51 \%$ \\
\hline
\end{tabular}

\begin{tabular}{|c|c|c|c|}
\hline Yes & $18 \%$ & $16 \%$ & $66 \%$ \\
\hline No & $24 \%$ & $19 \%$ & $57 \%$ \\
\hline
\end{tabular}

\begin{tabular}{|c|c|c|c|}
\hline$\stackrel{ㄷ}{\underline{\underline{O}}}$ & $15 \%$ & $15 \%$ & $70 \%$ \\
\hline No & $23 \%$ & $18 \%$ & $60 \%$ \\
\hline
\end{tabular}

Min. Base: 8,819 (unweighted achieved employment outcome); 9,730 (unweighted not achieved an employment outcome)

Wellbeing experience

During the in-depth qualitative interviews several respondents noted the way that engagement with Talent Match had helped build up their confidence and self-esteem in social settings which were of ten low at the point of entry onto the programme:

My confidence is ten times better than it were. I still get shy but I wouldn't have been able to come and speak to you before at all, l'd just have said no.

It certainly helps with the confidence I feel cos if this had been a few years back I would have just sat down and shut up cos I wasn't in that place where I was comfortable doing it.

I would still be at home watching my TV and that [without Talent match support], I rarely used to go out before I joined Talent Match, confidence issue and being frustrated at not having opportunities compared to a sibling or a friend, things like that would get me down so without them I don't know where l'd be.

In some cases, it was clear that personal support to improve mental health and wellbeing was the most valuable component of engagement with Talent Match. In the 
following example, one participant describes this as the primary reason for getting involved rather than general employment-related support as they were already confident in their CV writing and interview skills:

I've done CVs in the past so it was just minor bits that they changed,... Interview skills as well l'm pretty sorted with that ... I was going through depression and before I went to Talent Match I didn't leave my house for two months. It was basically somewhere to escape to and help me try and build myself as a person ... If it wasn't for Talent Match I probably wouldn't have got past it, that was the biggest aim for Talent Match.

For some interviewees, personal support from Talent Match advisers helped to address difficult relationships in their home lives in a way that appeared to reduce anxieties and position them better to undertake training or look for work:

[My adviser] helped me a lot in myself, and at the time I wasn't really in a happy place. I don't get on with me mum and stuff and when I was down Nicola would bring me back up, helping me with advice and try and get my confidence back to apply for jobs and stuff.

I was in a relationship but it was a bit of a roller coaster, I've got rid of him now. I felt really low and I went to speak to a lady from Talent Match and it was nice... with everything that was going on I was in a bit of a dark place... when I was going through a hard time she was there for me and made me feel so much better and made me believe in myself, it was like I was a new person. But then when I got back on me feet I didn't really use Talent Match as much.

It was also apparent from some interviews that progression in terms of personal wellbeing was, in itself, a foundation for improvements in their ability to look for and secure work, as the two examples below attest. In the second quote, for example, improvements in confidence made through attending both the steering group and a creative arts course (Imagineers) are credited with enhancing interview skills and, ultimately, gaining employment. This highlights the value of a broad package of interventions that can support personal well-being and, in the long run, increase capacity to search for, and secure, paid work.

It's made a huge difference cos if I hadn't been on Tallent Match I wouldn't be as well prepared for an interview. I never would have had that six month job [working in a charity shop] ... I went for therapy so I would have been a lot worse mentally as well [without it].

But Talent Match has helped me a lot with my confidence as well cos I went to the first steering group and didn't speak to no-one, then I spoke to someone ... I think Talent Match just went over the moon for my confidence cos l've learnt so much... I wouldn't probably have [found a job as an events steward] if I hadn't gone to Imagineers from Talent Match. I would have probably not had the confidence to apply for that job ... just going to Imagineers and Talent Match, it's got me good at interviews as well cos I can explain things more).

Moving closer to the labour market

The 'proximity to the labour market' measure that has been created by the evaluation team has been used to quantify the extent to which young people have been supported to move closer to employment. The measure assesses how likely a given young 
person is to be in work given their characteristics, experiences and competencies. Figure 3.5 compares the proportion of participants in the two categories closest and furthest to the labour market at entry to the programme, at three months and at the end (six, 12 or 18 months depending on which is the latest data available).

Talent Match supported young people to move closer to the labour market both in terms of those furthest from the labour market and those closest to it. The percentage of young people in the two furthest categories decreased from 56 per cent to 43 per cent by three months after starting on the programme and then to 34 per cent by the end. Conversely the percentage in the two categories nearest to the labour market increased from 29 per cent of participants at the beginning to 41 per cent at three months and to 52 per cent at their last response.

Focusing on young people who did not get a job while on the programme revealed a similar trend. Despite having not achieved this outcome many had been supported in progressing towards employment. On entry to the programme 67 per cent of young people who did not find work were in either of the two categories furthest from the labour market. This percentage had reduced to 58 per cent three months after starting on the programme and to 50 per cent by the last response. The percentage of participants who had not found work but were in either of the two categories nearest to the labour market increased from 20 per cent at baseline to 35 per cent by their last response.

Figure 3.5: Proportion of young people in the two categories nearest and furthest to the labour market at different stages of the programme

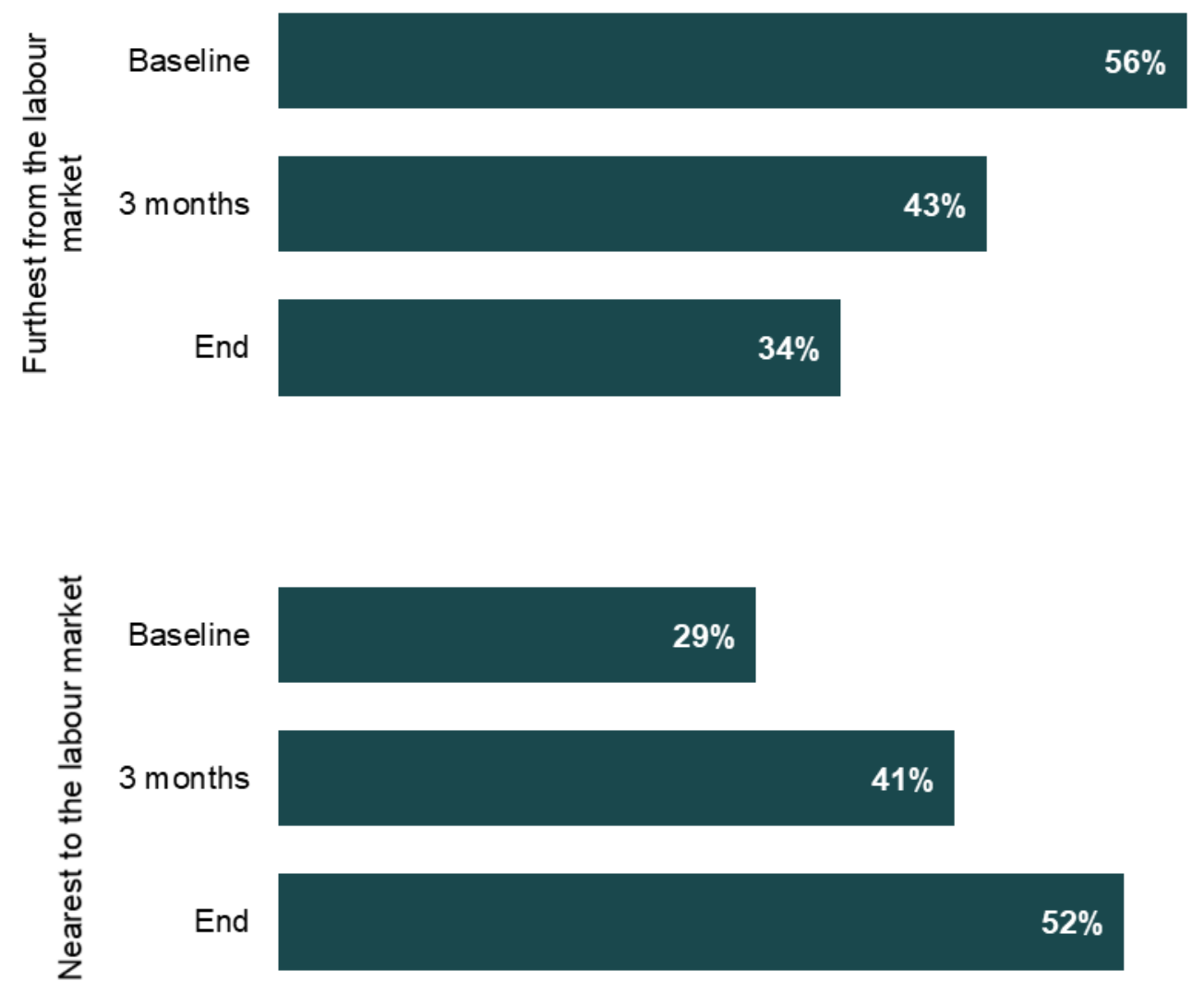

Base: 23,588 (unweighted Baseline); 15,924 (unweighted 3 months); 14,837 (unweighted 6/12/18 month (End))

The qualitative interviews with participants supported this finding. One interviewee had achieved significant progress to becoming 'work ready', often in the face of significant 
barriers. One participant with learning difficulties, for example, had secured a number of work placements through Talent Match and had also engaged in several activities though the local youth panel. This helped boost his confidence in his e mployability and sharpen career aspirations, and he was looking to secure a job in administration:

\begin{abstract}
In terms of the last year [my goals have] been made a lot clearer cos if this was me a couple of years back I wouldn't have known what I were doing, what I wanted to do, but since these placements and everything else I've got a more defined goal as to where I want to end up. So I would say it's helped tremendously, what l've been doing and how l've done it, to help me get to where I am.
\end{abstract}

Other interviews have made significant progress towards achieving long-term career goals. One participant was undertaking a one-year diplomato become a nursery nurse when first interviewed and was also contemplating applying for a university course to study to become a primary school teacher. When re-interviewed, she had successfully made that transition by securing a place on a teaching degree course at university that will qualify her to realise her 'dream'. Another participant aiming to retake GCSEs to qualify for university had achieved this goal and was also successfully involved in events management in her spare time:

I'm in Uni, I've completed my college course, making a lot of money, finished me driving [test and run a] successful event night in Liverpool once a month.

Some interviews talked positively about how Talent Match support helped to develop or crystallise employment aspirations, which is clearly an important part of pathways into meaningful work. In the first example below, a volunteer placement organised by Talent Match working with adults with learning difficulties had inspired goals to work in the caring profession. In the second, a work placement as a photographer within the Talent Match programme had lent credence to ambitions that had previously felt unrealistic to work in the digital industry:

It has changed the whole path of the career that I thought l'd never want.

If you'd asked me at the start of Talent Match what I wanted to do I'd be 'urgh' and not know what I wanted to do but through doing this ... it's helped along the way ... to find where I wanted to be.

Another interviewee described how her career pathway had been shaped by Talent Match. During the first meeting with her key worker she explored employment options that could fulfil a vague aspiration to work with people. This subsequently led her to enrol on a course to train as a nursery nurse and, later, to secure a place at university to study to become a primary school teacher. She credits her Talent Match adviser with helping to distil loose goals into a concrete employment pathway she was able to act upon:

She encouraged me to do it and brought it out of me. She gave me options, routes I could go down. I knew in mind that I wanted a nurturing role but I couldn't put my finger on what I could do to fulfil that need. Once I spoke to the key worker [for the first time] I realised I wanted to be a nursery nurse.

Other interviewees reflected on how Talent Match support had helped to increase their motivation to find work. The first respondent below notes, for example, how personalised support had a more motivating effect than interventions from Jobcentre Plus which failed to account for individual needs and circumstances: 
It's giving you that bit more motivation behind you so you don't feel like a robot ... cos the Jobcentre just say you're going to have to pay for [courses]. Well I can't l've got bills, I've got kids to look after, they don't take that into account, they just see you as a number.

I wouldn't say it's made me more optimistic, l'd say it's made me more inclined to look for work ... cos if I don't look for work I'm just going to end up sitting on my arse and doing nothing and I don't want to do that cos that's boring. I'd rather be out there actually doing something.

After I got rejected from the Marines I was in quite a bad place and Talent Match got me into the working place, got me more motivated and switched on and really helped me out with that sort of stuff and they helped me to try and get into university, they've helped me apply for college courses ... I've never really met a group of people that help-out as much as Talent Match or want to do as much as Talent Match. My Journey

\section{My Journey}

At all stages of data collection, participants were asked to indicate how accomplished they felt they were with certain sets of skills using the My Journey scale. The My Journey scale was developed by the Prince's Trust and is shown in Appendix Two to this report.

The scale runs from one to six where: one represents "I find this skill really difficult and I don't care", and six signifies "This skill is a strength of mine and I excel at it."

Figure 3.6 shows how young people's scores changed between their baseline and last response, with the results broken down by whether they had managed to secure work, or not. For those who had secured work, between 44 per cent and 61 per cent gave a higher score at their last response when compared to the baseline across the six measures.

The numbers of young people reporting a positive improvement were lower on all My Journey measures for those not achieving an employment outcome, although a sizable number still reported improved scores suggesting movement closer to the labour market. Similarly, the proportion giving a lower score on each measure was higher for those who did not achieve an employment outcome. Of concern for those who did not achieve an employment outcome is that around one fifth or more gave a more negative response on each of the measures. 
Figure 3.6: My Journey - individual change from baseline to 3/6/12/18 months by whether they had secured work (yes) or not (no)

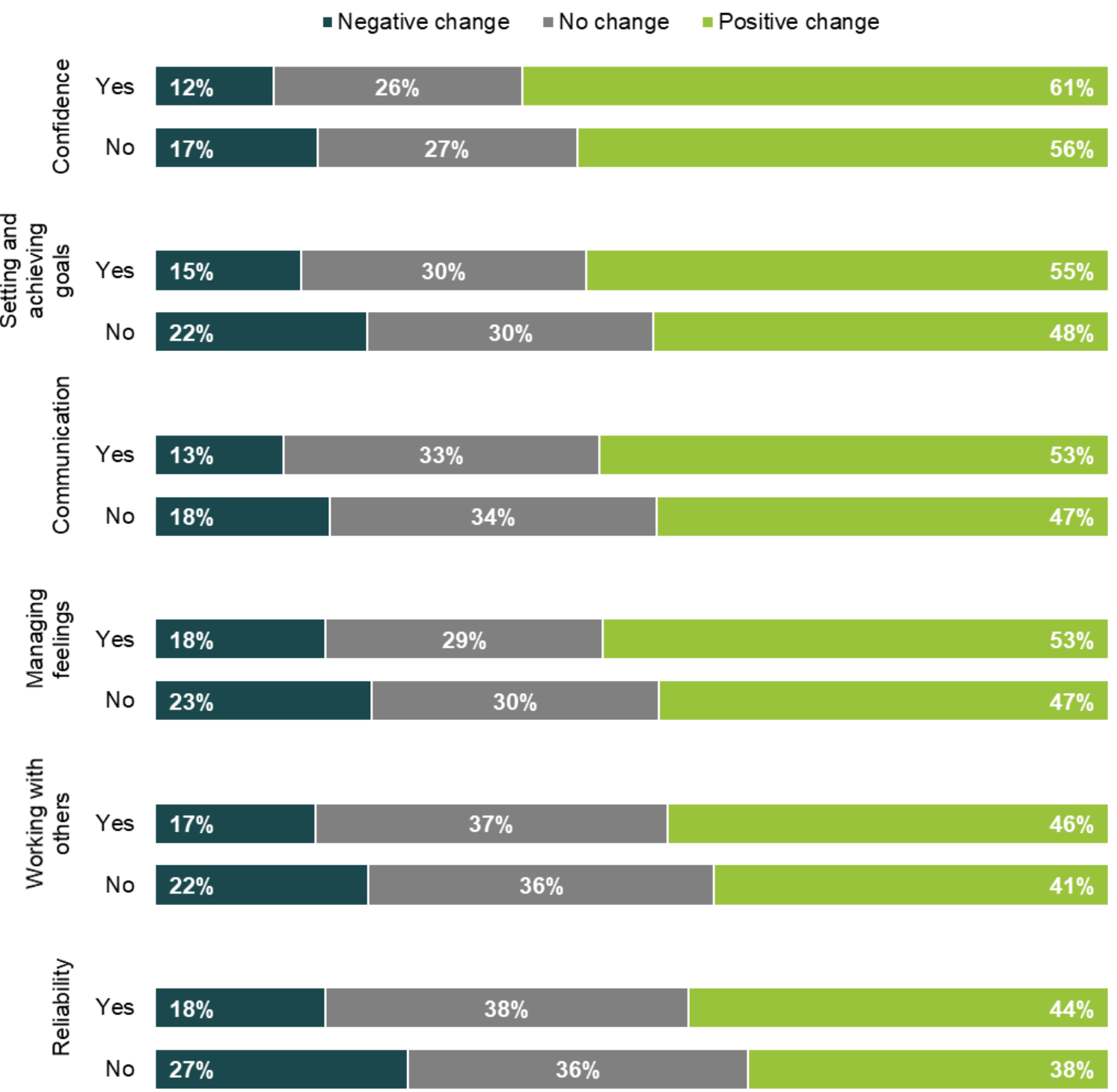

Min. Base: 10,028 (unweighted secured work); 9,067 (unweighted not secured work)

\section{LAL}

This single 20-year-old male was living with his parents and claiming Personal Independence Payments prior to their participation in Talent Match. He had a disability and poor mental health. He was looking for work in the retail sector but identified a number of other labour market barriers including a lack of basic skills, low confidence, and a lack of job-specific skills. His highest qualifications were Level 3 (AS/A levels).

During his time on the Talent Match programme he received a range of help including one-toone support, IAG, support with travel, advice on personal development and volunteering. However, progression was not evident during his time on the programme as he was no closer to the labour market. The principal effect of the Talent Match programme seems to have been improvements in confidence and mental health. In terms of the former, he had felt sufficiently confident to join the Youth Board which he likened to a 'family'. 


\section{Positive labour market actions}

In follow-up CDF surveys participants were asked whether they had completed any positive labour market actions since starting on the programme. These labour market actions included undertaking work experience, applying for jobs, completing a course or gaining a job.

Figure 3.7 below shows the proportion of young people who stated they had undertaken specific actions at any follow-up stage. Results are broken down by whether a participant found a job or not. The figure shows that event amongst participants who did not gain a job 80 per cent had applied for jobs since starting on the programme and 60 per cent had attended at least one interview. As expected, these figures are lower than those for young people who had gained a job: 97 per cent and 93 per cent respectively.

Notable differences also emerged in the percentage that had:

- Undertaken some form of work experience - 67 per cent of participants who had achieved an employment outcome compared to 52 per cent of participants who had not.

- Taken up additional training - 69 per cent of participants who had achieved an employment outcome compared to 61 per cent of participants who had not.

- Completed a training course - 48 per cent of participants who had achieved an employment outcome compared to 40 per cent of participants who had not.

These differences are to be expected. Nonetheless it is important to note that even when participants had not gained a job they had completed many positive labour market actions which increased their likelihood of achieving this outcome. Where more significant differences are highlighted - such as undertaking work experience and applying for jobs - it may be inferred that these are more key labour market actions which increase the likelihood of a participant finding employment. 
Figure 3.7: Actions undertaken since starting on the Talent Match programme by whether an employment outcome was achieved

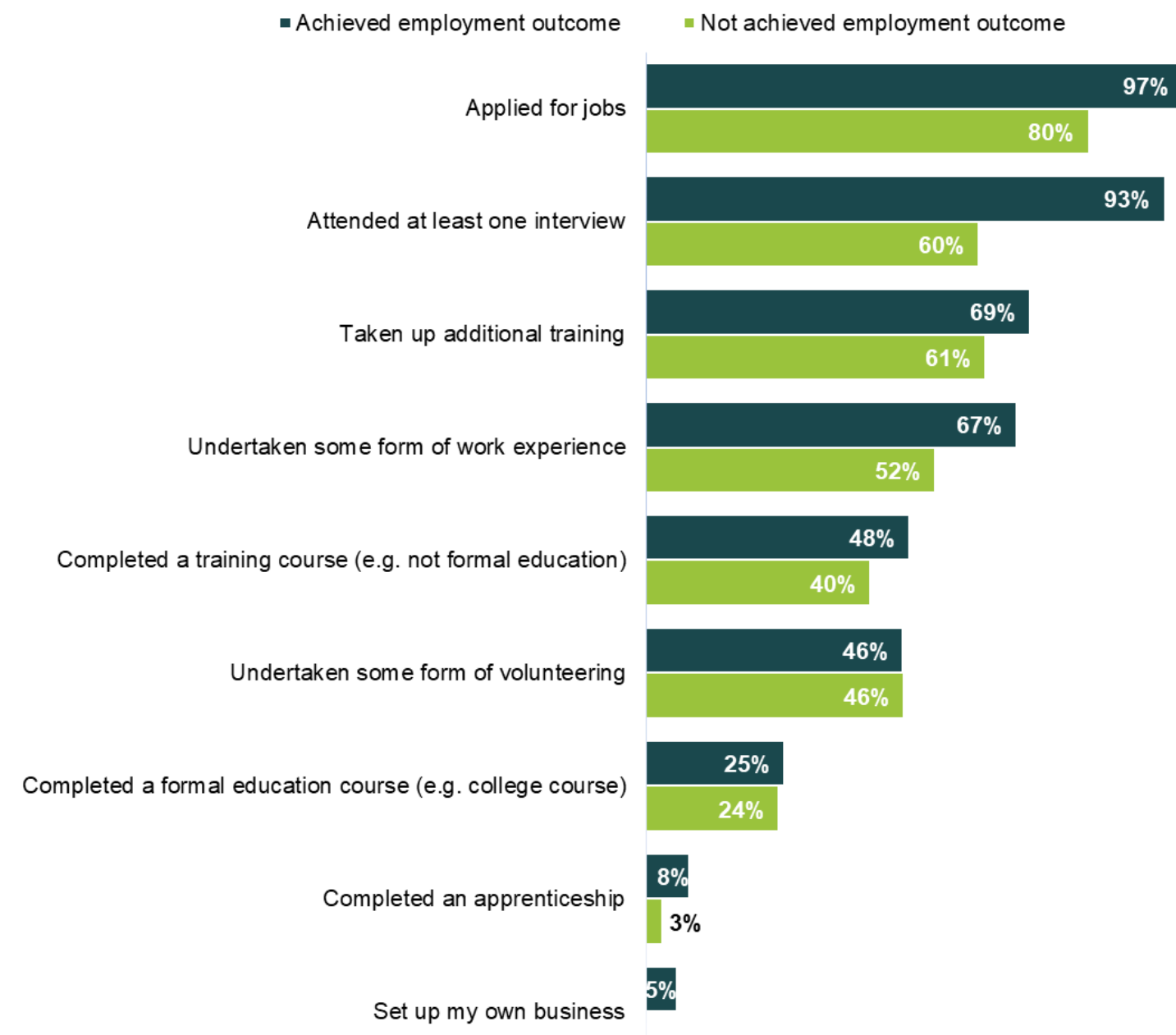

Base: 10,211 (unweighted achieved employment outcome); 9,235 (unweighted not achieved an employment outcome)

Figure 3.8 details the active steps young people who had not achieved an employment outcome had taken to find work in the four weeks before they were surveyed at their last survey point. Over half ( 55 per cent) said they had searched for jobs/information about jobs on the internet. Almost two fifths ( 39 per cent) said they had applied directly to an employer. Only two per cent had taken steps to start up their own business. 
Figure 3.8: Active steps taken by respondents who had not achieved an employment outcome to find work in the past four weeks (6/12/18 month followups)

Searched for jobs/information about jobs on the internet

Applied directly to an employe

Studied or replied to advertisements

Asked friends or contacts

Contacted a private employment agency or job centre

Taken steps to start your own business

$2 \%$

Base: 6,338 (unweighted)

\subsection{Conclusion}

This chapter has reported many of the key employment, employability and wellbeing outcomes achieved by Talent Match participants. Summarising these:

- 46 per cent of participants were supported into employment/self-employment, including 17 per cent for whom this was sustained (employment for at least six months or self-employment/enterprise for at least 12 months).

- A sizeable majority of young people were positive about the work that they had found. Across nearly all of the aspects of job satisfaction considered over four in five participants who had found work reported a positive response.

- Even when employment outcomes were not achieved many Talent Match participants were found to have improved their job readiness and well-being and had completed positive actions towards getting ajob, such as putting a CV together, applying for a job and attending an interview.

The following four implications can be drawn from the analysis presented in this chapter:

- The average cost of supporting young people into employment is affected by the job readiness of participants and the health of the local labour market. This has important implications for designing and setting expectations for employment initiatives such as Talent Match. In particular, lower employment outcome expectations and significant additional resourcing are required when supporting those furthest from the labour market in weaker labour market contexts.

- Although the vast majority of participants were satisfied in the jobs that they had found, where issues existed, they often related to increasing ly common features of the modern labour market (such as zero-hours contracts and underemployment). 
Addressing these requires a substantial labour market intervention targeted at the availability, quality and conditions of jobs. This was well beyond what Talent Match tried, or would have been able to achieve.

- Talent Match has highlighted the importance of valuing progression towards the labour market, rather than just hard 'into employment' outcomes. This includes improving skills and competencies, improving wellbeing and the completion of positive labour market actions such as work-related training, work placements, applying for jobs and taking part in interviews.

- The support provided by Talent Match partnerships and the experience of finding employment were not always enough to address low levels of reported wellbeing. Wellbeing worsened for between aquarter and a third of young people who did not find employment. Whilst lots of factors determine levels of subjective wellbeing, that a significant group of young peopleare reporting low levels of wellbeing should raise concerns not just for future employment programmes but more broadly for policies supporting young people. 


\section{Explaining Outcome Change}

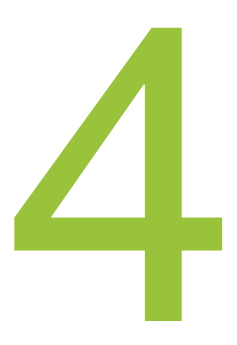

\subsection{Introduction}

Chapter 4 considers the individual, programme and wider labour market factors that have contributed to, or hindered, the likelihood of participants gaining employment/self-employment. It includes assessing the impact of:

- personal socio-demographic characteristics

- their baseline proximity to the labour market

- the support young people received

- the nature of the Talent Match partnership

- the influence of wider local labour market characteristics.

The purpose of this analysis is to inform the design of youth employment initiatives, highlighting the factors which maximise the likelihood of participants finding a job. It also considers contextual factors which mediate and moderate the scale of job outcomes, informing expectations about the scale of outcomes that are likely to be achieved in different contexts.

A two-stage statistical modelling approach has been used to test and analyse the influence of participant, programme and wider labour market factors on the likelihood that a young person had gained either employment or self-employment. More detail about this approach is contained within the Talent Match Evaluation Technical Appendix. ${ }^{17}$

The next section provides an overall consideration of the relative importance of factors associated with the individual characteristics of the young people, the partnerships they were engaged with and where they lived. The proceeding section then highlights factors that emerged as being statistically associated with the likelihood that a young person had gained either employment or self-employment.

\subsection{The relative importance of young person, partnership and area factors}

This issue is important as it puts into context the relative importance of characteristics relating to the young person compared to the influence of the wider area in which they live and the partnership that they engaged with.

Characteristics relating to the young people were found to explain most of the variation in likelihood that they were able to secure employment/self-employment (99 per cent).

17 See https://blogs.shu.ac.uk/talentmatch/ 
Where they live, and the partnership that they engaged with, explained just one per cent of the variation in the likelihood of a participant securing work. ${ }^{18}$

However, place and partnership factors were statistically significant at a 0.01 level. This means, although less important than characteristics relating to the young person, the likelihood that a participant gained a job was affected by where they lived and the Talent Match partnership that they engaged with. This supports the need for labour market policies to focus beyond the actions of individual jobseekers (for instance through also working directly with employers) and to take into account the context of local labour markets.

\subsection{Factors associated with gaining an employment outcome}

The statistical modelling exercise identified a number of factors where there is sufficient statistical evidence of an association with the likelihood of gaining a job. Table 4.1 sets out the factors that emerged from this analysis. The key factors linked to the likelihood of getting a job can be summarised as follows:

- Young person specific characteristics, in particularly their initial distance from the labour market, physical health and educational attainment.

- Receiving larger packages of support.

- Completing positive labour market actions such as attending interviews, applying for jobs and completing an apprenticeship.

- Improved job readiness. This was most pronounced for improved overall proximity to the labour market, job specific skills, motivation, teamwork skills and reliability.

- The strength of the local labour market: there was a negative relationship between the level of unemployment in the area and the likelihood that a Talent Match participant gained work. This means that a participant in an area with a higher unemployment rate is statistically less likely to secure a job compared to a similar participant in an area with a lower unemployment rate.

${ }^{18}$ Note the analysis considered the impact of place at a LEP level. If it had been conducted at a lower level of geography, for example at a local authority level, the effect of area is likely to have been greater. 
Table 4.1: Factors associated with the likelihood of securing employment/selfemployment

\begin{tabular}{|c|c|}
\hline \multicolumn{2}{|l|}{ Young person specific factors } \\
\hline Increased likelihood & Decreased likelihood \\
\hline Attended at least one interview & Undertaken some form of volunteering \\
\hline Improved motivation skills & $\begin{array}{l}\text { Have a disability or illness which limits } \\
\text { activities }\end{array}$ \\
\hline Initial proximity to the labour market & $\begin{array}{l}\text { Taken up additional training during Talent } \\
\text { Match }\end{array}$ \\
\hline Change in proximity to the labour market & $\begin{array}{l}\text { Completed a formal education course (e.g. } \\
\text { college course) }\end{array}$ \\
\hline $\begin{array}{l}\text { Number of types of support received from } \\
\text { Talent Match }\end{array}$ & On or completed the Work Programme \\
\hline Improved specific skills for a particular job & $\begin{array}{l}\text { Improved short and long-term careers } \\
\text { goals }\end{array}$ \\
\hline Applied for jobs & Improved ability to put together a CV \\
\hline Improved teamwork skills & Identified additional training to take up \\
\hline $\begin{array}{l}\text { Classified as a Hidden NEET when first } \\
\text { engag ed with Talent Match }\end{array}$ & $\begin{array}{l}\text { Involved with social services when first } \\
\text { eng aged with Talent Match }\end{array}$ \\
\hline $\begin{array}{l}\text { Improved understanding of the skills } \\
\text { employers are looking for }\end{array}$ & $\begin{array}{l}\text { Live in a deprived Lower Super Output } \\
\text { Area (neighbourhood) }\end{array}$ \\
\hline \multicolumn{2}{|l|}{ Completed an apprenticeship } \\
\hline \multicolumn{2}{|l|}{ Improved reliability } \\
\hline \multicolumn{2}{|l|}{ Improved management of feelings } \\
\hline \multicolumn{2}{|l|}{$\begin{array}{l}\text { Improved understanding of how to set up own } \\
\text { business }\end{array}$} \\
\hline \multicolumn{2}{|l|}{ Receiving drug / alcohol support (at baseline) } \\
\hline \multicolumn{2}{|l|}{ Male } \\
\hline \multicolumn{2}{|l|}{ Achieved 5 GCSEs } \\
\hline \multicolumn{2}{|l|}{ Being an older young person } \\
\hline \multicolumn{2}{|l|}{$\begin{array}{l}\text { Improved understanding of a specific job or } \\
\text { area of work of interest }\end{array}$} \\
\hline \multicolumn{2}{|l|}{ Mixed or Asian Ethnicity } \\
\hline \multicolumn{2}{|l|}{$\begin{array}{l}\text { Involved in education, training, skills } \\
\text { development (at baseline) }\end{array}$} \\
\hline \multicolumn{2}{|l|}{ Local labour market level factors } \\
\hline Increased likelihood & Decreased likelihood \\
\hline
\end{tabular}

Living in a LEP area with a higher unemployment rate (in June 2016) 
Many of these factors seem to reflect what we know about employability and the operation of labour markets. However, there are some factors which require further consideration. For example, it is not clear why being 'Hidden NEET' or 'receiving drug/alcohol support' would increase the likelihood of a participant finding a job. We could speculate that perhaps Hidden NEETS have not been claiming benefits and have not actively participated in the labour market prior to engaging with Talent Match; whilst perhaps a prior experience of receiving drug/alcohol support gave individuals a lot more wider support then they would have received on a traditional labour market programme.

Similarly, it is unclear why factors such as 'undertaken volunteering' or 'improved ability to put together a CV' would be associated with a decreased likelihood of finding a job. It may reflect how partnerships target volunteering opportunities to those furthest from the labour market as an initial step in gaining positive experiences and/or because volunteering diverts people away from job search.

\subsection{Conclusion}

This chapter has considered factors that are associated with the likelihood of a young person securing employment/self-employment. The results of this analysis can inform the design, targeting and expectations of future youth employment initiatives.

Factors relating to the young person explained nearly all of the variation in the likelihood of a participant gaining a job. However, the area where participants live, and the partnership that they engaged with, were also found to affect their likelihood of securing work.

Both the health of the local labour market and young people's initial level of job readiness (particularly their initial distance from the labour market, physical health and educational attainment) were found to be associated with the likelihood of finding employment. These factors will mediate and moderate the scale of job outcomes that a youth employment initiative will achieve in a given area with a given client group. This also underpins the partnership typology differences in cost per participant and cost per job outcome presented in Tables 3.1 and 3.2.

The analysis also identified activity and outcomes that are associated with an increased the likelihood of finding a job. These can be used to inform the design and focus of future youth employment initiatives:

- Larger packages of support provide by Talent Match partnerships were found to increase the likelihood of participants gaining employment.

- Completing positive labour market actions such as attending interviews, applying for jobs and completing an apprenticeship were associated with an increased likelihood of finding employment.

- Improved job readiness is associated with an increased likelihood of finding employment. The strongest relationships and hence most important aspects to target were identified as being overall proximity to the labour market, job specific skills, motivation, teamwork skills and reliability. 


\section{Employment additionality of Talent Match}

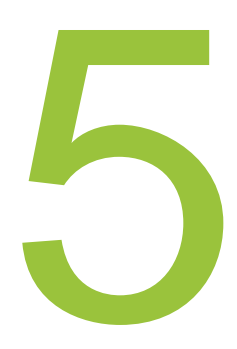

\subsection{Introduction}

This chapter assesses the extent to which the employment and self-employment outcomes measured in Chapter Three occurred because of - and are attributable to the Talent Match programme. In evaluation terms this is called the additionality of the programme. Considering the contribution that Talent Match made is an important part of the impact evaluation. It accepts that a proportion of young people would have gained a job even without the support of the programme interventions. This is because labour market situations are fluid, with young people entering (and leaving) jobs over time for a multitude of reasons, not all related to the programme itself. These reasons may include changes in personal circumstances (e.g. improvements in health and wellbeing), engagement in other employment initiatives and the health of the wider economy. However, this is not to say that the programme has not made a positive difference to young people's lives and employment prospects, but rather other factors mean that they would have got a job even without participation in Talent Match.

The assessment considers:

- An overview of the method adopted.

- An assessment of impact on employment outcomes compared to a matched Labour Force Survey comparator - the primary assessment of additionality on outcomes.

- Participant perceptions of the importance of Talent Match support in securing a job.

- Qualitative reflections from young people about the difference that Talent Match has made to them.

\subsection{An overview of the method}

The evaluation followed the Treasury's Green Book guidance to assess of the degree to which participation in Talent Match contributed to a young person getting a job. A quasi-experimental approach was used to estimate the contribution of Talent Match. The analysis compared the number of Talent Match participants who gained a job in a 12-month period to job outcomes for a group of similar young people. The comparator group was drawn from the Labour Force Survey Five Quarter Longitudinal Panel; an employment survey run by the Office of National Statistics. Propensity score matching was used to ensure that the comparator group had similar characteristics to the Talent Match participants. 
In the absence of a Random Control Trial (RCT) the approach provides a high level of scientific rigour, ${ }^{19}$ and the resulting analysis is robust when compared to other evaluations of employment initiatives in the UK. Because of this it is likely to have also provided a harsher assessment of impact, for example with no scope for optimism bias.

Despite these strengths, however there were complexities and weaknesses in the data which affect the resulting estimates. These include:

- The matching process could only cover a limited number of aspects of employability and job readiness; ${ }^{20}$ this means there may be unobservable differences between the characteristics of Talent Match participants and the matched Labour Force Survey sample which bias the comparison.

- There were only 682 young people in the Labour Force Survey sample who could be considered in the matching of whom just 589 were matched to one of the 10,373 Talent Match participants; this limits the confidence that can be placed on the precision of the estimated level of additionality.

- Despite the matching process improving the representativeness of the Labour Force Survey sample to the Talent Match participants there remained notable differences between the characteristics ${ }^{21}$ of the two groups which may have biased the estimates.

- The analysis was conducted based on 10,373 Talent Match participants who completed a 12 month CDF response; thus excluding participants who were no longer engaged or could not be contacted by their respective partnership to complete a response; the evidence suggests that this is likely to overestimate the number who gained an employment outcome.

In response to these limitations this report provides a range for the possible additionality of the programme. The upper limit compares the proportion of Talent Match participants who completed a 12 month CDF response who gained a job to the matched comparator from the Labour Force Survey. Whereas the lower limit compares the proportion gaining a job across all Talent Match participants (46 per cent) to the matched comparator group.

\subsection{Employment outcomes compared to a matched Labour Force Survey comparator}

Fifty-eight per cent of Talent Match respondents had entered employment in the 12 month period compared to just 42 per cent of matched Labour Force Survey respondents. This difference ( 16 percentage points) is statistically significant at a level greater than the 0.005 .

This implies that 28 per cent ${ }^{22}$ of participants who gained an employment outcome would not have done so had it not been for their participation in Talent Match. The remaining 72 per cent who secured a job would have done so without participating in the programme, for example due to improvements in personal circumstances,

\footnotetext{
${ }^{19}$ As assessed by scales that grade this asp ect of evaluation quality, for example the Maryland Scientific Methods Scale.

${ }^{20}$ These included: age, gender, ethnicity, whether they were actively seeking work, whether they have a limiting disability, their highest qualification, whether a number of key benefits were being claimed, when they were last employed, the level of unemployment in their local authority and the year of the survey response.

${ }^{21}$ For more information please see the Talent Match Evaluation Technical Appendix.

${ }^{22}$ Calculate by dividing the difference between the Talent Match sample and LFS matched group who gained a job (16 percentage points) by the percentage of Talent Match sample who gained a job (58 per cent).
} 
participation in other initiatives and an increased availability of jobs in their area. This provides the upper estimate for the additionality of Talent Match.

Applying the 28 per cent level of additionality to the number of participants who achieved employment/self-employment and secure employment/self-employment outcomes (provided in Section 3.2) means:

- 3,298 participants found employment/self-employment who would have been unlikely to have done so had it not been for Talent Match, representing 13 per cent of the total number participating in the programme. The average cost per additional person into employment/self-employment is $£ 29,149$ - based on the full cost of the programme including delivery and non-delivery specific costs.

- 1,237 participants found secure employment/self-employment who would have been unlikely to have done so had it not been for Talent Match, representing five per cent of the total number participating in the programme. The average cost per additional person into sustainable employment/self-employment is $£ 77,713$ based on the full cost of the programme including delivery and non-delivery specific costs.

A lower limit estimate for the additional impact of Talent Match is based on the total proportion of participants who gained a job. In Section 3.2, 46 per cent of participants were identified as having gained a job. Comparing this percentage to the 42 per cent of matched comparator young people who gained a job give a lower nine per cent estimate for the additional impact of Talent Match. Applying this to the number of participants who achieved employment and secure employment outcomes (provided in Section 3.2) means:

- 1,035 participants found employment/self-employment who would have been unlikely to have done so had it not been for Talent Match, representing four per cent of the total number participating in the programme. The average cost per additional person into employment/self-employment is $£ 92,909$ - based on the full cost of the programme including delivery and non-delivery specific costs.

- 388 participants found secure employment/self-employment who would have been unlikely to have done so had it not been for Talent Match, representing one per cent of the total number participating in the programme. The average cost per additional person into sustainable employment/self-employment is $£ 247,702$ based on the full cost of the programme including delivery and non-delivery specific costs.

The true level of additionality is likely to lie between these two estimates.

It is important to view the impact of Talent Match in light of the relative scale of influence that the programme would be expected to have over and above other factors that affect the likelihood of a young person finding a job over a given timeframe. This includes changes in personal circumstances, involvement in mandatory and other voluntary labour market interventions and job search as well as the growth in the supply of jobs in wider labour market. It is also important to point to the value that Talent Match participants gave to the support that they had received, which is outlined in Sections 5.3 and 5.4 .

Both the lower (nine per cent) and upper (28 per cent) estimate suggest that Talent Match has achieved a high level of additionality compared to previous interventions targeted a young people. For example: 
- The Future Jobs Fund is estimated to have increased the probability of being in unsubsidised employment by an average of approximately 10 percentage points over a 27 to 104 week time period. ${ }^{23}$

- The New Deal for Young People is estimated to have reduced the probability of unemployment after 12 months by 17 per cent for men and 16 per cent for women. ${ }^{24}$

- A meta-analysis of 180 youth intervention programmes from around the world found the mean effect size to be 5.9 percentage points over the medium term. ${ }^{25}$

In making these comparisons it is important to note that most of these studies were measuring a different impact: the likelihood of being in employment (or not unemployed) at a given time point rather than the probability of gaining any job for any time duration within the 12 month period. Also, Talent Match is relatively well-funded per participant compared to other programmes which is likely to enable it to achieve higher levels of impacts.

\subsection{Young people's perceptions of the importance of Talent Match}

Participants were on the whole very positive about the importance of the support that they had received from Talent Match in helping them secure employment or selfemployment.

Young people who had managed to secure employment or self-employment were asked a follow up question about how important the support they received through the Talent Match programme been in helping themgain employment. Seven out of ten (70 per cent) stated the support had been very important (Figure 5.2). A further 25 per cent said the support had been quite important. Just five per cent thought that their support from Talent Match had not been very important (four per cent) or not important at all (one per cent).

${ }^{23}$ Department for Work and Pensions (2012) Impact and Costs and Benefits of the Future Jobs Fund. Department for Work and Pensions.

https://assets.publishing.service.gov.uk/government/uploads/system/uploads/attachment data/file/223120/impact s costs benefits fjf.pdf

${ }^{24}$ Wilkinson, D. (2003) New Deal for Young People: Evaluation of Unemployment Flows, Policy Studies Institute Research Discussion Paper 15. http://www.psi.org.uk/docs/rdp/rdp15-new-deal-for-young-people.pdf

${ }^{25}$ Card, D., Kluve, J. and Weber, A. (2015) What Works? A Meta Analysis of Recent Active Labor Market

Program Evaluations, IZA Discussion Paper No.9236 http://ftp.iza.org/dp9236.pdf 
Figure 5.2: How important has the support you received through the Talent Match programme been in helping you gain employment?

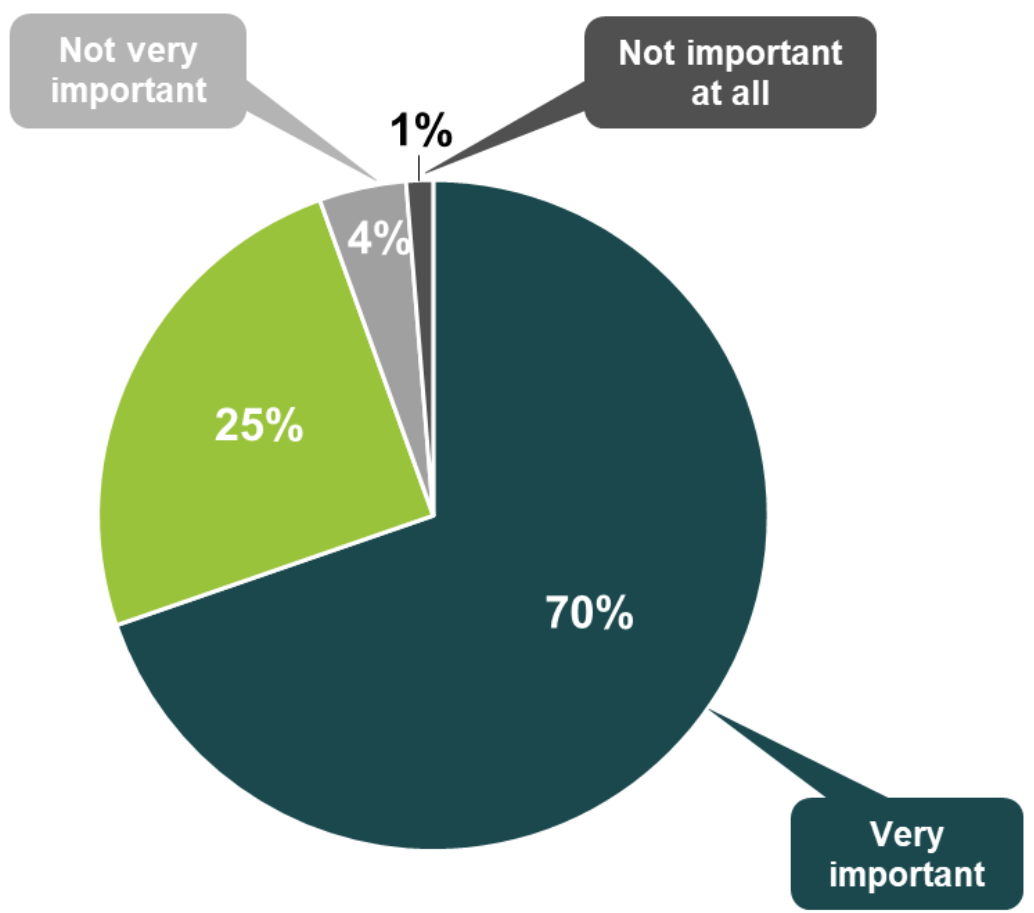

Base: 5,510 (unweighted)

\subsection{Qualitative reflections about the difference Talent Match made}

Many interviewees who took part in the in-depth qualitative interviews were clear that Talent Match had played an important role in their progression into the labour market.

In some cases the support provided was financial, as in the case of one interviewee for whom Talent Match funded training that eventually enabled him to find work in the security industry. This was not a step he would have taken by himself given the costs of training:

I'd thought of it but I knew how much it was to get through the course.

Others directly credited Talent Match with making them aware of, and supporting them to access, training and employment opportunities they might otherwise not have heard about:

Without Talent Match I don't know what l'd be doing now, no doubt I'd probably still be on Jobseekers [Allowance] doing practically nothing and feeling rubbish, which is what I did before...I'd say it's made the world of difference because being involved with [Talent Match] I've had training opportunities and the two placements l've had, without Talent Match I wouldn't even have heard about them.

I got what I wanted from them and I always will be grateful for that, got myself a long term job. [My adviser] helped me apply for work at Marks and Spencer I think which helped me get experience and helped in the interview to get the job where l'm at now. 
One of their mentors sat down with me and we ... worked together to fill in the application and she had experience in that sort of thing, she knew what to put in it so it was very helpful... I don't think I would have found it [without Talent Match].... I'd probably still be on benefits.

In some cases, it was clearly the practical preparation that helped support progression into work. One interviewee who had secured employment described in detail how their Talent Match adviser had played a critical role in helping them to prepare in depth for the interview:

[My adviser] did the interview training for me and he also did the typing on the computer, we were really careful, printed the maps out and everything, put in the company information. He helped me do a bit of revising on the insolvency laws and that's why we got the best interview probably through Talent Match cos [he] passionately trained me for every single in depth about what an interview's going to do.

For others, this practical support also helped to steady pre-interview nerves, showing how effective practical support can have an emotional component too:

I've got a part-time job but / think I would not have got that job if it weren't for Talent Match cos I think they've boosted me up so much... Yeah I think Talent Match helped me get [a second job] cos they gave me more confidence. I was a bit nervous about the interview and I said to Talent Match about what should I do in the interview and they helped me out a lot and they talked about the travel, how would you travel there, so it was really good.

There was also a sense among some that improvements in employability were enduring in that interviewees could now find work without direct support from Talent Match. One participant, for example spoke of how they would not need further support if they lost their job and had to look for employment again:

I guess it's a good sign really, they've made me strong enough to be independent:

It was also notable that in some cases Talent Match advisers actively sought to steer participants away from the 'low-pay-no pay' cycle towards career pathways involving more highly skilled or secure work. For example, one participant described how Talent Match had at first helped him secure a string of temporary jobs after he approached them following a six month spell of unemployment:

Well I was job hunting for about 6 months... at first I was a bit sceptical, I was like [Talent Match] is going to be another one of these things, and then it took me about six weeks to decide l'm just going to go and have a look what it's like and then about two weeks after I had a job so I was just like, Jesus, this is good... I've had 22 jobs and quite a lot of that, probably about 10 of those jobs were through Talent Match. (

However, over time his Talent Match adviser began to encourage him to think about longer-term options and eventually supported him to a switch to a career in retail:

Whenever they'd get me a job in a factory or warehouse they'd say to me it's not ideal, it's not what you want to be doing for the rest of your life. They'd always say to me there's more to you, you can achieve more... you can do something better than this....they'd try and find out 
what I actually what I want to do and that's how I found out that I wanted to do sales... after about my twentieth job in a warehouse and factory. I kind of need a change now and said to them about sales or retail, they got me a job in a shop within a week. I had to go to the interview and I got it, changed jobs after about three or four months of being there ....so it's kind of good.

The comments above provide clear indication of how advisers worked to support participants to recognise, and act upon, career aspirations that could help them to embark on more stable or satisfying employment pathways.

Whilst a significant number of participants reported progression towards or within the labour market due to Talent Match support, others were more equivocal about the value of interventions received. Some noted the limits of Talent Match in terms of, for example, their inability to help themovercome the perceived lack of jobs in local labour markets:

I'm not sure, for me it helped rebuild my confidence in CV skills and job applications but then I felt cos of the job market around [here], I think that was quite limited, but you can't really expect Talent Match to go "we've got these sort of jobs that have just popped up out of the blue"

Other interviewees also felt they could found have work without Talent Match support, even if they had found it useful at the time. One respondent who secured paid employment as a catering assistant expressed a view that they could have found that position anyway, whilst acknowledging that Talent Match support with her CV and interview preparation had been useful.

Some interviewees able to access support from other sources were also cautious in attributing progress to Talent Match and small minority of those who had found employment had clearly achieved this independently of Talent Match, although they did reflect that Talent Match had been helpful. One interviewee with ambitions to set up his own enterprise to support disabled people had found sales work through his own efforts. His comments indicated how support from Talent Match had tailed off with his change in career objectives:

We were doing work with people with disabilities, just sporting activities but then that kind of fizzled out and I was too busy... so I was just there by myself thinking about other ideas I could do, I was speaking to one of my other friends and he showed me how to get into [sales]. Since then l've just been doing that.

The point here is not that Talent Match had somehow failed but, rather, that the support provided did not, in the end, shape career destinations. Despite this, the interviewee did note that support to access a course on working with young people may be helpful for future jobs.

A very small minority of interviewees also felt that Talent Match had not been able to help them realise specific career goals. One participant looking to find a job in IT in line with qualifications gained at college felt the service had not been able to help him effectively because they did not fully understand specialised roles:

There was only so much they could do...They were over-selling themselves... I never got anything from any of them so it was sort of a waste of time to be honest...all they could do was try and find me IT based things ... but obviously cos they didn't know IT themselves... When I was talking to them about it, it was all just going over their heads. 
Overall, the balance of evidence suggests that interviewees were more likely to suggest that Talent Match had acted as a catalyst of positive change than to reflect that support had made little or no impact upon career aspirations or progression achieved. This also reflects the level of additionality calculated in Section 6. All employment outcomes are not solely attributable to Talent Match, rather often Talent match is an important part of a range of person specific factors and context.

\subsection{Conclusion}

This chapter has made an assessment of Talent Match's contribution to the jobs gained by its participants. The upper estimate for additionality (28 per cent) found Talent Match to have led to 3,298 participants (13 per cent of all participants) gaining a job who would not have done so without participating in Talent Match. This includes 1,237 securing a secure job (five per cent of all participants). Based on the lower estimate of additionality (nine per cent) 1,035 participants (four per cent of all participants) are thought to have gained a job who would not have done so without participating in the programme. This includes 388 securing a secure job (one per cent of participants).

This level of additionality is high compared to other initiatives. The level of additionality reflects the relative scale of influence that Talent Match has on the factors affecting the likelihood of a young person finding a job, over and above other factors. This includes changes in personal circumstances, involvement in mandatory labour market interventions and job search as well as the growth in the supply of jobs in wider labour market that has taken place over the five years that Talent Match ran. This realistic understanding of additionality achieved by a well-funded youth employment initiative is important to inform expectations for other initiatives and the financial returns that they may achieve.

As we have noted throughout the report, the benefits of Talent Match should not simply be seen in terms of the employment and self-employment jobs gained. This is best highlighted through the improvements in job readiness and well-being. Individuals participating in Talent Match were overwhelmingly positive about their experience on the programme. Engagement was seen to be meaningful and the person-centred approach welcomed. Of course, Talent Match did not work well for all young people and some concerns were raised by a small group in the qualitative research around the benefits of the support provided. 


\section{LCR}

This single 22-year-old male was living with his parents and claiming JSA prior to participation in Talent Match. He had poor mental health and identified a range of other labour market barriers including lack of basic skills; low confidence, a lack of qualifications, lack of previous work experience and interview skills and a lack of job opportunities. His highest qualifications were Level 1 (GCSEs D-G). He was undertaking a Level 2 Gardening course and indicated that he was looking for employment in landscape gardening.

During his time on the Talent Match programme he had received a range of support including work experience and volunteering, help with interviews, one-to-one support, IAG, financial support and with travel. He rated the support received from TM as 'very good'. However, apart from a slight improvement in motivation to find work there was little evidence of progression during his time on the programme. Furthermore, he indicated that he regarded participation in the Talent Match programme as a failure if he was unable to secure employment.

The difference between the quantitative assessment of additionality (comparing the proportion of Talent Match participants gaining a job to a matched comparator from the LFS) and the perceived - qualitative - assessment of participants is important to note. Whilst both point to a Talent Match effect - increasing employment/selfemployment - there appears to be a discrepancy in the scale of this impact. 'Perception' viewpoints indicate a far higher level of additionality compared to the quantitative assessment. This should inform the evaluation literature on evaluating employment initiatives. 


\section{Costs and benefits of Talent Match}

\subsection{Introduction}

This chapter calculates the value of costs and benefits emerging from Talent Match at an aggregate level. The methodology underpinning the cost benefit analysis is based on the DWP Cost-Benefit Analysis framework (2013) ${ }^{26}$ and reflects the principles set out in the Treasury's Green Book. In broad terms it involves comparing the monetised value of outcomes that can be attributed to the programme against its costs to derive a Benefit Cost Ratio (BCR). That is analysis is based on net additional employment outcomes: the total (gross) number who gain a job minus those that are likely to have gained a job even in the absence of participation in Talent Match.

The analysis contained in this chapter considers:

- The cost of the programme.

- The additional income gained by Talent Match participants achieving an employment outcome.

- The economic output produced by Talent Match participants achieving an employment outcome.

- The additional social value from the improvement in life satisfaction achieved by Talent Match participants.

- The direct and indirect change in government spending due to:

- $\quad$ the reduction in benefit payments

- the additional income taxes received

- reductions in health service costs

- $\quad$ reduced costs of dealing with crime.

Throughout the analysis it has been conservatively assumed that:

- A sustained employment or self-employment outcome lasted for 52 weeks.

- A non-sustained employment or self-employment lasted for 13 weeks.

${ }^{26}$ Fujiwara, D. (2013) The Department for Work and Pensions Social Cost-Benefit Analysis framework. Methodologies for estimating and incorporating the wider social and economic impacts of work in Cost-Benefit Analysis of employment programmes. Working Paper no. 86. This document/publication is also available on the DWP website at: http://research.dwp.gov.uk/asd/asd5/rrs-index.asp 


\subsection{Cost of the programme}

Chapter 1 detailed the costs of the programme so far. In summary grant expenditure by the 21 partnerships was $\mathbf{2 9 6 . 1 4 4}$ million (up to 31 December 2018). This represented 91 per cent of the overall programme funding.

It is important to note that this is the total expenditure by the 21 Talent Match partnerships and included both delivery and non-delivery specific costs. An effort by the evaluation to separate out the more delivery specific costs proved unsuccessful. Therefore this assessment includes non-delivery specific costs some of which represent one-off costs (such as setting up the partnership) and others (such as evaluation and some elements of the test and learn approach) which would not be part of a 'mainstreamed' version of Talent Match. It is also the case that Talent Match did not directly focus on minimising costs. Instead it sought to provide freedom for partnerships to take a test and learn approach, facilitate the development of partnerships and capacity building and enable the delivery of more resource intensive activity to those who needed it.

\subsection{Additional income of participants achieving an employment outcome}

Responses to the CDF were used to estimate the additional income gained by Talent Match participants who entered work, after deducting tax, National Insurance and changes in benefits. It is estimated that a young person who managed to secure employment/self-employment gained, on average, an additional £153 net additional income per week. This is the difference between their benefit income at baseline and their net income from work (excluding income tax and National Insurance) and benefit income ${ }^{27}$ when they entered work.

Based on the assumed duration of work set out in the introduction to this Chapter it is estimated that participants who achieved a positive employment outcome gained a total of $£ 50.462$ million in net additional income. Adjusting for the level of additionality - outcomes that would not have occurred without the programme (calculated in chapter 5) - this provides (Table 6.1):

- $\quad £ 13.939$ million in additional income, based on the upper estimate of additionality compared to the baseline situation.

- $£ 4.373$ million in additional income, based on the lower estimate of additionality compared to the baseline situation.

${ }^{27}$ This is the difference in the value of benefit received between when they first secured work compared against their baseline return. This calculation includes: Jobseekers Allowance, Employment and Support Allowance, Income Support, Income Support for Lone Parents, Housing Benefit and Council Tax Benefit. 
Table 6.1: Additional income for participants achieving an employment outcome (after tax, national insurance and changes in benefits)

\begin{tabular}{|c|c|c|c|c|}
\hline & $\begin{array}{r}\text { Number } \\
\text { achieving } \\
\text { outcome }\end{array}$ & $\begin{array}{r}\text { Assumed } \\
\text { duration of } \\
\text { benefit } \\
\text { (weeks) }\end{array}$ & $\begin{array}{r}\text { Unit value } \\
\text { of net } \\
\text { additional } \\
\text { income (£ } \\
\text { per week) }\end{array}$ & $\begin{array}{r}\text { Total value } \\
\text { of net } \\
\text { additional } \\
\text { income }(\Sigma)\end{array}$ \\
\hline \multicolumn{5}{|l|}{ All employment outcomes } \\
\hline $\begin{array}{l}\text { Gained sustainable employment } \\
\text { Gained employment not }\end{array}$ & 4,479 & 52 & $£ 153$ & $£ 35,625,608$ \\
\hline sustainable & 7,461 & 13 & $£ 153$ & $£ 14,836,049$ \\
\hline Total & 11,940 & & & $£ 50,461,657$ \\
\hline \multicolumn{5}{|c|}{ Net additional employment outcomes: upper estimate } \\
\hline $\begin{array}{l}\text { Gained sustainable employment } \\
\text { Gained employment not }\end{array}$ & 1,237 & 52 & $£ 153$ & $£ 9,840,343$ \\
\hline sustainable & 2,061 & 13 & $£ 153$ & $£ 4,098,650$ \\
\hline Total & 3,298 & & & $\{13,938,993$ \\
\hline \multicolumn{5}{|c|}{ Net additional employment outcomes: lower estimate } \\
\hline $\begin{array}{l}\text { Gained sustainable employment } \\
\text { Gained employment not }\end{array}$ & 388 & 52 & $£ 153$ & $£ 3,087,274$ \\
\hline sustainable & 647 & 13 & $£ 153$ & $£ 1,285,896$ \\
\hline Total & 1,035 & & & $£ 4,373,170$ \\
\hline
\end{tabular}

\subsection{Economic output produced by participants achieving an employment outcome}

Table 6.2 calculates the economic output produced by Talent Match participants who gained an employment outcome: the value of the goods and services that they produced in their jobs. This has been calculated based on the assumption that an employee produces an economic output equivalent to their cost of employment. It also applies the benefit durations outlined in Section 6.1.

The analysis finds participants who achieved an employment outcome produced $£ 72.405$ million in economic output. Adjusting for additionality it is calculated that:

- $\quad £ 20.000$ million of this economic output would not have been achieved without participation in Talent Match, based on the upper estimate of the level of additionality.

- $\quad £ 6.275$ million of this economic output would not have been achieved without participation in Talent Match, based on the lower estimate of the level of additionality. 


\begin{tabular}{|c|c|c|c|c|}
\hline & $\begin{array}{l}\text { Number } \\
\text { achieving } \\
\text { outcome }\end{array}$ & $\begin{array}{r}\text { Assumed } \\
\text { duration } \\
\text { of benefit } \\
\text { (weeks) }\end{array}$ & $\begin{array}{r}\text { Unit value } \\
\text { of } \\
\text { economic } \\
\text { output (£ } \\
\text { per week) }\end{array}$ & $\begin{array}{r}\text { Total value } \\
\text { of } \\
\text { economic } \\
\text { output (£) }\end{array}$ \\
\hline \multicolumn{5}{|l|}{ All employment outcomes } \\
\hline $\begin{array}{l}\text { Gained sustainable employment } \\
\text { Gained employment not }\end{array}$ & 4,479 & 52 & $£ 219$ & $£ 51,117,716$ \\
\hline sustainable & 7,461 & 13 & $£ 219$ & $£ 21,287,636$ \\
\hline Total & 11940 & & & $£ 72,405,352$ \\
\hline \multicolumn{5}{|c|}{ Net additional employment outcomes: upper estimate } \\
\hline $\begin{array}{l}\text { Gained sustainable employment } \\
\text { Gained employment not }\end{array}$ & 1,237 & 52 & $£ 219$ & $£ 14,119,503$ \\
\hline sustainable & 2,061 & 13 & $£ 219$ & $£ 5,880,983$ \\
\hline Total & 3,298 & & & $£ 20,000,487$ \\
\hline \multicolumn{5}{|c|}{ Net additional employment outcomes: lower estimate } \\
\hline $\begin{array}{l}\text { Gained sustainable employment } \\
\text { Gained employment not }\end{array}$ & 388 & 52 & $£ 219$ & $£ 4,429,802$ \\
\hline sustainable & 647 & 13 & $£ 219$ & $£ 1,845,079$ \\
\hline Total & 1,035 & & & $£ 6,274,881$ \\
\hline
\end{tabular}

\subsection{Additional life satisfaction value gained by participants}

Section 3.5 highlights a sizable gain to life satisfaction for Talent Match participants. Typically, participants had a very low level of life satisfaction on entry to the programme, and this then improved towards the population average by their latest CDF response, some six to 18 months later. Capturing the value of these improvements for participants is therefore important if the cost benefit assessment is to be comprehensive and as such social value assessments have been recognised in guidance such as the Treasury's Green Book. Putting a value on intangible outcomes such as improved life satisfaction is a challenge as they are not traded and therefore do not have a market value. In response to this challenge several approaches have been developed to estimate the value of non-market outcomes. One such approach is life satisfaction valuation which has been used in this evaluation to monetise this gain for Talent Match beneficiaries. Our approach for this is described in more detail in the Talent Match Evaluation Technical Appendix, but in summary statistical modelling has been used to estimate the average improvement in life satisfaction between baseline and latest responses, given a range of young person characteristics such as their age, gender and ethnicity.

This improvement in life satisfaction is then monetised by calculating the additional household income that would produce the same increase in life satisfaction. This uses evidence from Fujiwara et al. (2014). The approach taken seeks to capture the total of life satisfaction gains in one step avoiding double counting, rather than individually valuing the life satisfaction improvements from, for example, volunteering or greater employability.

Based on this analysis the average gain in life satisfaction per Talent Match participant is 1.6 'life satisfaction points.' Using evidence from Fujiwara et al. (2014) an estimated $£ 22,000$ increase in household income would be required to produce the same improvement in life satisfaction (1.6 'life satisfaction points'). When viewed across all 25,885 Talent Match participants this equates to a significant £565.211 million gain in life satisfaction. As stated above this value represents the summation of the average gains that Talent Match participants experienced across outcomes which will have 
affected their life satisfaction; including from taking up volunteering opportunities, improved confidence, improved employability as well as from gaining employment. However, it is important to stress that this computed monetary value is not real additional money that the Talent Match participant will receive. Rather it is the equivalent value of household income that would provide an uplift in average life satisfaction achieved by an average Talent Match participant.

The level of additionality for the improvement in life satisfaction is likely to be significantly higher than for employment outcomes (28 per cent). For example the latest Homes and Communities Agency additionality guide estimates an average gross to net additionality ratio of 48 per cent for projects benefiting young people to promote personal and social development. ${ }^{28}$ In the absence of other reliable evidence this 48 per cent ratio has been applied to monetise the net additionality value of improved life satisfaction. However, it is more than likely that this will be an underestimate of the true level of additionality. Based on this the monetised value of the net additional improvement in life satisfaction is valued at $£ 285.538$ million.

Table 6.3: Value of improved life satisfaction

\begin{tabular}{lrrrr}
\hline & $\begin{array}{r}\text { Number } \\
\text { achieving } \\
\text { outcome }\end{array}$ & $\begin{array}{r}\text { Assumed } \\
\text { duration of } \\
\text { benefit } \\
\text { (weeks) }\end{array}$ & $\begin{array}{r}\text { Unit value of } \\
\text { life } \\
\text { satisfaction } \\
\text { (£ per annum) }\end{array}$ & $\begin{array}{r}\text { Total value of } \\
\text { improved life } \\
\text { satisfaction (£) }\end{array}$ \\
\hline $\begin{array}{l}\text { Gross outcome } \\
\text { Gain in life satisfaction }\end{array}$ & 25,885 & 52 & $£ 22,000$ & $£ 571,077,626$ \\
\hline Total & & & & $£ 571,077,626$ \\
\hline Net additional outcome & 25,885 & 52 & $£ 11,000$ & $£ 285,538,813$ \\
Gain in life satisfaction & & & & $£ 285,538,813$ \\
\hline Total & & & & \\
\hline
\end{tabular}

\subsection{The direct and indirect change in government spending}

\section{Exchequer savings}

Talent Match participants who secured an employment outcome will have led to increases in tax and National Insurance receipts and reduced benefit payments for the Exchequer (HM Treasury). The average values of these benefits to the Exchequer have been estimated from CDF responses provided by Talent Match participants who achieved an employment outcome.

Based on the benefit durations outlined above it is estimated that participants who achieved a positive outcome had provided a total benefit to the Exchequer of $£ 18.893$ million. Adjusting for additionality it is calculated that:

- $\quad £ 6.963$ million of this benefit to the Exchequer would not have been achieved without Talent Match, based on the upper estimate of additionality.

28 Homes and Communities Agency (2014) Additionality Guide Fourth Edition, https://assets.publishing.service.gov.uk/government/uploads/system/uploads/attachment data/file/378177/additio nality guide 2014 full.pdf 
- $£ 1.637$ million of this benefit to the Exchequer would not have been achieved without Talent Match, based on the lower estimate of additionality.

Table 6.4: Direct fiscal saving due to employment outcomes

\begin{tabular}{|c|c|c|c|c|c|}
\hline & $\begin{array}{r}\text { Number } \\
\text { achieving } \\
\text { outcome }\end{array}$ & $\begin{array}{r}\text { Assumed } \\
\text { duration of } \\
\text { benefit } \\
\text { (weeks) } \\
\end{array}$ & $\begin{array}{r}\text { Unit value of } \\
\text { Income Tax } \\
\text { and National } \\
\text { Insurance (£ } \\
\text { per week) } \\
\end{array}$ & $\begin{array}{r}\text { Unit value } \\
\text { of reduced } \\
\text { benefit } \\
\text { payments } \\
(£ \text { per } \\
\text { week) }\end{array}$ & $\begin{array}{r}\text { Total value } \\
\text { of benefit to } \\
\text { Exchequer } \\
(£) \\
\end{array}$ \\
\hline $\begin{array}{l}\text { All employment out } \\
\text { Gained sustainable } \\
\text { employment } \\
\text { Gained employment } \\
\text { not sustainable }\end{array}$ & $\begin{array}{l}4,479 \\
7,461\end{array}$ & 52 & $£ 15$ & $£ 43$ & $£ 13,338,641$ \\
\hline Total & 11,940 & & & & $£ 18,893,430$ \\
\hline $\begin{array}{l}\text { Net additional empl } \\
\text { Gained sustainable } \\
\text { employment } \\
\text { Gained employment } \\
\text { not sustainable }\end{array}$ & $\begin{array}{r}\text { ient outcome } \\
1,237 \\
2,061 \\
\end{array}$ & $\begin{array}{r}\text { s: upper estir } \\
52 \\
13 \\
\end{array}$ & mate & $£ 43$ & $\begin{array}{l}£ 3,684,339 \\
£ 1,534,582\end{array}$ \\
\hline Total & 3,298 & & & & $£ 5,218,921$ \\
\hline $\begin{array}{l}\text { Net additional empl } \\
\text { Gained sustainable } \\
\text { employment } \\
\text { Gained employment } \\
\text { not sustainable }\end{array}$ & $\begin{array}{r}\text { ient outcome } \\
388 \\
647 \\
\end{array}$ & $\begin{array}{r}\text { s: lower estin } \\
52 \\
13 \\
\end{array}$ & nate & $£ 43$ & $\begin{array}{r}£ 1,155,911 \\
£ 481,454\end{array}$ \\
\hline Total & 1,035 & & & & $£ 1,637,365$ \\
\hline
\end{tabular}

\section{Indirect impact on health service costs}

Fujiwara (2010) developed an approach to value the reduction in NHS costs incurred from moving into work. Updating the computed values into 2018 prices it is estimated that when an unemployed person moves into work they incur £602 less per annum in NHS costs per annum in 2018 prices. Whereas a person moving from Employment and Support Allowance into work incur $£ 1,204$ less in NHS costs per annum (in 2018 prices).

Based on these values the employment outcomes achieved by Talent Match participants will have led to a $£ 4.429$ million reduction in NHS costs. These are mainly due to reduced GP consultations.

When only net additional outcomes are considered the value the employment outcomes directly attributable to Talent Match will have led to a $£ 1.223$ million reduction in NHS costs, based on the upper estimate of additionality. Using the lower estimate of additionality Talent Match will have led to a $£ 384$ thousand reduction in NHS costs. 


\section{Indirect impact on crime costs}

As reported in Bivand and Simmonds (2014) ${ }^{29}$, Fujiwara (2010) ${ }^{30}$ finds that supporting people into work is associated with reduced costs of crime to public services. This is due to a relationship between crime and income levels. Table 6.4 applies Bivand and Simmonds (2014) estimated annual savings, in 2018 prices, to calculate the reduced costs of crime due to Talent Match participants achieving an employment ou tcome. Its shows:

- An estimated $£ 3.014$ million reduction in costs of crime to public services from Talent Match participants achieving an employment outcome.

- Of this value $£ 833$ thousand is directly attributable to Talent Match based on the upper estimate of additionality, or $£ 261$ thousand based on the lower estimate of additionality.

Table 6.5: Indirect savings from reductions in crime due to employment outcomes

\begin{tabular}{|c|c|c|c|c|}
\hline & $\begin{array}{c}\text { Number } \\
\text { achieving } \\
\text { outcome }\end{array}$ & $\begin{array}{r}\text { Assumed } \\
\text { duration of } \\
\text { benefit } \\
\text { (weeks) }\end{array}$ & $\begin{array}{r}\text { Unit value } \\
\text { of reduced } \\
\text { costs of } \\
\text { crime (£ per } \\
\text { annum) } \\
\end{array}$ & $\begin{array}{r}\text { Total value } \\
\text { of reduced } \\
\text { costs of } \\
\text { crime }(\varepsilon) \\
\end{array}$ \\
\hline \multicolumn{5}{|l|}{ All employment outcomes } \\
\hline Gained sustainable employment & 4,479 & 52 & $£ 475$ & $£ 2,127,894$ \\
\hline Gained employment not sustainable & 7,461 & 13 & $£ 119$ & $£ 886,148$ \\
\hline Total & 11,940 & & & $£ 3,014,042$ \\
\hline \multicolumn{5}{|c|}{ Net additional employment outcomes: upper estimate } \\
\hline Gained sustainable employment & 1,237 & 52 & $£ 475$ & $£ 587,757$ \\
\hline Gained employment not sustainable & 2,061 & 13 & $£ 119$ & $£ 244,810$ \\
\hline Total & 3,298 & & & $£ 832,567$ \\
\hline \multicolumn{5}{|c|}{ Net additional employment outcomes: lower estimate } \\
\hline Gained sustainable employment & 388 & 52 & $£ 475$ & $£ 184,401$ \\
\hline Gained employment not sustainable & 647 & 13 & $£ 119$ & $£ 76,806$ \\
\hline Total & 1,035 & & & $£ 261,207$ \\
\hline
\end{tabular}

\subsection{Conclusion, including the CBA calculation}

Talent Match has brought both fiscal benefits and wider public benefits. A summary of the estimates of the wider societal and narrow fiscal benefits is outlined below, alongside the cost of the programme (Table 6.6). All employment programmes will bring benefit to society/public (mainly for the individuals directly benefiting from a programme) and for government in terms of reductions in spending and greater receipts from taxation. These are two different things and so are considered separately: one is the valuation of wider public benefits whilst the other is the narrower direct

\footnotetext{
29 Bivand and Simmonds (2014) The Benefits Of Tackling Worklessness and Low Pay. Joseph Rowntree Foundation.

30 Fujiwara, D. (2010) The Department for Work and Pensions social cost-benefit analysis framework: Methodologies for estimating and incorporating the wider social and economic impacts of work in cost-benefit analysis of employment programmes. Department for Work and Pensions Working Paper No. 86.
} 
monetary (fiscal) effects on the public purse. It is important to consider both when developing a comprehensive assessment of the costs and benefits of an intervention.

The monetised value of the net additional public benefits considered is found to exceed the programme's cost:

- $£ 3.32$ of public benefit has been created fromevery $£ 1$ of cost, based on the upper estimate of additionality.

- $£ 3.08$ of public benefit has been created from every $£ 1$ of cost, based on the lower estimate of additionality.

The findings developed in this report suggest substantial investment is required to support young people who are most disadvantaged in the labour market. However, the nature of employment opportunities open to young people meant that many participants who found a job remained eligible for welfare benefits and had low levels of taxation and National Insurance responsibility. Therefore the evaluation did not identify a positive fiscal benefit from the programme.

When developing the rationale for programmes such as Talent Match it is therefore important to look beyond simple economic justifications and also consider the more substantial social benefits and value. Improved life satisfaction generates the most notable benefit, for which it is important to note that the monetised value is not real additional money - rather the household money equivalent to generate a similar uplift to life satisfaction. When only real money benefits are considered the costs of Talent Match significantly outweigh the benefits. This is an important finding in its own right about the scale of more immediate financial benefits that are likely to emerge from a labour market programme like Talent Match which targets those furthest from the labour market.

The evaluation has not considered the potential longer-term benefits of Talent Match for example in terms of the prevention of 'scaring effects' which negatively affect lifetime incomes (due to for example reduced workplace experience) and health situations. Although there is an established body of work that has considered the effects of unemployment on later labour market outcomes such as earning it has not been possible to apply these estimates to the evidence generated from Talent Match, particularly given:

- The extended periods of unemployment that many Talent Match beneficiaries had experienced may already have had a scarring impact.

- The limited evidence on lasting employment outcomes for participants: only 17 per cent gained sustainable employment.

- Many Talent Match participants gained part time and low income employment which is less likely to counter previous scarring, at least to the extent estimated in the literature. 
Table 6.6: Summary Benefit Cost Ratios

\begin{tabular}{|c|c|c|c|c|}
\hline & \multicolumn{2}{|c|}{ Public benefit } & \multicolumn{2}{|c|}{ Fiscal benefit } \\
\hline & $\begin{array}{l}\text { Net additional: } \\
\text { upper estimate }\end{array}$ & $\begin{array}{c}\text { Net } \\
\text { additional: } \\
\text { lower } \\
\text { estimate }\end{array}$ & $\begin{array}{c}\text { Net } \\
\text { additional: } \\
\text { upper } \\
\text { estimate } \\
\end{array}$ & $\begin{array}{c}\text { Net } \\
\text { additional: } \\
\text { lower } \\
\text { estimate } \\
\end{array}$ \\
\hline $\begin{array}{l}\text { Exchequer savings from employment } \\
\text { Additional income from employment } \\
\text { Economic output produced }\end{array}$ & $\begin{array}{l}£ 13,938,993 \\
£ 20,000,487\end{array}$ & $\begin{array}{l}£ 4,373,170 \\
£ 6,274,881\end{array}$ & $£ 5,218,921$ & $£ 1,637,365$ \\
\hline Reduced crime costs & & & $£ 832,567$ & $£ 261,207$ \\
\hline Reduced health service costs & & & $£ 1,223,479$ & $£ 383,850$ \\
\hline Value of improved life satisfaction & $£ 285,538,813$ & $£ 285,538,813$ & & \\
\hline $\begin{array}{l}\text { Value of benefits of the } \\
\text { programme }\end{array}$ & $£ 319,478,293$ & $£ 296,186,864$ & $£ 7,274,967$ & $£ 2,282,422$ \\
\hline Cost of the programme & $\{96,144,383$ & $\{96,144,383$ & $\{96,144,383$ & $\{96,144,383$ \\
\hline Benefit Cost Ratio & $£ 3.32: £ 1$ & $£ 3.08: £ 1$ & $£ 0.08: £ 1$ & $£ 0.02: £ 1$ \\
\hline
\end{tabular}




\section{Key findings and implications}

\subsection{Introduction}

This report has assessed the outcomes and impact of Talent Match. It has explored how Talent Match was delivered across 21 partnerships working in different labour market conditions and with different groups of young people. At the heart of Talent Match have been the following:

- a personalised approach to supporting young people

- working with young people often furthest from the labour market

- being delivered on a voluntary basis

- engagement and involvement of young people in the design and delivery of the programme

- the leadership of individual partnerships by voluntary and community sector organisations.

\subsection{Key Findings}

Talent Match surfaced the complex and deep-seated challenges young people faced in securing long lasting and fulfilling employment in England. Whilst much was already known about extrinsic factors (such as low qualification levels) less was known about intrinsic factors (such as low levels of wellbeing). Moreover, many of these factors are inter-related.

The programme, on the whole, worked with those furthest from the labour market in localities where employment outcomes may be hardest to achieve. Moreover, whilst youth unemployment has fallen considerably since its peak in 2012, the barriers faced by many young people participating in Talent Match have not necessarily been solved by a greater availability of jobs.

Nevertheless, we find overall that:

- Talent Match supported almost 26,000 young people over the course of the programme.

- Talent Match has supported young people who are often those furthest from the labour market and who face substantial challenges to labour market participation, including low levels of mental health and wellbeing. 
- Almost half of the programme participants moved into employment, and 17 per cent sustained employment for six months or more.

- Many young people would not have moved into work without the support of Talent Match (up to 28 per cent would not have gained a job without participation in Talent Match).

- Talent Match participants moving into work reported high levels of job satisfaction.

- Being in a stronger local labour market (with lower levels of unemployment) and having a greater level of job readiness are associated with a greater likelihood of finding work.

- Talent Match helped support participants to improve their wellbeing. The percentage of participants with a high life satisf action more than doubled from nine to 24 per cent, to just below the national aver age. Seventy per cent of young people who gained a job reported improved life satisfaction. Even amongst those participants who did not find a job, three fifths (60 per cent) still reported an improvement in their life satisfaction.

- At least $£ 3.08$ of public value has been generated for every $£ 1$ spent on Talent Match programme delivery. This means that there is a positive social benefit associated with Talent Match.

- Substantial investment is required to support young people who are most disadvantaged in the labour market. However, the nature of employment opportunities open to young people meant that many participants who found a job remained eligible for welfare benefits and had low levels of taxation and National Insurance responsibility. Therefore, the evaluation did not identify a positive fiscal benefit from the programme.

\subsection{Implications}

Talent Match was an innovative programme containing a range of experimental and novel features and with an explicit objective to support young people who were facing labour market disadvantage. Beyond the narrow scope of impact, the participative and inclusive approach was found to improve the legitimacy of the programme and Talent Match needs to be understood as a wider youth engagement and capability building programme as opposed to one that was narrowly focused on employment outcomes. Improving job readiness, employability and well-being for individuals, as well as involving young people and developing sustainable models of holistic support were equal to the programme's aims to support participants into sustainable jobs.

This has important implications for assessments of impact and value for money and the following implications can be drawn from the analysis:

- In order to achieve the work outcomes that it did Talent Match provided resource intensive in-depth, person-centred packages of holistic support to its participants. This has important implications for designing and setting expectations for employment initiatives. In particular lower employment outcome expectations and significant additional resourcing are required when supporting those furthest from the labour market in weaker labour market areas. There is also a need for a substantial demand-side intervention to increase the absolute number of jobs in weaker labour market contexts and to improve the access of young people to jobs. This will require a large-scale interventions and is likely to go far beyond what programmes such as Talent Match can plausibly achieve.

- Although the vast majority of participants were satisfied in the jobs that they had found, where issues existed they often related to increasingly common features of 
the modern labour market (such as zero-hours contracts and underemployment). Addressing these will require significant national economic policy interventions that affect the nature of jobs in the economy as well as their terms and conditions, again something well beyond what Talent match tried, or would have been able to achieve.

- Talent Match has highlighted the importance of capturing a wider range of employability and well-being outcomes. This includes improving skills and competencies, and improving wellbeing as well as the completion of positive labour market actions such as work-related training, work placements, applying for jobs and taking part in interviews. The cost benefit analysis reveals how the fiscal benefits of Talent Match are lower than the cost of the programme, primarily due to the operation of the tax and benefits system which uses financial mechanisms (in the form of reduced tax liability and access to welf are benefits) to support those who gain low paid employment. Therefore the case for Talent Match lies in the substantial social value that it has provided by improving the life satisfaction of its participants though, for example, raising their confidence and employability as well as supporting young people into work.

- It is important to note however that the support provided by Talent Match partnerships was not always enough to address low levels of reported wellbeing amongst young people participating in the programme. For example, life satisfaction got worse for just under a quarter of young people who did not find employment. Whilst lots of factors determine levels of subjective wellbeing, that a significant group of young people are reporting low levels of wellbeing should raise concerns not just for future employment programmes but more broadly for policies supporting young people. Negative labour market experiences will be a contributing factor to these issues and low wellbeing will act as a barrier to achieving sustained work. Consequently, interventions addressing the causes and symptoms of low mental health and wellbeing need to be a core feature of holistic employability support.

As such, additional benefits to future programmes could be derived through the following:

- A clearer assessment of which young people in a local area the partnership has the capability to support. As a voluntary programme without mandated referral routes Talent Match partnerships did need to support those who engaged. However, greater focus of support after this point may have yielded more benefits in specific targeting of those furthest from the labour market. This may have been helped by a more critical reflection by partnerships as to which groups of young people they could help most effectively.

- The wider development of a local network or ecosystem of employment support, including education and training providers, Jobcentre Plus, health and mental health services, employers, and the voluntary and community sector was needed to avoid duplication. Many Talent Match partnerships sought to convene this, and with some success, however many also faced considerable barriers and had to fall back on delivering the support to young people without being able to engage other partner organisations.

- And possibly whilst partnerships took a broad approach to 'test and learn' there may have been greater efficiencies by taking a genuinely innovative approach which targeted and tested more specific approaches. This might be in terms of either working with more particular groups of young people, trying more specific interventions, or looking more closely at the outcomes which were being sought. 
These lessons can be distilled into recommendations for public policy, for funders of the voluntary and community sector, for commissioners, and for local VCS organisations.

- Public Policy. Talent Match has surfaced the complex and deep-seated challenges many young people face. At the time of Talent Match, other programmes were not directly addressing these challenges. The evidence from the programme calls for a rethink into the main direction of youth policy.

- VCSE Funders. Talent Match intervened at a local - Local Enterprise Partnership - level. This was a novel level for the National Lottery to work at and on balance was the right one. However, it also brought additional costs in terms of developing and then coordinating partnerships at this new level.

- Commissioners. Local commissioners of youth employment interventions, such as Combined Authorities, may bring greater convening powers than was possible under Talent Match. This may also bring efficiencies in terms of more streamlined governance. However, a key benefit of Talent Match - around the role of VCSE organisations in engaging young people - should not be lost.

- VCSE Organisations leading partnerships. This role was a necessary one to ensure local coordination and consistent approaches to performance management. The skills and capabilities of organisations to play this role did however vary.

Youth unemployment is likely to increase in the future and consequently may become a national policy priority. Talent Match demonstrates the benefits of local approaches in supporting those who are furthest from the labour market. 


\section{Appendix 1: Characteristics of Talent Match participants}

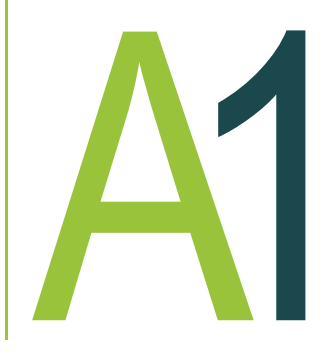

Gender

Almost two thirds (62 per cent) of young people participating in Talent Match were male. In contrast just under half (48 per cent) of all NEETs in England are male.

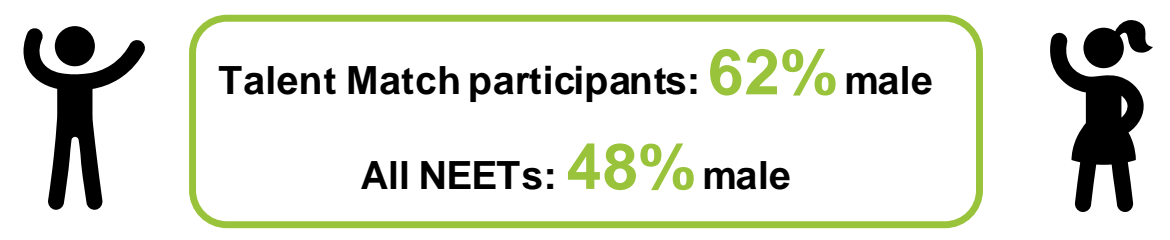

Source and bases: Baseline survey $(25,838)$, Labour Force Survey July - September 2018 (580)

This pattern remained largely constant through the programme. On the whole, partnerships did not intend to target one gender more than the other. However, the figures may mask additional gendered barriers to labour market participation including caring responsibilities and lone parenthood.

Age

Young people aged 20 years or under were more likely to engage with Talent Match. Talent Match participants were on average slightly younger than NEETs across England, who were more concentrated in the 22-24 year old age range.

Figure A2.1: Age of participants

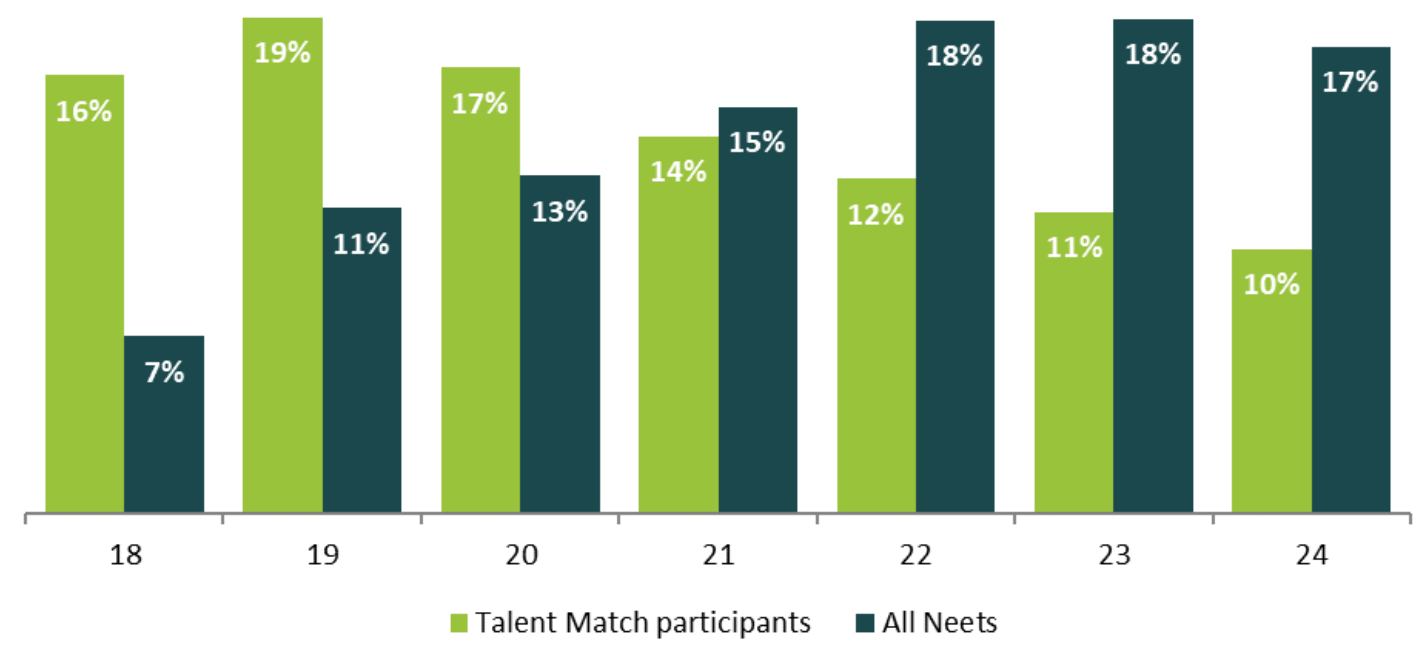

Source: Baseline survey (25,863), Labour Force Survey July - September 2018 (580)

Note: . $3 \%$ of TM participants were 17 at baseline, and .5\% were over 24 


\section{Ethnicity}

Twenty two per cent of Talent Match participants identified as being from an ethnicminority group (all categories except for 'White British' and 'White Irish'). This is higher than amongst all NEETs in England (16 per cent).

\section{Figure A2.2: Ethnicity of participants}

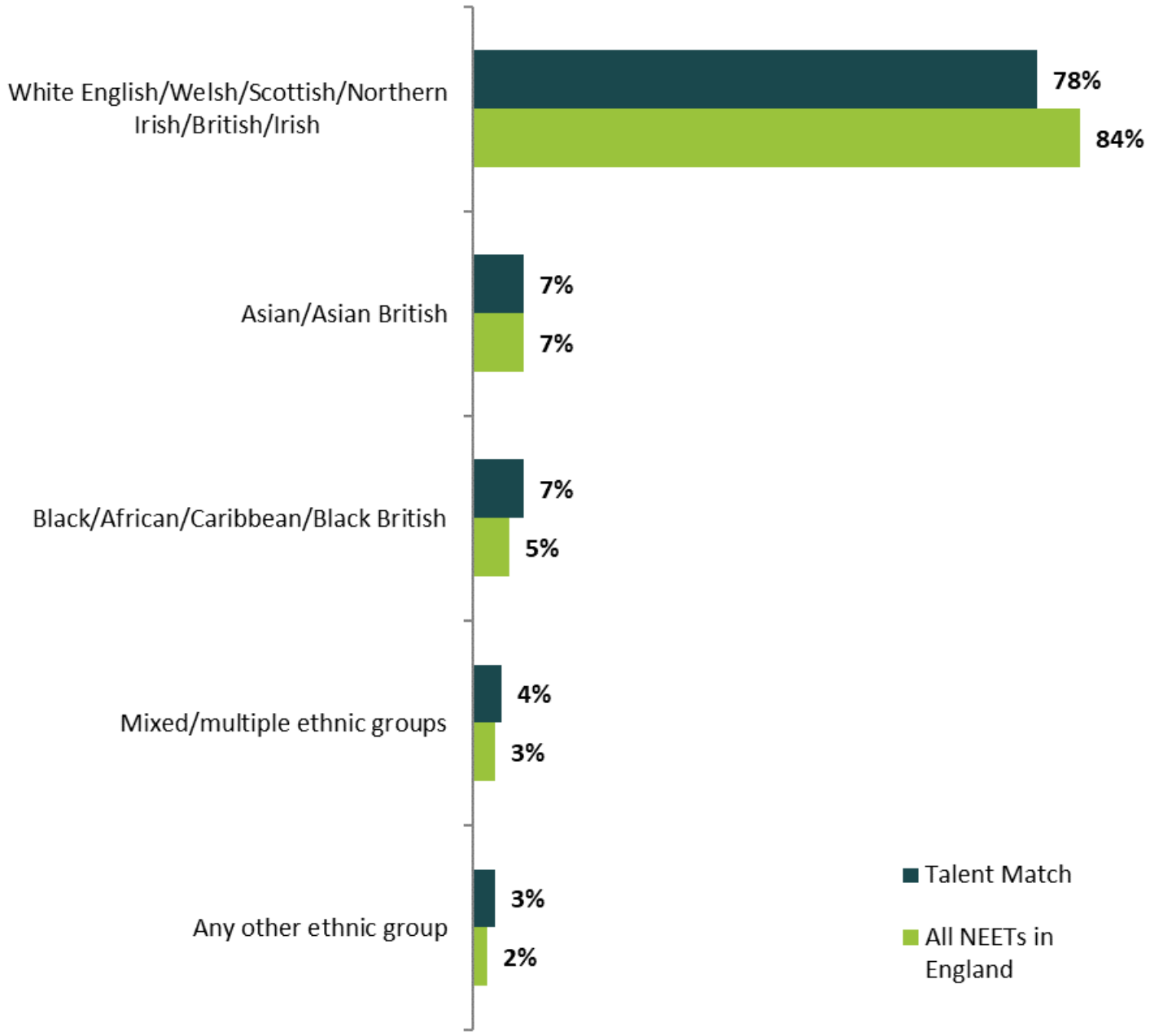

Source: Baseline survey $(25,884)$, Labour Force Survey July - September 2018 (580)

\section{Disability}

Almost one quarter of Talent Match participants indicated some form of disability (23 per cent). This is lower than the percentage of NEETs nationally who have a disability (41 per cent), though the national survey question is much more inclusive.

The percentage of Talent Match participants with a limiting disability (8 per cent) is much lower than in the national population of NEETs (32 per cent). What was perhaps most striking is that twenty six per cent of Talent Match participants also reported having previously experienced mental ill health, something reflected in the wider measure of wellbeing, discussed below. 
Figure A2.3: Disability that limits activities

Talent Match participants
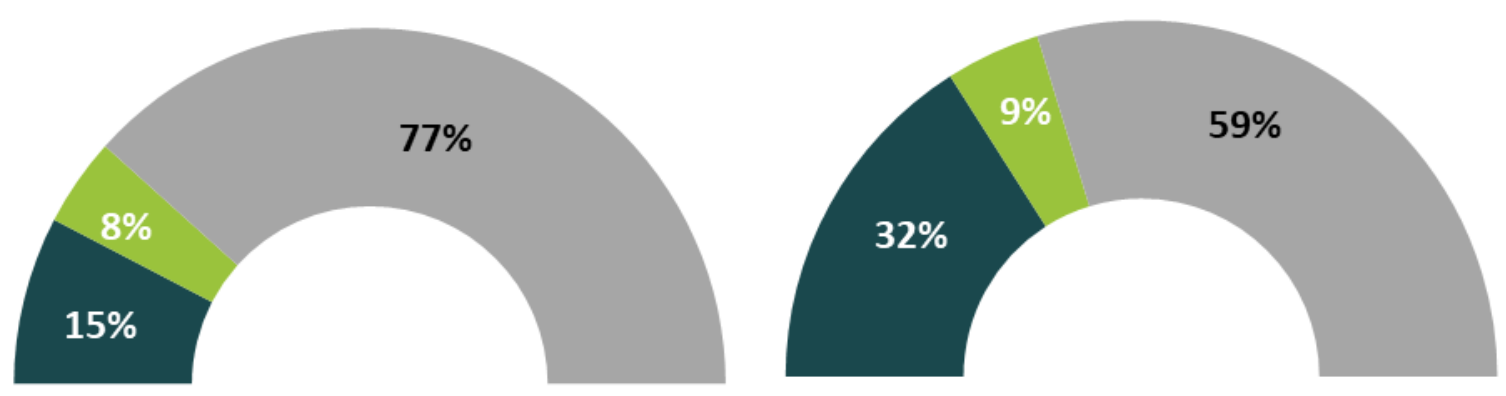

Yes and limits activities $\square$ Yes but does not limit activities $\square$ No long term disability

Source: Baseline survey (25,792), Labour Force Survey July - September 2018 (578)

\section{Wellbeing}

Overall, Talent Match participants were less satisfied with their lives compared to NEETs across England. Nearly three times as many Talent Match participants reported a 'low' life satisfaction compared to the proportion of NEETs in England: 29 per cent and 10 per cent respectively.

Figure A2.4: Wellbeing of participants

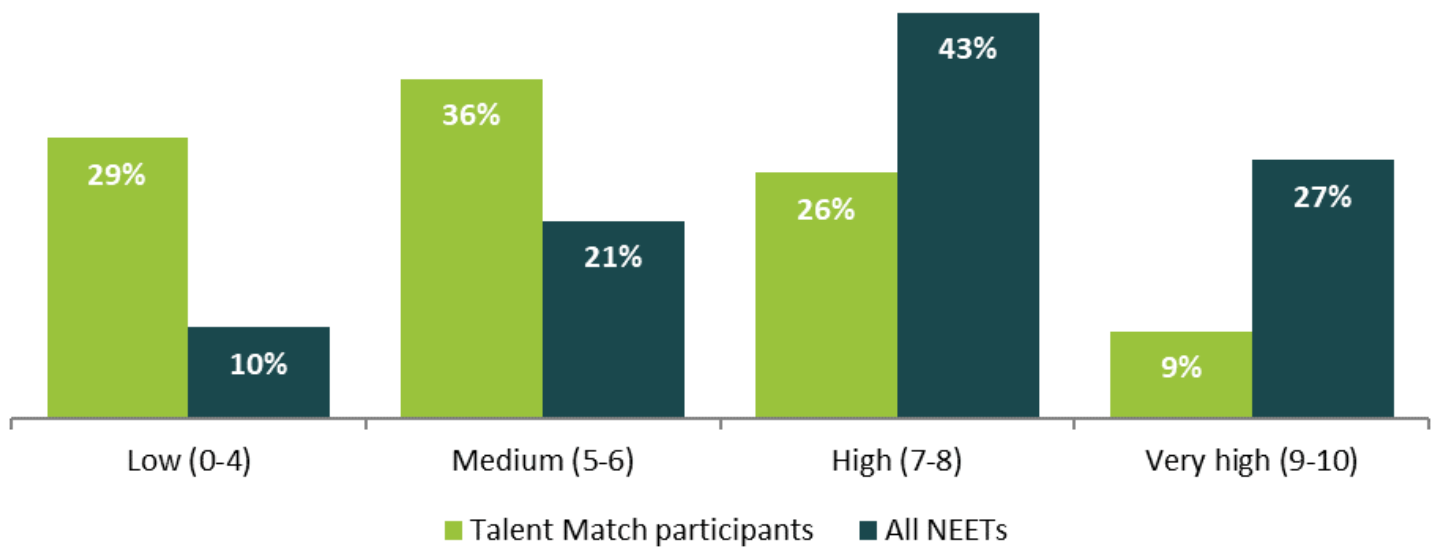

Source: Baseline survey $(25,305)$, Annual population survey (772)

Support for young people reporting low wellbeing was a key feature of the Talent Match programme and informed how local provision was shaped.

\section{Qualifications}

Sixty eight per cent of Talent Match participants had not achieved five GCSEs $A^{*}-C$ including English and Maths (or equivalent) at the baseline (FigureA2.5). This is the same proportion for all NEETs nationally.

Analysis of the reported highest qualification achieved reveals:

- 55 per cent of Talent Match participants had a GCSE as their highest qualification (55 per cent). 
- 16 per cent of Talent Match participants had at least one AS or A-level as their highest-level qualification.

- Only four per cent of Talent Match participants had a higher level of qualification.

- Eight per cent of participants had no qualifications at all.

Figure A2.5: Five GCSEs A*-C including English and Maths (or equivalent)

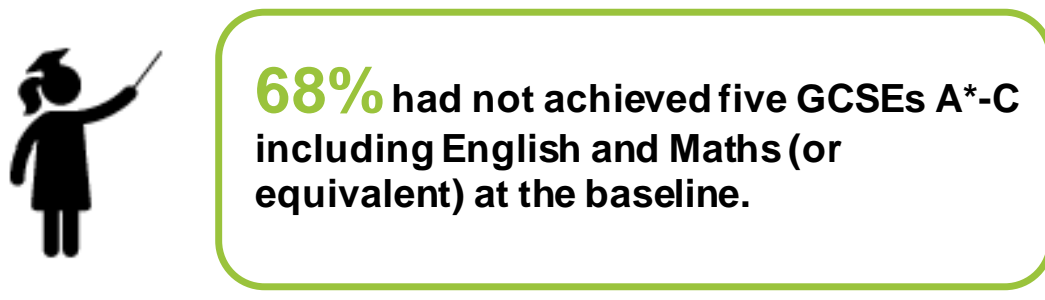

\section{This compares to $68 \%$ for all NEETs nationally}

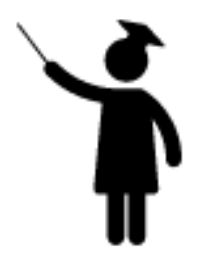

Source: Baseline survey $(24,662)$, Labour Force Survey (secure lab)

\section{Benefits}

Over three quarter of Talent Match participants ( 77 per cent) were in receipt of abenefit. This compares to 54 per cent of all NEETs in England.

"Hidden NEETs" are young people who were not receiving benefits and were not working (either less than 16 hours per week or 16 hours or more a we ek), selfemployed, on apprenticeship, in formal education or in training at the baseline stage. Just over one in five participants were classified as a hidden NEET.

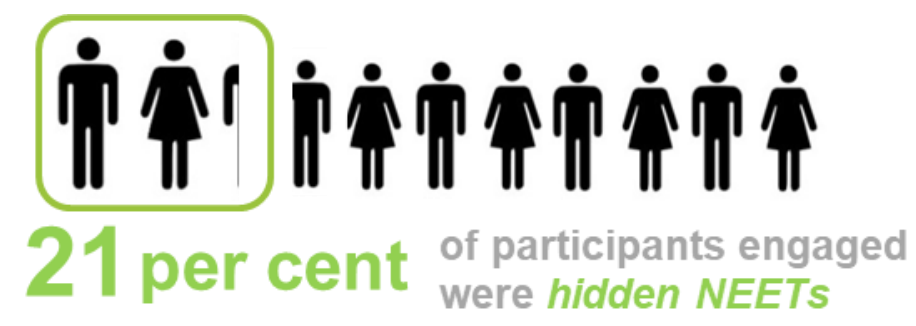

Source: Baseline survey $(25,835)$

Of those Talent Match participants who indicated that they received benefits, the most common type was Job Seekers Allowance (49 per cent), followed by Universal credit (21 per cent) and Housing Benefit (20 per cent). Disability benefits were less common, with 16 per cent claiming Employment and Support Allowance and 11 per cent Personal Independence Payments or Disability Living Allowance.

Child Tax Benefit (nine per cent) and Child Tax Credit (eight per cent) were each claimed by fewer than one in ten participants. This result reflects the findings that only 16 per cent of participants had a child. 
Figure A2.6: Benefit receipt

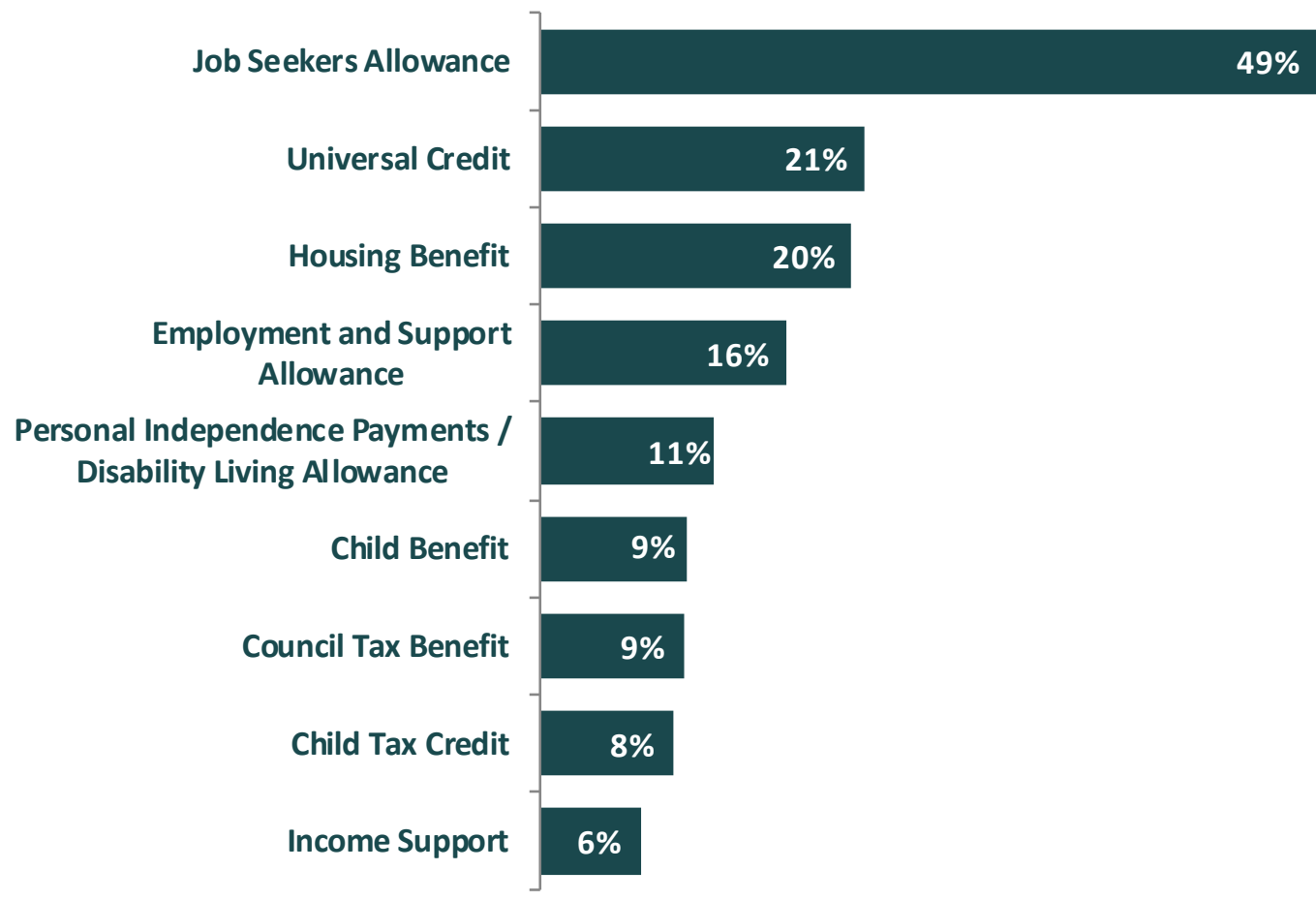

Source: Baseline survey $(19,887)$

Note: not shown - Carer's allowance - 1\%, Don't know - 1\%, Other - 1\%, JSA Severe Hardship Payments (16-18 year olds only) - 0\% 


\section{Appendix 2: My Journey Scale}

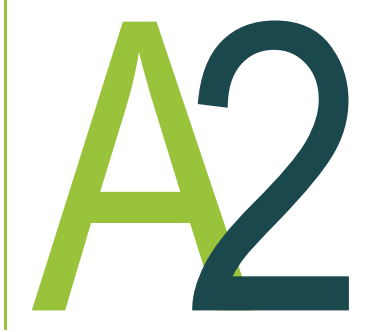

\section{My Journey Scale}

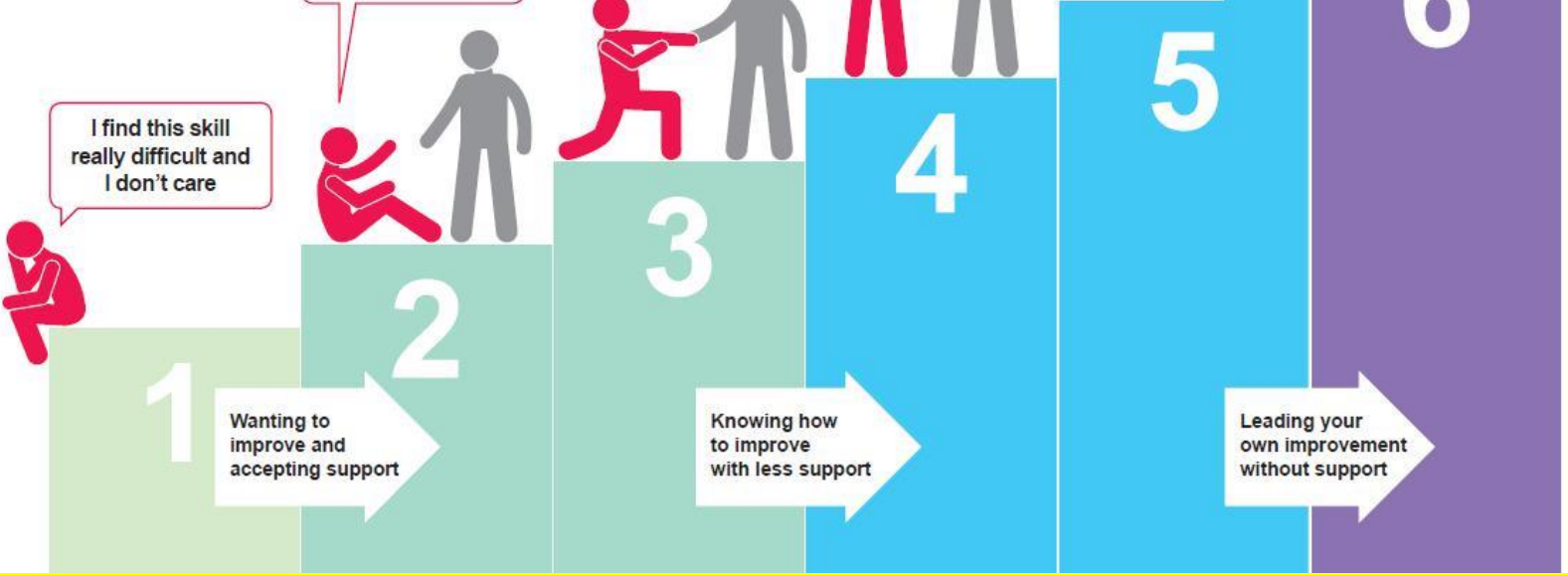




\section{Sheffield Hallam University}

Talent Match Evaluation: Understanding the impact and value of Talent Match

DAMM, Christopher <http://orcid.org/0000-0002-7355-3496>, PEARSON, Sarah <http://orcid.org/0000-0001-5049-5396>, SANDERSON, Elizabeth <http://orcid.org/00000003-1423-1670>, WELLS, Peter <http://orcid.org/0000-0002-5200-4279> and WILSON, Ian <http://orcid.org/0000-0001-8813-3382>

Available from the Sheffield Hallam University Research Archive (SHURA) at:

http://shura.shu.ac.uk/26571/

\section{Copyright and re-use policy}

Please visit http://shura.shu.ac.uk/26571/ and http://shura.shu.ac.uk/information.html for further details about copyright and re-use permissions. 